\section{Sleep and Cognition in Old Age}

The oldest age groups now constitute the fastest growing segment of the world population and the number of people aged 80 years and older is set to increase dramatically worldwide in the forthcoming decades. The demographical changes make it increasingly important to achieve better understanding of the many changes that accompany aging. The overall aim of this thesis is to enhance our understanding of subjective sleep disturbance and cognition, which are two major determinants of health in normal and pathological aging.

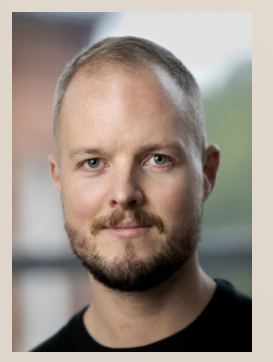

Johan Skoog is a clinical

neuropsychologist at the

memory clinic at the

Sahlgrenska University Hospital

in Gothenburg, Sweden.

He began his research in the

H70 Birth Cohort Studies in

2003 and initiated his $\mathrm{PhD}$

studies at the University of

Gothenburg in 2015 .

\section{SLEEP AND COGNITION IN OLD AGE}

Birth Cohort Differences, Dementia, and Biomarkers of Alzheimer's Disease
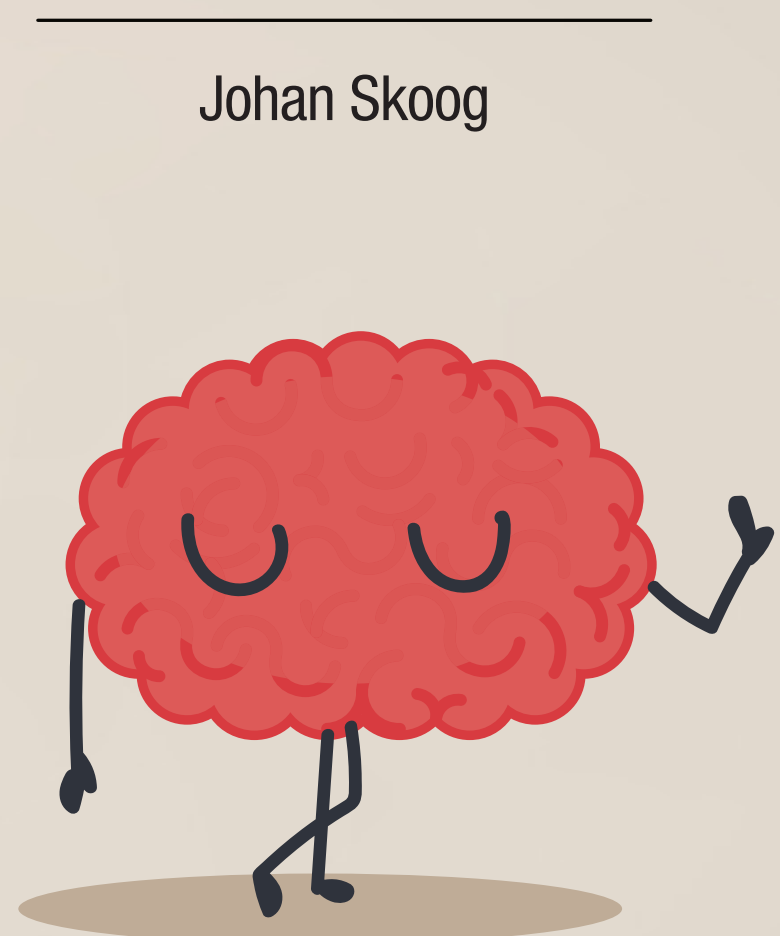

DEPARTMENT OF PSYCHOLOGY

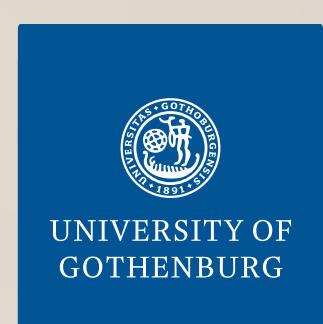




\section{Sleep and Cognition in Old Age}

Birth Cohort Differences, Dementia, and Biomarkers of Alzheimer's Disease

Johan Skoog 
Doctoral Dissertation in Psychology

Department of Psychology

University of Gothenburg

Dec 4, 2020

(C) Author Johan Skoog 2020

johan.skoog@gu.se

Cover page: Picture "Brain character" by Baluchis from Adobe Stock. Cover page graphically illustrated by Johan Skoog

ISBN: 978-91-8009-142-8 (PRINT)

ISBN: 978-91-8009-143-5 (PDF)

http://hdl.handle.net/2077/66865

Printed in Sweden 2020

Printed by Stema Specialtryck AB, Borås 
"There is a time for many words, and there is also a time for sleep."

- Homer, The Odyssey, Book 11 



\section{Abstract}

Skoog, J. (2020). Sleep and Cognition in Old Age; Birth Cohort Differences, Dementia, and Biomarkers of Alzheimer's Disease. Department of Psychology, University of Gothenburg, Sweden.

The oldest age group now constitutes the fastest growing segment of the world population. It is therefore imperative to better understand the alterations that follow both normal and pathological aging. The focus for this thesis is on two major determinants of health and wellbeing in older people, namely subjective sleep disturbance and cognition. Data were drawn from the H70 Birth Cohort Studies, comprising representative samples of older people living in Gothenburg, Sweden. In Study I, we examined birth cohort differences regarding prevalence of insomnia (i.e., difficulties initiating sleep, maintaining sleep, and early morning awakenings) in two cohorts of 70-year-olds born three decades apart and followed over nine years. The later-born cohort showed lower prevalence of insomnia at age 70 compared with the earlierborn cohort. However, the prevalence of insomnia increased with age in the later-born but was stable in the earlier-born cohort. In Study II, we investigated cognitive status and change measured by the Mini-Mental State Examination (MMSE) among 97-year-olds followed over three years. We found that MMSE scores at baseline were related to dementia at baseline, but not to development of dementia during follow-up. Those who died during the threeyear follow-up had lower MMSE scores than those who survived. Furthermore, participants with more education had higher MMSE scores, but there was no association between education and cognitive change. In Study III, which was a multicenter study, including additional samples from Stockholm and Finland, we investigated whether poor sleep in midlife and late life was associated with an elevated risk of developing dementia in late life. We found that midlife insomnia and late-life terminal insomnia (i.e., early morning awakenings) and long sleep duration were associated with a higher late-life dementia risk. In Study IV, we investigated if poor sleep was related to cerebrospinal fluid (CSF) markers of Alzheimer's disease (AD) and if these associations were moderated by possession of the apolipoprotein $(A P O E) \varepsilon 4$ allele. We found that reduced sleep, increased sleep and taking sleep medication were associated with markers of amyloid plaque accumulation (amyloid $\beta 42 / 40$ ratio). However, among APOE\&4-carriers, reduced sleep was also associated with markers of AD-related neurodegeneration (total tau, phosphorylated tau) and synaptic dysfunction (neurogranin). Conclusions: The main findings from the thesis imply that age-related increases in the prevalence of insomnia are postponed to higher ages in later-born cohorts. Educa- 
tion can still account for individual differences in cognitive performance even at these advanced ages but might not protect against cognitive decline. Different types of sleep problems may play varying roles during the life course concerning dementia risk where insomnia could potentially be more important in midlife while terminal insomnia or long sleep duration may be more critical later in life. In addition, sleep may play a vital role in the early processes of $\mathrm{AD}$ by potentially decreasing clearance or increasing production of amyloid $\beta$. This suggests that improving sleep could be one potential candidate for dementia prevention. A better understanding of sleep disturbances and cognition in old age may guide clinicians in making health care decisions and when designing person-oriented interventions that improves health and wellbeing in future older generations. 


\section{Svensk sammanfattning}

De äldsta åldersgrupperna tillhör den snabbast växande delen av befolkningen $i$ världen. Det är beräknat att antalet personer i världen som är över 80 år och äldre kommer öka från 143 miljoner år 2019 till 426 miljoner år 2050. Det kommer därför bli ännu viktigare att förstå de olika förändringar som är förknippade med både normalt och sjukligt åldrande. Det övergripande syftet med avhandlingen är att undersöka två faktorer som påverkar hälsan och funktionen hos äldre personer, nämligen sömnstörningar och kognition. Sömnstörningar är relaterat till både kroniska sjukdomar och ökad dödlighet medan en intakt kognition ofta är en nyckel till ett lyckat åldrande. Tidigare studier på sambandet mellan sömnstörningar och kognition har antytt ett komplext samband där dålig sömn kan vara en riskfaktor, ett tidigt symtom men även en bidragande orsak till en kognitiv sjukdom (ex. demens). Att studera sambandet mellan sömn och demens är därför viktigt både för att studera de tidiga processerna vid Alzheimers sjukdom men också för att hitta potentiellt förändringsbara riskfaktorer för demens. Emellertid är både de kort- och långsiktiga effekterna av hur sömnproblem påverkar kognitionen på populationsnivå relativt okända.

Alla studier innehöll data från H70-studierna i Göteborg där urvalet var representativt för äldre personer som bor i Göteborg. I Studie I undersöktes om det fanns så kallade födelsekohortsskillnader i förekomst av insomni (d.v.s. svårigheter att somna, nattliga uppvaknanden, vakna för tidigt på morgonen) i två födelsekohorter av 70 -åringar födda med 30 års mellanrum. Den senare födda kohorten hade lägre förekomst av insomni vid 70 års ålder jämfört med den tidigare födda kohorten. Förekomsten av insomni ökade med stigande ålder i den senare men inte i den tidigt födda kohorten. I Studie II undersöktes kognitiv status och förändring som mättes med Mini Mental Test (MMT) hos 97-åringar som följdes under tre år. De som hade en demenssjukdom hade lägre MMT-poäng än de utan demenssjukdom. Det fanns ingen statistiskt signifikant skillnad mellan de som utvecklade demens under undersökningens gång och de som aldrig utvecklade demens. De som dog under den tre år långa uppföljningen hade lägre MMT-poäng än de som överlevde. Deltagare med högre utbildning hade högre MMT-poäng, men det fanns ingen koppling mellan utbildning och kognitiv nedgång. Studie III var en multicenterstudie där det förutom data från $\mathrm{H} 70$ också ingick studier från Stockholm och Finland. Syftet var att undersöka om sömnstörningar i medelåldern och bland yngre äldre var relaterat till en ökad risk att utveckla demens senare i livet. Insomni i medelåldern, tidiga uppvaknanden och att sova längre $\mathrm{i}$ yngre äldre ålder var kopplat till en högre risk att utveckla demens senare i livet. I Studie IV undersöktes kopplingen mellan subjektiv sömnstörning och 
preklinisk Alzheimers sjukdom och om associationerna påverkades av om deltagarna var bärare av genvarianten Apolipoprotein E (APOE) ع4. Alla sömnvariabler var kopplade till lägre nivåer av $A \beta 42 / A \beta 40$-ratio, men det fanns inga signifikanta skillnader mellan de som sov sämre gällande nivåer av total tau, fosforylerat tau, neurofilament eller neurogranin. Däremot var minskad nattsömn kopplat till högre nivåer av total tau, fosforylerat tau och neurogranin hos personer som var bärare av genvarianten $A P O E \varepsilon 4$.

Sammanfattningsvis så är en möjlig förklaring till fynden i Studie I att förbättringarna i levnadsvillkoren under senaste decennierna har lett till att också sömnen förbättrats i senare födda kohorter. Att dessa skillnader försvinner med stigande ålder indikerar att en eventuell åldersrelaterad ökning av sömnproblem förskjuts till ett senare skede för senare födda kohorter. Resultatet i Studie II, att högre utbildning påverkade kognitionen över åtta decennier efter att man slutfört sin skolutbildning, kan relateras till att individer med högre utbildning kan ha en reservkapacitet som gör att de hanterar skador i hjärnan bättre och att de därför får en mer intakt kognition senare i livet. Samtidigt är det möjligt att när en person med högre reservkapacitet väl går ner kognitivt så kan de befinna sig längre fram i sjukdomsförloppet vilket gör att högre utbildning kanske inte skyddar mot kognitiv nedgång. Resultaten från Studie III indikerar att vissa typer av sömnproblem kan ha olika betydelse under vissa delar av livet, och identifierar ytterligare en faktor som kan hjälpa till att förebygga demens. Detta visar på vikten av att man i sjukvården är noga med att upptäcka sömnstörningar och att ge sömnhygieniska råd till patienter. Slutligen så indikerar fynden att dålig sömn kan ha betydelse vid de allra första processerna vid utvecklingen av Alzheimers sjukdom. Detta skulle kunna ske genom att dålig sömn leder till minskad utrensning eller ökad produktion av beta-amyloid. Dessa processer kan sedan utvecklas till senila plack i hjärnan. Det här kan betyda att en förbättrad sömn också är en möjlig del i att förhindra Alzheimers sjukdom.

En ökad förståelse av sömnstörningar och kognition hos äldre kan hjälpa kliniker att ta bättre beslut i sjukvården och genomföra personorienterade interventioner som förbättrar hälsan och välmåendet i framtida äldre generationer. 


\section{List of scientific papers}

This thesis consists of a summary and the following four papers:

I. Skoog, J., Jonsson, H., Sigstrom, R., Ostling, S., Falk, H., Waern, M., Thorvaldsson, V., Skoog, I., \& Johansson, B. (2019). Do later-born birth cohorts of septuagenarians sleep better? A prospective population-based study of two birth cohorts of 70-year-olds. Sleep, 42(1-8).

https://doi.org/10.1093/sleep/zsy204

II. Skoog, J., Backman, K., Ribbe, M., Falk, H., Gudmundsson, P., Thorvaldsson, V., Borjesson-Hanson, A., Ostling, S., Johansson, B., \& Skoog, I. (2017). A longitudinal study of the Mini-Mental State Examination in late nonagenarians and its relationship with dementia, mortality, and education. Journal of the American Geriatrics Society, 65(6), 1296-1300.

https://doi.org/https://doi.org/10.1111/jgs.14871

III. Sindi, S., Kåreholt, I., Johansson, L., Skoog, J., Sjöberg, L., Wang, H. X., Johansson, B., Fratiglioni, L., Soininen, H., \& Solomon, A. (2018). Sleep disturbances and dementia risk: A multicenter study. Alzheimer's \& Dementia, 14(10), 1235-1242.

https://doi.org/https://doi.org/10.1016/j.jalz.2018.05.012

IV. Skoog, J., Zetterberg, H., Blennow, K., Kern, S., Johansson, B., Skoog, I. \& Thorvaldsson, V. (2020). A populationbased study on sleep and CSF-markers of Alzheimer's disease: The influence of the APOE $\varepsilon 4$ allele. Manuscript submitted for publication. 



\section{Table of contents}

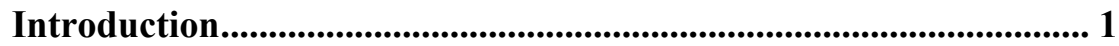

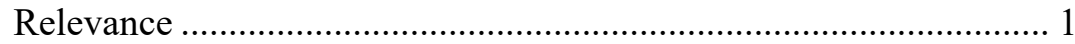

Aging - individual and population level ........................................... 1

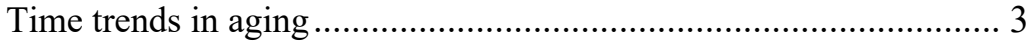

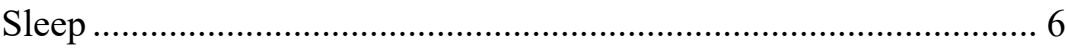

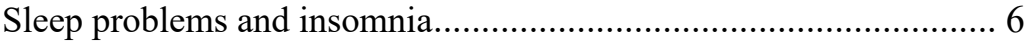

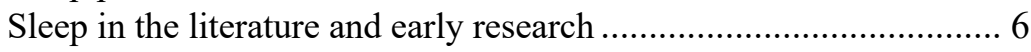

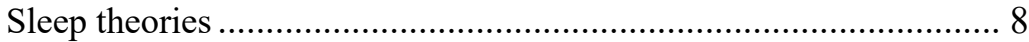

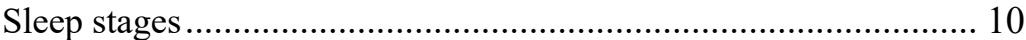

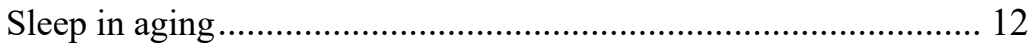

Time trends in sleep problems and insomnia ................................ 12

Cognition and dementia............................................................... 15

Cognitive aging, cognitive reserve, and terminal decline ................ 15

Major cognitive disorder............................................................ 16

Cerebrospinal fluid markers of Alzheimer's disease ....................... 17

Preclinical Alzheimer's disease ................................................. 18

The relationship between sleep and dementia.................................. 21

Sleep, dementia and markers of preclinical Alzheimer's disease..... 21

Apolipoprotein E \&4, Alzheimer's disease, and sleep...................... 22

Summary of studies ........................................................................................... 25

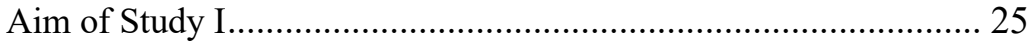

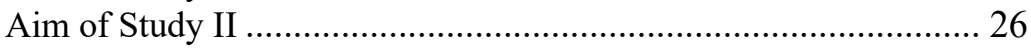

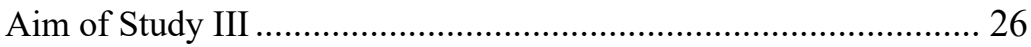

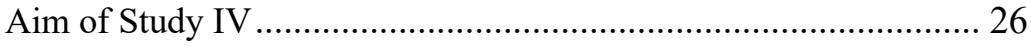

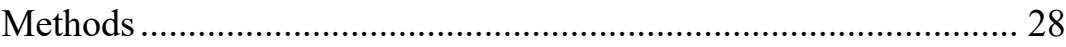

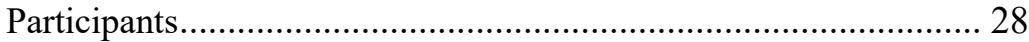

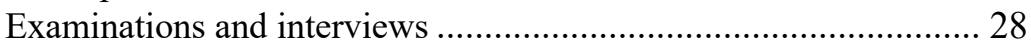

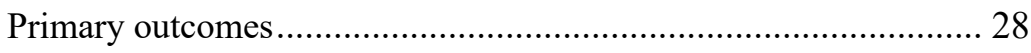

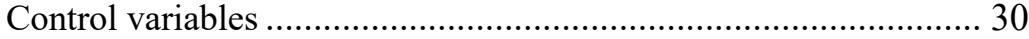

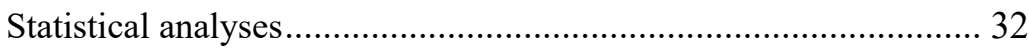

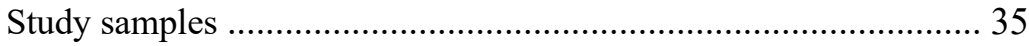

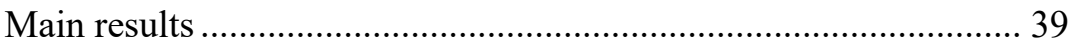

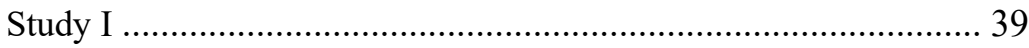

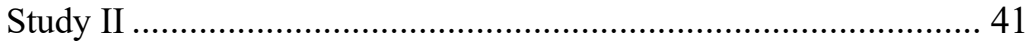

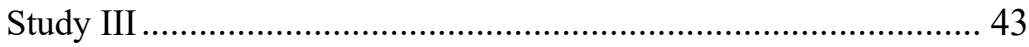

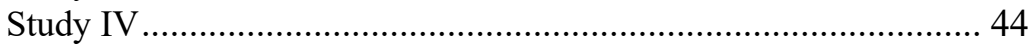




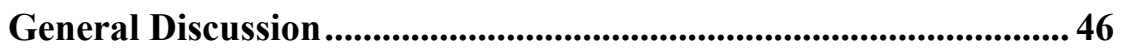

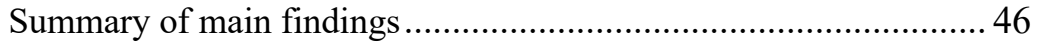

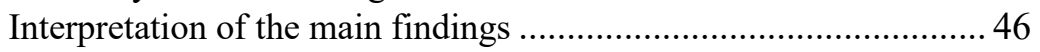

Methodological considerations................................................... 51

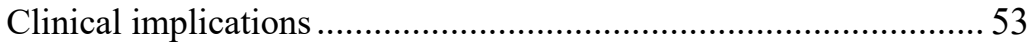

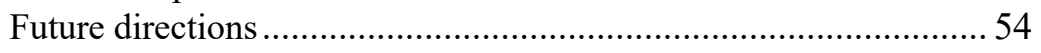

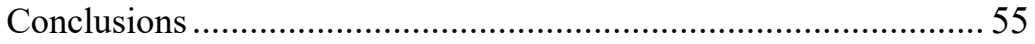

Acknowledgments ...........................................................................5 5

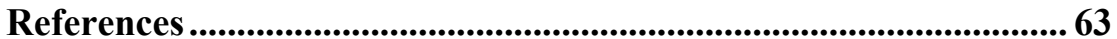




\section{List of figures and tables}

Figure 1. Life expectancy from 1543 to 2015 in Sweden and Worldwide ............ 2

Figure 2. Time trends in three cohorts born 1901-07, 1930 and $1944 \ldots \ldots \ldots \ldots \ldots . . . .5$

Figure 3. Two-process model of sleep regulation............................................. 9

Figure 4. Brain Wave patterns on EEG during different sleep stages. ................ 11

Figure 5. A model integrating Alzheimer's disease biomarkers .......................20

Figure 6. Prevalence of insomnia in two birth cohorts of 70-year-olds followed

until age 79

Figure 7. Prevalence of insomnia in two birth cohorts of 70-year-olds followed until age 79 as stratified by sex.

Figure 8. Estimated mean MMSE score from age 97 to 100 in relation to age at onset of dementia

Figure 9. Reduced sleep in relation to A $\beta 42 / A \beta 40$-ratio, t-tau, p-tau, and neurogranin and stratified by APOE $\varepsilon 4$-status 45

Figure 10. Three scenarios for cohort differences late in life. .50

Table 1. Study cohort, birth year, design, age, sample size and statistical analyses in the four studies from the thesis 38

Table 2. Associations between sleep parameters and dementia risk in final models

Table 3. Estimated associations between subjective sleep measures and $\mathrm{A} ß 42 / \mathrm{A} \beta 40$ ratio as derived from the linear multiple regression models 



\section{Abbreviations}

$\mathrm{A} \beta \quad$ Amyloid beta

AD Alzheimer's disease

ADL Activities of daily living

AQP4 Aquaporin-4

APOE Apolipoprotein E

CBT-I Cognitive behavioral therapy for insomnia

CNS Central nervous system

CPRS Comprehensive Psychopathological Rating Scale

CSF Cerebrospinal fluid

DSM Diagnostic and Statistical Manual of Mental Disorder

FDG Fluorodeoxyglucose

ECG Electrocardiography

EEG Electroencephalography

EOG Electrooculography

HDI Highest density interval

HR Hazard ratio

JAGS Just another Gibbs sampler

MCI Mild cognitive impairment

MCMC Markov chain Monte Carlo

MRI Magnetic resonance imaging 


$\begin{array}{ll}\text { NFL } & \text { Neurofilament light } \\ \text { NFT } & \text { Neurofibrillary tangles } \\ \text { NREM } & \text { Non-rapid eye movement sleep } \\ \text { OR } & \text { Odds-ratio } \\ \text { P-Tau } & \text { Phosphorylated tau } \\ \text { PET } & \text { Positron-emission tomography } \\ \text { REM } & \text { Rapid eye movement } \\ \text { SWS } & \text { Slow-wave sleep } \\ \text { T-Tau } & \text { Total tau }\end{array}$




\section{Introduction}

The introduction to this thesis presents a brief background on aging, covering how changes in life expectancy, and time trends may challenge our current concepts of aging. The introduction continues with descriptions of sleep, cognition and major cognitive disorder (i.e., dementia), and describes their relationship.

\section{Relevance}

The focus for this thesis is to enhance our understanding of two major determinants of health in older people: subjective sleep disturbance and cognition. Previous studies have linked poor sleep to several chronic diseases including hypertension, cardiovascular disorders, diabetes, cancer, and even cognitive disorders (Medic et al., 2017), while an intact cognition is one of the key components for health and wellbeing in old age. The relationship between poor sleep and cognition is complex and studies have suggested that poor sleep can be a risk factor, an early symptom or even a contributing factor of major cognitive disorder (Ju et al., 2013; Yaffe et al., 2014). Therefore, to study the relationship between sleep and dementia is not only to investigate factors involved in the processes of Alzheimer's disease (AD), but also to find potentially modifiable risk factors for dementia. However, both the short- and long-term consequences of sleep for cognition in the general population is still largely unknown.

\section{Aging - individual and population level}

Aging is typically described as a gradual loss of functions of various kinds, such as loss of muscle mass, lung function, hearing and eyesight and immune function, as well as an increased risk of accumulation of chronic disorders, such as cardiovascular disorders and cancer. However, a recent review by Ferrucci et al. (2020) have suggested that factors associated with aging, such as physical or cognitive decline, is a function of the interaction between the processes that induces damages and the processes that are protective or increase resilience against damages. These are typically degenerative, biological processes such as genomic instability, shorter telomere length, epigenetic alterations, and proteostasis (Lopez-Otin et al., 2013). Whether these factors reflect the processes that increase damage or increase resilience, or even a combination of these remains largely unknown. There are also behavioral or 
lifestyle factors that may increase resilience such as physical exercise, a healthy diet, social networking, and even a good night's sleep, but also environmental factors such as cognitive stimulation through education or occupational complexity. Moreover, there are now an abundance of evidence indicating that aging itself is changing.

Figure 1 shows the worldwide life expectancies in Western and developing countries from 1543 to 2015 . In the United Kingdom, the country with the longest gathered time series, life expectancy fluctuated around 40 years with little differences up until the $19^{\text {th }}$ century. In the 1860 s, Swedish women held the world record with an average lifespan of 45 years (Oeppen \& Vaupel, 2002). However, large improvements then occurred in technology, infrastructure, welfare, education, and living conditions. Due to these changes, life expectancy increased dramatically, almost linearly with no signs of slowing down worldwide (Christensen et al., 2009). In Sweden, life expectancy increased to 85 years for women and 81 years for men in 2018, and the world record is currently held by Hong Kong women, with an average life expectancy of 88 years (United Nation, 2019).

Figure 1. Life expectancy from 1543 to 2015 in Sweden and Worldwide

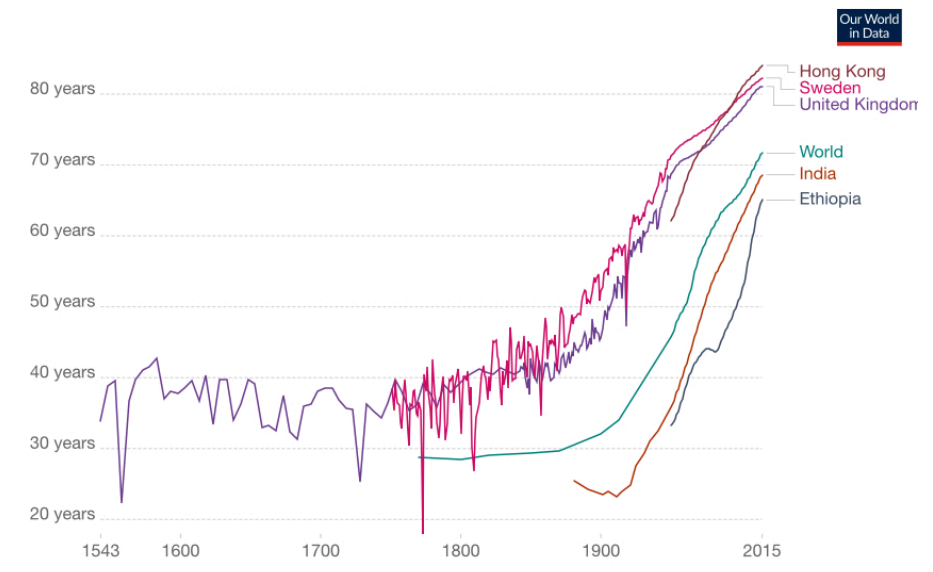

Notes: Acquired and modified by the author from Riley (2005), Clio Infra (2015), and UN Population Division (2020) at Our World in Data (2020). 
Accompanying these major changes in life expectancy, the age segments of the population are also changing. Specifically, the oldest age groups show the largest increases. It is expected that the number of people aged 80 years and older is likely to increase from 143 million in 2019 to 426 million in 2050 worldwide, and that the largest increments in the oldest ages are projected to be in Africa and Asia (United Nations, 2020).

One consequence of these demographic changes is that health care systems will face major challenges related to compromised health. For example, according to the World Alzheimer Report (2019), more than 50 million people worldwide were living with dementia in 2019, and this number is expected to increase to 152 million by 2050 . Moreover, the costs of dementia are now estimated to be 1 trillion USD per year and are expected to be doubled by 2030. On the other hand, due to the time trends described below, more people in this age group are also likely to live longer with better physical and cognitive health (Christensen et al., 2013). It, therefore, is increasingly important to understand the changes that accompany both normal and pathological aging where we potentially could prevent or counteract many negative outcomes.

\section{Time trends in aging}

In the 1960s, Werner Schaie suggested three types of influences when studying developmental processes: age, cohort, and the total environmental impact at a given time point (Schaie, 1965). He observed the developmental outcomes as a function of the interactions among all these factors. A related concept was suggested by Blanchard et al. (1977). They defined the age effect as something that occurs in all cohorts independently of time periods, and period effects as a change during a specific time period that affects all living cohorts (a good example of a period effect is the coronavirus crisis). A birth cohort is a type of cohort, defined by time of birth. Birth cohort effects are commonly referred to as variations or differences across birth cohorts when compared at the same ages. These variations can be shown as differences in health outcomes as due to several historical events and environmental factors that have shaped a birth cohort as they move together in time (Gerstorf et al., 2011; Rydberg Sterner, 2020). Differences between age and the period effects for the birth cohorts addressed in this thesis are illustrated in Figure 2. However, Rosow (1978) have criticized the concept of cohort as being too crude, too broad, or too general. For example, even though individuals in a cohort may be exposed similarly to an event (e.g., period effect), the assumption that all individuals in a cohort are affected somewhat uniformingly is probably not true. Most often, there is a large variation within each cohort that affect how people are able to cope with an event. For example, the 
period effect of the coronavirus crisis is largely dependent on age. For younger people, the effect of the pandemic might relate to factors such as social distancing or closed schools, while the effect for older people might be more related to risk of morbidity, or even death.

Knowledge on whether societal and environmental changes during the last decades have resulted in birth-cohort effects on factors such as sleep and cognition, can be acquired through population-based studies on birth cohorts born at similar dates with data collection conducted at different time periods (Wu et al., 2017). These studies have found that, in general, later-born cohorts are typically cognitively and physically healthier than earlier-born cohorts (Crimmins et al., 1996; Flynn, 1984; Schaie et al., 2005). These outcomes is similar to findings from the H70 Birth Cohort Studies, where laterborn cohorts, on average, are less dependent in their activities of daily living (ADL), more engaged in leisure activities (Falk et al., 2014), healthier (Wilhelmson et al., 2002), more sexually active (Beckman et al., 2008), have lower prevalence of cardiovascular disorders (Zhi et al., 2013) in comparison with earlier-born cohorts. However, is has also been suggested that the prevalence of depression (Wiberg et al., 2013) and alcohol consumption (Waern et al., 2014) have increased between the 1970s and 2000s. In addition, also the prevalence of dementia decreased in 85-year-olds, from 30\% in 1986-87 to $22 \%$ in 2008-10 (Skoog et al., 2017). There are, however, few studies that have investigated cohort differences using a longitudinal study design. A relevant account, in this context, is the compression of morbidity hypothesis (Fries, 1980; Fries et al., 2011). According to this hyphotesis, it is assumed that age at onset of chronic diseases is postponed in later-born birth cohorts and that most of the morbidity, therefore is compressed into a shorter time period. For example, cognitive level has improved substantially in later-born birth cohorts (Flynn, 1984; Karlsson et al., 2015; Sacuiu et al., 2010), but later-born birth cohorts may also experience a steeper cognitive decline with age (Thorvaldsson et al., 2017). Most factors that positively affect later-born birth cohorts can be expected to be directly or indirectly related to sleep, but it is still unclear whether, or to what degree, these time-trends have influenced the prevalence of insomnia in older people. 


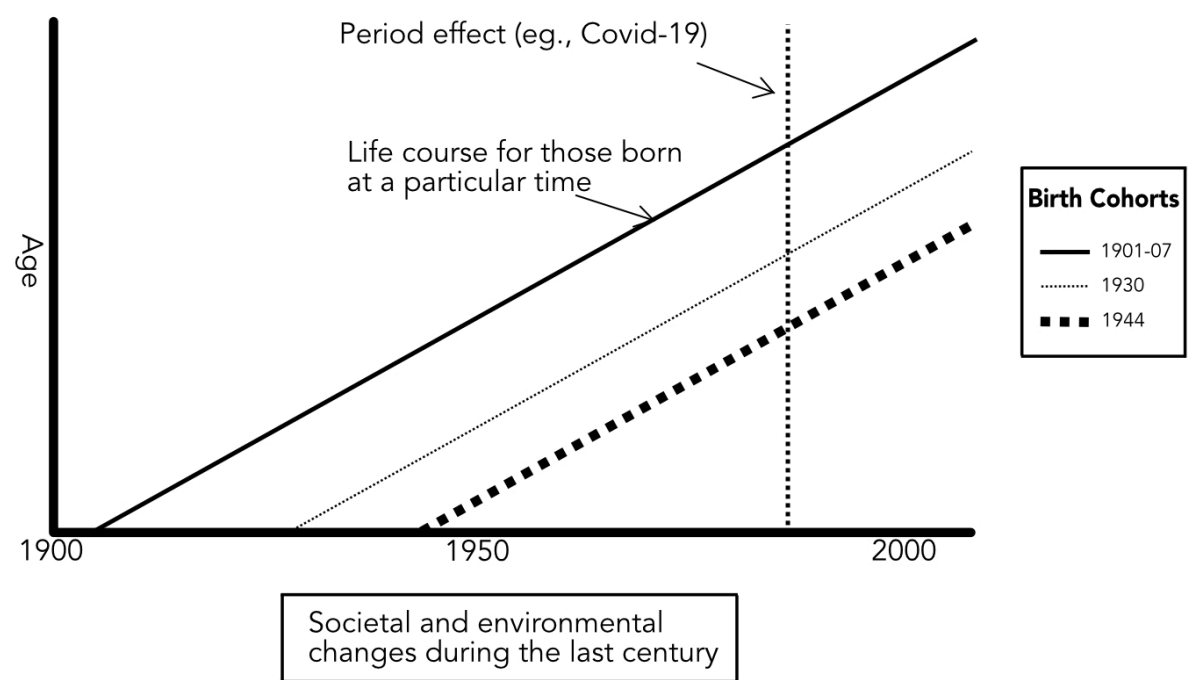

Notes: Acquired and modified by author from (Skoog, 2016). 


\section{Sleep}

In order to gain a broader understanding of sleep, this chapter begins with a short historical background of sleep in both the classical literature and early research. The chapter then continues with descriptions of sleep theories relevant for this thesis and also describes the stages of sleep. An overview of sleep and insomnia in aging follows, and finally an overview of time trends of sleep problems and insomnia is presented.

\section{Sleep problems and insomnia}

Insomnia disorder is defined in the Diagnostic and Statistical Manual of Mental Disorders $5^{\text {th }}$ edition (DSM-5) (American Psychiatric Association, 2013) as a predominant complaint of dissatisfaction with sleep quantity or quality, associated with one (or more) of the following symptoms:

1. Difficulty initiating sleep (also referred to as initial insomnia)

2. Maintaining sleep (i.e., frequent awakenings or problems returning to sleep after awakenings) (also referred to as middle insomnia)

3. Early morning awakenings with inability to return to sleep (also referred to as terminal insomnia).

\section{Sleep in the literature and early research}

The first known documentation of sleep stages was the Indian script "Upanishad", written ca 1000 B.C. In Chandogya Upanishad, human existence was divided into four stages of consciousness: the waking, the dreaming, the deep dreamless sleep, and the superconscious (see Mallick \& Inoue, 1999). However, historically sleep has been regarded as a passive state of being, and this is a view held until the middle of the $20^{\text {th }}$ century. As a consequence of the normative view of sleep as a passive state, sleep has also been closely related to death in the classical literature. For example, Samuel described in the Bible that the deepest sleep resembles death "No one saw or knew about it, nor did anyone wake up. They were all sleeping, because the Lord had put them into a deep sleep" (1 Sam. 26:12. New International Version). Also, in Homer's Iliad, when Aphrodite came to Lemnos, she met sleep as the brother of death (Homer, 1955). The Greek philosophers have also theorized on sleep. Alcmaeon suggested that sleep occurs due to the withdrawal of the blood from the body to the larger blood-flowing vessels. He proposed that we are awake when the blood diffuses back to the body again (see Huffman, 2017). Even Shakespeare wrote about the importance of sleep. In Macbeth, Act 2, Scene 2, Macbeth said "Sleep that soothes away all our worries. Sleep that puts each day to rest. Sleep that relieves the weary laborer and heals hurt minds. Sleep, the main course in life's feast, and the most nourishing" (see 
Chopra \& Tanzi, 2015). When taking a historic perspective, it is also worth considering the impact of the invention of the light bulb in the late 19th century. The invention had a significant influence on sleep habits and some researchers have even suggested that the invention of the light bulb was solely responsible for reducing sleep by up to two hours per night in the general population The observant reader may also note that this is a perfect example of a period effect that have affected sleep behavior in later-born birth cohorts.

Systematic sleep research was first initiated in the late $19^{\text {th }}$ and early $20^{\text {th }}$ century. In 1875, the English scientist Robert Caton invented the electroencephalograph (EEG) for measuring brain waves in dogs (Caton, 1875), and half a century later, in 1929, Berger and Gloor developed the first EEG for humans (Berger \& Gloor, 1969). The golden standard for measuring sleep is still considered to be EEG. It is noteworthy, given the focus for this thesis that already in 1924, Jenkings and Dallenbach (1924) had conducted the first known systematic experiment on the relationship between sleep and memory function. They found that memory retention was better after a night of sleep as compared to being awake for the same time. However, they continued to think of sleep as a passive state and explained their results with a lack of sensory inference during sleep (Walker \& Stickgold, 2006). Emphasis of sleep as an active process did not begin until 1937, when Loomis, Harvey, and Hobart, using EEG, identified the five stages of sleep (Loomis et al., 1937). It was now clear that sleep was not merely a passive state of being, but was, rather, a period of high activity. Kleitman and Aserinsky (1953) systematically documented rapid eye movement (REM), and its distinction from nonrapid eye movement (nREM) using electrooculography (EOG). A student of Kleitman, William Dement (1957), showed that sleep comprises different stages, repeated four or five times per night. Ten years later, Rechtschaffen and Kales (1968) introduced a scoring system based on EEG to classify the different sleep stages in humans. This classification, with small changes in 2007 (i.e., Stage 4 was eliminated and Stages 3 and 4 were combined into Stage 3) (American Academy of Sleep Medicine., 2007), has been broadly used in sleep research up to the present day. Lastly, a major breakthrough in sleep research in recent years has been the discovery of the glymphatic system by Maiken Nedergaard et al. (2012) which is reviewed in the subsequent section. This discovery is especially important for this thesis. 


\section{Sleep theories}

The glymphatic system

Due to the brain's lack of a lymphatic system, it was previously unknown how the brain can remove waste products from neural activity (Sun et al., 2018). Maiken Nedergard et al. (2012) have suggested that the brain must clear waste products in an alternative way. Through experiments in mice, using imaging, they identified a pathway for fluid transport. This was a system of channels, formed by astroglial cells, that functioned to remove proteins and metabolites from the central nervous system (Jessen et al., 2015). The researchers labelled this system the glymphatic system, due to its dependence on glia cells and the similarities to the lymphatic system in the body. Interestingly, the same research group found in a subsequent study that metabolic waste products of neural activity were cleared out of the brain faster during sleep, as compared to when awake (Xie et al., 2013). Furthermore, one of the proteins that was cleared out faster during sleep was amyloid $\beta$ $(\mathrm{A} \beta)$, a protein believed to play an important role in the development of dementia caused by Alzheimer's disease (AD). Thus, one component to understand the early processes of $\mathrm{AD}$, and maybe even protect against $\mathrm{AD}$ could be to increase clearance of $A \beta$ through sleep, and in that way reduce $A \beta$ accumulation in the brain. Later in the introduction, a description will be given on how the identification of this system have affected research on sleep and dementia.

\section{Two-process model of sleep and wake regulation}

One of the most widely used models to describe sleep is the two-process model of sleep-wake regulation (Borbely, 1982) (see Figure 3). This model gives an intuitive approach to understand sleep problems and insomnia and is, therefore, frequently referred to in books on sleep and in clinical settings. This model comprises the homeostatic sleep drive, the pressure to sleep, the so-called Process S. Process S is regulated, in part, by increasing adenosine, a metabolic byproduct that accumulates the longer we are awake (Dworak et al., 2010; Mander et al., 2017; Porkka-Heiskanen et al., 1997). Thus, the longer awake, the more sleep pressure. The other factor included in this model is the circadian drive for arousal, the circadian rhythm, the so-called Process $\mathrm{C}$. The circadian rhythm goes up and down repeatedly throughout the day controlled by the circadian pacemaker. When process $\mathrm{S}$ approaches its lower levels, it triggers awakening, and at its highest level, it triggers sleep. Later during the evening, when process $\mathrm{S}$ is high and circadian drive for arousal is low, sleep onset occurs. During the morning, when circadian drive for arousal is rising, and sleep pressure is low, wake up occurs (Borbely et 
al., 2016). Van Cauter et al. (2000) have found that changes in the homeostatic sleep drive could be early biomarkers of aging, while the parts of sleep that are under the control of the circadian pacemaker may be relatively well preserved until late in life.

In relation to sleep problems and insomnia, it has been suggested that dysfunction in sleep pressure or circadian rhythm may results in reduced tendency to sleep during the desired sleep period, which could eventually lead to insomnia (Levenson et al., 2015). Also, sleep restriction, a method using mild sleep deprivation to increase sleep pressure, is one of the main components of cognitive-behavioral therapy for insomnia (CBT-I) (Morin, 2004).

Figure 3. Two-process model of sleep regulation

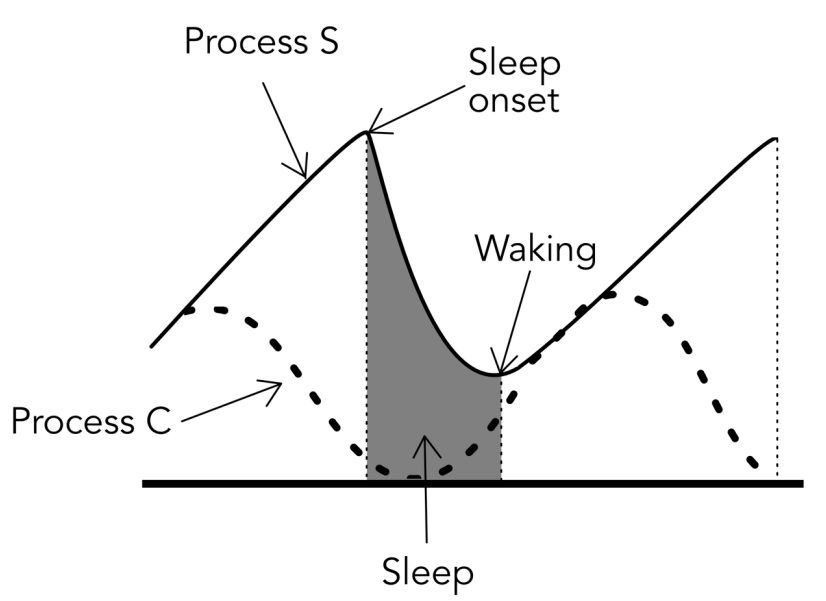

Notes: Illustrations adapted by the author from The two-process model of sleep regulation: A reappraisal (Borbely et al., 2016). 


\section{Sleep stages}

The classification of sleep comprises four stages; three stages of nREM sleep and one stage of rapid eye movement (REM) sleep (see Figure 4). The sleep stages are detected through polysomnography using several measurements, including EEG (electrical activity of the brain), electrocardiography (ECG) (electrical activity of the heart), electrooculography (EOG) (eye movement), and electromyography (EMG) (muscle tonus).

\section{NREM Stage 1}

Figure 4 shows wave patterns at the different sleep stages. The first stage is a transition between being awake and asleep. The waves are called alpha waves when awake, and during transition into sleep, the waves slow down and are then called theta waves. At stage 1, a person is easy to wake up and sleeps lightly with eyes closed.

\section{NREM Stage 2}

Stage 2 occurs when the body is preparing for deeper sleep. The heart rate goes down, and the body temperature gets lower. Brain activity slows, but in this stage, two peculiar activities called sleep spindles and K-complexes are common. Sleep spindles are a sudden burst of rapid, rhythmic brain waves. These brainwaves look like spindles on an EEG and are, therefore, called sleep spindles and can occur both in lighter and deeper sleep. K-complexes are instead large, slow waves and occur mostly in deep sleep (Cash et al., 2009). Both sleep spindles and K-complexes have been associated with sleepdependent memory consolidation (Cox et al., 2012). The density of both sleep spindles and K-complexes decreases with age (Crowley et al., 2002), and this decrease may be even more pronounced in mild cognitive impairment (MCI) and AD (Prinz et al., 1982).

\section{NREM Stage 3}

Stage 3 sleep is also known as slow-wave sleep (SWS) due to the low frequency of the waves. These slow waves are called delta waves and this state is, therefore, sometimes known as delta sleep. Waking up at this stage can sometimes lead to disorientation. Impaired stage 3 sleep have previously been linked to the early stages of AD (Lucey et al., 2019; Mander et al., 2015).

\section{REM Sleep}

The fourth state is called REM sleep. This state is characterized by rapid eye movement and low muscle tonus throughout the body. This is a state of light sleep and the brain waves are similar to when awake. Due to higher brain activity, intense dreaming may also occur in REM sleep. 


\section{Sleep cycles}

Each stage generally lasts between five to 20 minutes and all three phases are passed before reaching REM sleep. Every sleep cycle lasts for approximately 90 minutes and occurs four to six times per night. SWS is more prominent during the early part of the night but reduces in strength and duration across the sleep period. In contrast, REM sleep increases in frequency and duration over the sleep period, from approximately 10 minutes during the first circle to almost an hour during the last (Rasch \& Born, 2013).

Figure 4. Brain Wave patterns on EEG during different sleep stages.

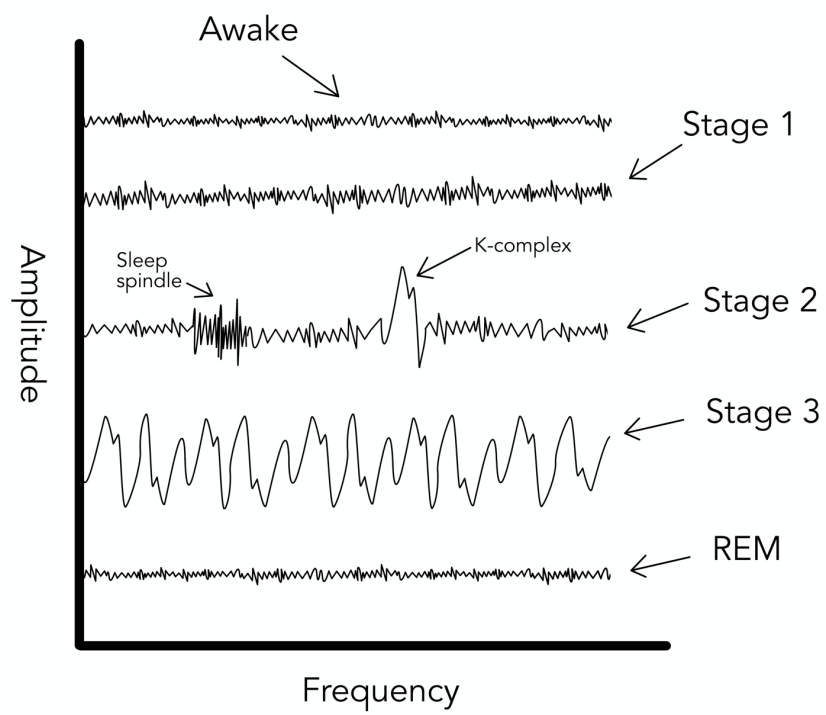

Notes: Illustrations adapted by the author from Lumen Learning: https://courses.lumenlearning.com/suny-hccc-ss151-1/chapter/stages-of-sleep 


\section{Sleep in aging}

Many changes in sleep, both physiological and psychosocial, occur during the process of normal aging. For example, older people tend to report more early awakenings, increased sleep onset latency, reduced sleep efficiency (i.e., the ratio of time spent asleep compared to the amount of time spent in bed), more day-time naps and shorter sleep duration compared to younger adults (Ancoli-Israel, 2009; Cajochen et al., 2006; Roepke \& Ancoli-Israel, 2010). A large meta-analysis by Ohayon et al. (2004), covering 65 studies, including a total sample of 3,577 individuals aged five to 102 years, found that in adults, total sleep time, sleep efficiency, proportion of both SWS and REM sleep decreased with age, while sleep latency, proportion of stage 1 sleep, proportion of stage 2 sleep, and number of awakenings after sleep onset increased with age. They also found that only sleep efficiency continued to decrease after age 60 . They therefore suggested that a large amount of agerelated changes in sleep patterns occur already in middle age or earlier. Other studies have shown that among healthy individuals, sleep continuity, and SWS is generally reduced in older ages, but older adults without sleep disorders are less sleepy during the daytime compared to younger adults (Dijk et al., 2010). Furthermore, older people may wake up more frequently during the night compared to younger people, but they tend to fall back to sleep at the same rate as their younger counterparts (Klerman et al., 2004). This suggests that it is the transition from being asleep to being awake that is more affected by aging than the transition from awake to asleep.

The term insomnia is often used and defined in various ways in the literature (Roth, 2007) and, therefore, prevalence rates vary extensively depending on study populations and definitions used (Ohayon, 2002). However, most studies show that insomnia is more common in older as compared to younger age groups (Chiu et al., 1999; Roepke \& Ancoli-Israel, 2010). A study from Hong Kong found that $75 \%$ of individuals aged 75 and older reported sleep disturbances, while 35\% reported insomnia (Chiu et al., 1999). However, with more restrictive criteria, the prevalence rates may decrease to $20 \%$ to $40 \%$ in older people (Foley, 1995; Vitiello, 1997).

\section{Time trends in sleep problems and insomnia}

There are relatively few studies focusing on time trends in insomnia, and even fewer have used a birth-cohort study design that allows comparisons across different birth cohorts.

A Brazilian study from Sao Paolo (Santos-Silva et al., 2010) investigated period effects in individuals aged 20 to 80 years, in three different surveys conducted in 1987, 1995 and 2007. They found a progressive increase of 
sleep complaint over time with the largest increases between 1995 and 2007. The largest increase was found among women.

A survey of time trends targeted a Norwegian population aged 18-years and older in 1999-2000 and in 2009-2010. They found that sleep onset insomnia, dissatisfaction with sleep, daytime impairment, and insomnia according to DSM-IV, as well as use of sleep medication increased with time (Pallesen et al., 2014).

Kronholm et al. (2008) have reported mixed results when reanalyzing all available data from surveys carried out in Finland from 1972 to 2005. They found a minor decrease in sleep duration and that the proportion of people who slept seven hours had increased. However, the proportion of extreme sleepers, that is those who slept less than six hours or more than nine hours, remained unchanged.

An English study, using data from three mental health surveys carried out in 1993, 2000, and 2007 among people aged 16-64 years found that insomnia symptoms and insomnia diagnoses were more prevalent in 2007 compared to in 1993 (symptoms: $35.0 \%$ in 1993 versus $38.6 \%$ in 2007 and insomnia diagnosis 3.1\% in 1993 versus 5.8\% in 2007) (Calem et al., 2012).

A Scottish study from Glasgow (Green et al., 2012) using a sample of 57year-olds born in the 1930s and 1950s, and followed for 20 years, used a latent class analyses to identify four classes; healthy, episodic sleep problems, chronic, and development of sleep problems during the 20-year followup. Those born in the 1930s were more likely than those born in the 1950s to belong to the chronic sleep problem group or to the group who developed sleep problems.

A report from the Prospective Study of Women from Gothenburg, born in 1908, 1914, 1918, 1922, 1930, 1942, and 1954 examined 1968-69, 1980-81 and 2004-2005 at ages 38 and 50 years found that in 38-year-olds, sleep problems were more common and sleep duration shorter for later-born cohorts. There were also fewer who slept more than nine hours (11\% vs. 3.5\%) in later-born birth cohorts (Bjorkelund et al., 2002). However, no significant differences were found for the 50-year-olds. Another report from this study found that the proportion of women complaining of sleeping problems almost doubled in both age groups: from 18\% in 1968 to 32\% in 2004 in 38-year-old women, and from $22 \%$ to $42 \%$ in 50 -year-old women (Rowshan Ravan et al., 2010).

It is of note that, most of these studies, except for the Prospective Study of Women and the study from Glasgow, can only account for the age effect during a given period and may thus ignore the effect of birth cohort. Although studies of period effects are important when investigating general trends for the entire population, these period effects might not show changes that are 
specific for a certain birth cohort. This may be especially important in older ages, where sleep problems in general are more common in older compared to in younger ages. Therefore, the large societal and environmental changes during the last century that could affect factors related to sleep might not be shown in these studies. 


\section{Cognition and dementia}

In this chapter, findings on cognition in normal and pathological aging are briefly presented and it is shown that this distinction is not always well defined. Then the two concepts, cognitive reserve and terminal decline, are introduced. The chapter continues with a description of pathological aging, such as major cognitive disorder, or dementia, and describes biomarkers for the most common type of dementia, Alzheimer's disease (AD). Lastly, the long preclinical phase of dementia is addressed.

\section{Cognitive aging, cognitive reserve, and terminal decline}

Aging affects the brain in several ways by reducing brain size and affecting vasculature, as well as cognition (Peters, 2006). Although dementia and other cognitive disorders are common in older ages, those not diagnosed with dementia might also experience a decline in cognition associated with aging (Harada et al., 2013). It has been shown that normal aging is commonly accompanied by an age-related decline in several cognitive domains including processing speed, memory, and logical reasoning (Deary et al., 2000; Nyberg et al., 2012).

Many studies have shown that the degree of brain pathology does not always correspond well with cognitive performance. Some people may have a larger reserve capacity, which make them cope better with severe brain damage (Stern, 2002). For example, brain autopsy findings from The Medical Research Council Cognitive Function and Ageing Study (MRC CFAS) indicate that as much as one fourth of individuals free from dementia met pathologic criteria for AD (Neuropathology Group. Medical Research Council Cognitive \& Aging, 2001).

Concerning the reserve capacity, a distinction is often made between a passive brain reserve (Satz, 1993), which is often quantified with measures of total brain volume or neuronal count, and a more active cognitive reserve (Stern, 2002, 2009), which is often indexed by individual differences in cognitive abilities while holding brain pathology constant. As an example of this theory, two individuals can have the same brain reserve capacity but still express clinical symptoms differently due to individual differences in cognitive reserve (Stern, 2009). Factors that affect cognitive reserve can be all events that shape an individual's brain and cognition as acquired over the lifespan by education, type of occupation, and major life events. Studies investigating cognitive reserve commonly use proxy measures of this reserve such as socio-economic status or level of education (Opdebeeck et al., 2016). There is an abundance of evidence indicating that individuals with higher education achieve higher levels of cognition (Lövdén et al., 2020). Results on whether individuals with higher education also experience less cognitive 
decline with age are inconsistent. Higher education has been suggested to protect against cognitive decline (Christensen et al., 2009; Stern, 2002), but several studies now reports that higher education is rather associated with levels of cognitive performance than cognitive change (Cadar et al., 2017; Lovden et al., 2020; Piccinin et al., 2013; Seblova et al., 2020).

During the last years of life, a decrease in function may occur in several domains, including cognition (Hulur et al., 2016), and this is commonly referred to as terminal decline (Kleemeier, 1963; Palmore \& Cleveland, 1976; Riegel \& Riegel, 1972; Siegler, 1975). This phenomenon have been observed in several longitudinal studies of older people (Gerstorf et al., 2008; Johansson \& Berg, 1989; Thorvaldsson et al., 2008). Terminal decline may become more important with age, since it is an indicator of subsequent mortality, but may be especially important among the oldest old due to their high mortality rates. However, Riegel and Riegel (1972) have suggested that death may strike more randomly in older ages and that the differences in cognition between survivors and non-survivors may, therefore, be less pronounced in these age groups. However, a study by Muniz-Terrera et al. (2011) found that dying at an older age was associated with lower cognitive performance two years before death and with a faster decline. One reason for the latter could be that individuals who die at older ages may have a higher prevalence of other diseases that influence cognition, and this could be reflected by differences in rate of cognitive decline. For younger individuals, these differences may be less evident. However, other studies have found little evidence for this claim, and have suggested that age at death moderated cognitive level of performance, but not terminal decline in cognition (Thorvaldsson et al., 2006).

\section{Major cognitive disorder}

Major cognitive disorder (American Psychiatric Association, 2013), or dementia, is a clinical syndrome caused by neurodegeneration. The most common pathologies are AD, vascular dementia, Lewy body disease, and frontotemporal dementia. Dementia is characterized by a progressive decline in cognition and capacity for independent living (Prince et al., 2013).

Although chronological age is the most important risk factor for dementia, age itself does not cause dementia. Studies have shown that dementia incidence increases exponentially with age from age 65 up to age 90 and doubles approximately every five years (Corrada et al., 2010; Jorm \& Jolley, 1998). However, it is still unknown if this doubling continues after age 90 years (Fratiglioni et al., 2000). Some studies report that the prevalence of dementia continues to increase after age 90 years (von Strauss et al., 1999), while others suggests that it levels off or reaches a plateau in very old ages (Kliegel et 
al., 2004; Ritchie \& Kildea, 1995; Wernicke \& Reischies, 1994). In addition, the relationship between the most common pathologies and dementia may be stronger in younger old than in older old populations and some studies even suggest that $\mathrm{AD}$ or vascular dementia may not have the same pathological relevance on cognition after the age of 90 years (Andersson et al., 2012; Savva et al., 2009).

The most common form of dementia is AD. The disease is named after the psychiatrist and neuroanatomist Alois Alzheimer (see Hippius \& Neundorfer, 2003). The first described AD patient was the 50-year-old woman Auguste Deter, who five years before her death, showed symptoms of paranoia, memory disturbance, aggression, and confusion. Alzheimer's report from the autopsy noted distinctive plaques (now called amyloid plaques, which are aggregates of misfolded proteins) and tangled bundles of fibers (now called neurofibrillary or tau-tangles, which are aggregates of hyperphosphorylated tau protein) in the brain tissue. These features are still considered to be the two main neuropathological hallmarks of AD. Later, Emil Kraepelin, a German psychiatrist and the founder of the psychiatric diagnostic classifications included "Alzheimer's disease" in the 3rd edition of his book Psychiatrie in 1910. The disease is characterized by a progressive decline in memory, executive function, language, and other areas of cognition (McKhann et al., 2011). Pathologically, the disorder is characterized by the formation of amyloid plaques, neurofibrillary tangles, neuronal loss, synaptic loss, brain atrophy, and inflammation (DeTure \& Dickson, 2019). Accumulation of $A \beta$ is assumed to initiate the process involving a pathogenic cascade that eventually leads to AD (Hardy \& Selkoe, 2002).

\section{Cerebrospinal fluid markers of Alzheimer's disease}

The brain's pathology and metabolism are reflected in the cerebrospinal fluid (CSF) (Niemantsverdriet et al., 2017). The core CSF biomarkers for AD are low levels of $\mathrm{A} \beta 42$, and high levels of total tau (T-tau), and phosphorylated tau (P-tau) (Blennow et al., 2001; Niemantsverdriet et al., 2017).

\section{Amyloid $\beta$}

Amyloid $\beta$ is a protein found in the central nervous system (CNS). Its longest isoform consists of 42 amino acids (A 342 ) as a result of cleavage of amyloid precursor protein (APP) by $\beta$ - and $\gamma$-secretases (Portelius et al., 2011). Amyloid $\beta 42$ is highly insoluble and aggregates into extracellular $A \beta$ deposits in the $\mathrm{AD}$ brain. This is detected by decreased levels of $\mathrm{A} \beta 42$ in CSF (Niemantsverdriet et al., 2017). Furthermore, A $\beta 42$ is believed to mirror accumulation of plaques in the brain, thus, the more plaques in the brain, the less $\mathrm{A} \beta 42$ are left in the CSF. Therefore, studies have commonly found an 
inverse association between CSF A $\beta 42$ and amyloid plaques accumulation in the brain (Strozyk et al., 2003). In addition, it has been shown that the ratio between $A \beta 42$ and $A \beta 40$ are better than $A \beta 42$ alone to identify brain amyloid deposition in preclinical AD (Janelidze et al., 2016). This ratio also accounts for individual differences in production of amyloid.

\section{Tau}

In patients without $\mathrm{AD}$, tau is a highly soluble protein in neurons (Noble et al., 2013). In AD patients, an imbalance between kinases and phosphatases results in a hyperphosphorylation of tau, that eventually leads to intraneuronal accumulation into neurofibrillary tangles (NFT). Then, tau and phosphorylated tau proteins are released into the extracellular space, resulting in increased tau levels in CSF (Niemantsverdriet et al., 2017).

\section{Neurogranin}

Neurogranin is a post-synaptic protein and a marker of synaptic dysfunction. It has been shown that the density of neurogranin is increased in $A D$ and it is associated with aggregation of both CSF t-tau and p-tau (Thorsell et al., 2010), and to cognitive decline (De Vos et al., 2016). Due to its association with cognitive decline, it has been suggested that neurogranin may be more related to the disease process of $\mathrm{AD}$ than the other core biomarkers described above (Fyfe, 2015).

\section{Neurofilament light}

Neurofilament light chain (NFL) is a neurofilament protein particularly rich in myelinated axons (Lin et al., 2018). Axonal damage releases NFL into the CSF, and thus, higher levels of NFL indicate more axonal damage in the brain. Although NFL have been associated with AD (Mattsson et al., 2017), it is also related to several other neurodegenerative disorder. Therefore, NFL may have limited usability as a specific marker of AD. However, high concentrations of NFL in preclinical AD may indicate a more rapid disease progression (Zetterberg et al., 2016).

\section{Preclinical Alzheimer's disease}

The diagnosis of preclinical AD is based on pathological levels of $A \beta$ and tau proteins obtained from either CSF or positron-emission tomography (PET) in persons without cognitive symptoms. Alzheimer's disease is known for a long asymptomatic preclinical phase and pathophysiological changes can occur long before clinical manifestations (Aisen et al., 2017). It has been suggested that CSF A $\beta$ may be reduced as long as 20 years before the actual diagnosis of dementia, while CSF tau can be elevated approximately 15 years 
before the clinical manifestation of AD (Dubois et al., 2016). Thus, in this preclinical phase individuals with intact cognition can fulfil the pathological criteria for the disease (DeTure \& Dickson, 2019). The prevalence of $A \beta$ pathology increases with age and a large meta-analysis of 2,914 participants aged 18 to 100 years from 55 studies has demonstrated an increase with age in cognitively normal individuals from $10 \%$ at age 50 years to $44 \%$ at age 90 years (Jansen et al., 2015). Findings from the H70 Birth Cohort Studies show that as many as one fourth of cognitively intact 70-year-olds had amyloid pathology and one third had tau-pathology in CSF (Kern et al., 2018) as classified according to the A/T/N system criteria (Jack et al., 2016).

Figure 5 shows a version of the Jack's model (Jack et al., 2013), which is a widely used model to illustrate the preclinical phase of AD. The black line illustrates the threshold for when the first detection of biomarkers is potentially possible, and the gray area marks the zone where changes can be detected through biomarkers. According to this model, $A \beta$ is the first biomarker to reach above the detection threshold and can first be detected in CSF and then on PET scans (red dotted line). Then, an acceleration of tauopathy is proposed to occur, which can be detected in CSF (blue dotted line). Also, recently, tau-specific tracers have been developed for use with PET scans (Leuzy et al., 2019; Saint-Aubert et al., 2017). After the increase in tau, neurodegeneration can become detectable by magnetic resonance imaging (MRI) (purple line), and lastly, cognitive impairment becomes evident (green area), which severity may depend on the individual's reserve capacity. This model has also been described elsewhere (see Jack et al., 2013; Jack et al., 2010). 
Figure 5. A model integrating Alzheimer's disease biomarkers

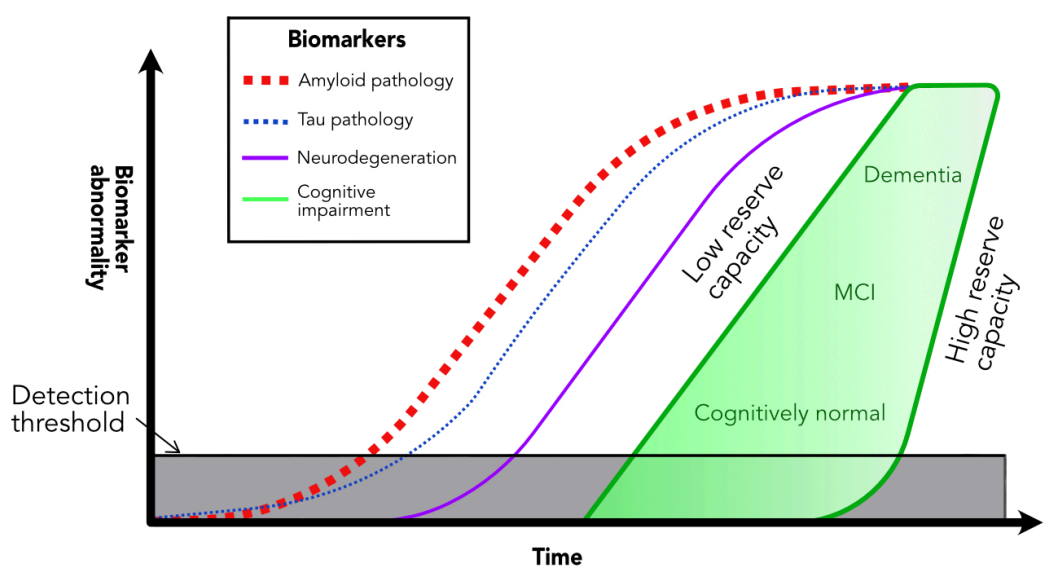

Notes: Acquired and modified by the author from Fig 6 from Jacks model (2013) 


\section{The relationship between sleep and dementia}

Interestingly, Alois Alzheimer noted in his report that even the first AD patient, Auguste Deter, had troubles with her sleep as part of her dementia disorder. This chapter describes the relationship between sleep and dementia, and biomarkers of $\mathrm{AD}$ and also introduces the apolipoprotein $\mathrm{E}(A P O E)$ gene and its function in AD.

\section{Sleep, dementia and markers of preclinical Alzheimer's disease}

Since the discovery of the glymphatic system (Iliff et al., 2012), interest have grown substantially in studying the association between sleep and AD (see Fan et al., 2019; Mander et al., 2016; Wang \& Holtzman, 2020). This is not only with the purpose to investigate factors involved in the processes of AD, but also to find potentially modifiable risk factors for dementia, given the assumption that certain lifestyle habits may lead to a lower risk of developing dementia later in life (Baumgart et al., 2015; Edwards III et al. 2019). However, the relationship between sleep and AD is complex and studies have shown that poor sleep can be a risk factor for late life dementia (Benedict et al., 2015; Bokenberger et al., 2017) and cognitive decline later in life (Sindi et al., 2018), or act as an early symptom of a subsequent dementia disorder (Prinz et al., 1982; Westerberg et al., 2012). It is, therefore, suggested that the relationship between sleep and cognition could be bidirectional and poor sleep can both be a symptom and a contributing factor to dementia (Ju et al., 2013; Yaffe et al., 2014). A limitation of the relatively few previous studies with long follow-ups is that dementia diagnoses were based only on registry data and not from diagnoses based on symptoms from clinical examinations. Studies have shown that dementia diagnoses from registries often underestimate the prevalence and the incidence of dementia, especially in the early stages of the disease (Krysinska et al., 2017; Ritchie et al., 2016). Thus, given the long preclinical phase of dementia, it is difficult for these studies to disentangle whether poor sleep is a symptom of the disease or a risk-factor.

Sleep seems to be involved in the early pathogenesis of AD. Mice models suggests that $A \beta$ aggregation increases during sleep deprivation (Kang et al., 2009) and it has been suggested that metabolic waste products are cleared faster from the brain during sleep (Xie et al., 2013). This clearance may be stronger during SWS (Hablitz et al., 2019), although others argue that the clearance mostly occurs during wakefulness (Gakuba et al., 2018). Similar findings have been reported in humans where a recent pilot study suggested that sleep deprivation may rather increase $A \beta$ production than decrease $A \beta$ clearance (Lucey et al., 2018). In addition, one study reported increased $A \beta$ burden on PET scans after one night of sleep deprivation (Shokri-Kojori et al., 2018), while another study showed no effect on CSF amyloid deposition 
after five consecutive nights of partial sleep deprivation (Olsson et al., 2018). Also, a recent study suggested that acute sleep loss increased blood levels of total tau (t-tau), but not levels of A $\beta$ or NfL (Benedict et al., 2020).

The associations between sleep disturbances, measured both objectively and subjectively, and the early biomarkers of $\mathrm{AD}$, have so far only been investigated in a few epidemiological studies. These studies have linked sleep disturbances to AD-related neuropathology on PET scans or CSF in cognitively normal individuals (Spira et al., 2013; Liguori et al., 2014; Sprecher et al., 2015; Sprecher et al., 2017; Winer et al., 2019), and in persons with mild cognitive impairment (MCI) and severe dementia (Liguori et al., 2014). However, markers of neurodegeneration and synaptic dysfunction, such as neurofilament light (NFL) and neurogranin, were not associated with sleep parameters in one of the studies (Sprecher, 2017). This study was, however, based on data from a convenience sample. It is, therefore, possible that the findings were not representative for the general population.

\section{Apolipoprotein E $\varepsilon 4$, Alzheimer's disease, and sleep}

The $\varepsilon 4$ allele of the $A P O E$ gene is the strongest genetic risk factor for $\mathrm{AD}$ (Liu et al., 2013). The APOE gene includes three polymorphic alleles; $\varepsilon 2, \varepsilon 3$ and $\varepsilon 4$. The $\varepsilon 2$ is believed to be protective against $\mathrm{AD}$, whereas the $\varepsilon 4$-allele is a risk factor (Kim et al., 2009). The prevalence of the $\varepsilon 4$ allele varies by country, but among AD patients in the Western world, the frequency of the $\varepsilon 4$ allele in both hetero and homozygotes is about $40 \%$ compared to $14 \%$ in the general population (Farrer et al., 1997). APOE \&4 is believed to influence $\mathrm{A} \beta$ in several ways through metabolism, clearance and increased $\mathrm{A} \beta$ production (Kim et al., 2009).

The $A P O E \& 4$ allele have in previous studies frequently been specified as a moderator between lifestyle factors, such as physical activity or diet, and markers of preclinical AD. Brown et al. (2013) have found that $\varepsilon 4$ carriers who were physically inactive had more amyloid deposition than physically inactive non-carriers. Furthermore, Head et al. (2012) suggested that $\varepsilon 4$ carriers with a non-active lifestyle could have an increased risk of amyloid deposition. However, previous studies on the relationship between sleep, the $A P$ $O E \varepsilon 4$ and preclinical AD have yielded mixed results. One study found that the $A P O E \& 4$ allele acts as a moderator in the relationship between sleepwake cycle and $A \beta$ accumulation (Hwang et al., 2018), while others found no interaction (Brown et al., 2016). Furthermore, one study found that better sleep attenuates the association between the presence of the $A P O E \varepsilon 4$ allele and both AD incidence and development of tau pathology (Lim et al., 2013). The reason for these findings may be that the possession of the $\varepsilon 4$ allele makes people more vulnerable to the effect of reduced sleep. It is also possi- 
ble that carriership of the $A P O E \varepsilon 4$ allele increases the risk for sleep disturbance, as shown in one study (Wang \& Lung, 2012). 



\section{Summary of studies}

The oldest age groups now constitute the fastest growing segment of the world population and the number of people aged 80 years and older is set to increase dramatically worldwide in the forthcoming decades. The demographical changes make it increasingly important to achieve better understanding of the many changes that accompany aging. The overall aim of this thesis is to enhance our understanding of subjective sleep disturbance and cognition, which are two major determinants of health in normal and pathological aging. Poor sleep is associated with chronic diseases and all-cause mortality, while intact cognition is one key component for health and wellbeing in older people. Previous studies on the relationship between poor sleep and cognition have suggested a complex relationship where poor sleep can be a risk factor, an early symptom, or even a contributing factor for major cognitive disorder (i.e., dementia). Therefore, to study the relationship between sleep and dementia is not only important for investigating factors involved in the processes of $\mathrm{AD}$, but also for finding potentially modifiable risk factors for dementia. However, both the short- and long-term consequences of sleep on cognition in the general population is still largely unknown.

\section{Aim of Study I}

Studies focusing on time trends of insomnia are rare and most studies have investigated period effects during the time of examination rather than the effect of being born in a specific birth cohort. It is of note that most of these studies show that the prevalence of insomnia and sleep disturbance increase in cohorts examined during later time periods. Although studies of period effects are important when studying general population trends, these effects cannot reveal effects that are specific for a birth cohort or age group. Previous studies have shown that the large societal and environmental changes during the last century have positively influenced the general health of older people born in later-born birth cohorts. Most of these factors are directly or indirectly related to sleep to a varying degree but it is still not known if these changes have influenced the prevalence of insomnia in older people. It is, therefore, possible that the prevalence of insomnia in older age groups is overestimated. Our hypothesis was that the large environmental influences over the last decades have positively affected sleep and thus reduced insomnia in later-born cohorts.

The specific aim of Study I was to test this hypothesis by investigating if there were birth-cohort differences in the prevalence of insomnia in older 
adults. Data were drawn from two population-based birth cohorts born up to three decades apart and followed longitudinally from age 70 to 79 years.

\section{Aim of Study II}

It is well known that the incidence of dementia increases with age, but it is still not clear whether the prevalence of dementia continues to increase after age 90 years or if it levels off and reaches a plateau in very old age. There are very few longitudinal studies on cognition after age 95 years and little is therefore known about the course of dementia in relation to age-related cognitive decline. Also, the decline prior to death, the so-called terminal decline phenomenon, may be especially important in oldest-old individuals due to their high mortality rates. It has, however, been suggested that the effect of cognition on subsequent mortality may even level off among the oldest old. Only a few studies have hitherto investigated how cognitive level and change are influenced by impending death and education in this very old age group.

The specific aim of Study II was to examine whether cognitive status measured by the Mini-Mental State Examination (MMSE) could predict dementia and subsequent mortality in 97-year-olds who were followed over three years while controlling for their education and sex.

\section{Aim of Study III}

Previous studies have suggested a bidirectional relationship between sleep and dementia. Poor sleep is assumed to either be a risk factor for dementia or/and an early symptom of a subsequent dementia disorder. Studies have also suggested that improving lifestyle factors early in life could decrease the risk of developing dementia. The preclinical phase of dementia is long which requires long follow-ups to study if poor sleep represents a potential risk factor for subsequent dementia. Most previous studies on sleep and dementia have often used short follow-ups, sex specific samples, or dementia diagnoses based only on registry data. Registries are known for both underestimating the prevalence of dementia and only capturing diagnoses very late in the disease process.

The specific aim of Study III was to test if poor sleep in midlife and late life was a risk factor for the development of late-life dementia. We used a multicenter approach with three population-based studies from Sweden and Finland.

\section{Aim of Study IV}

The causes of $\mathrm{AD}$ are still largely unknown which makes it important to know more about the clinical correlates during the long preclinical phase of AD. Previous studies on the relationship between sleep and the early bi- 
omarkers of $\mathrm{AD}$ are few and have either been limited to data from convenience samples or clinical samples, which make it difficult to draw conclusions for the general population.

The $A P O E \& 4$ allele is the strongest genetic risk factor for $\mathrm{AD}$ and the $A P O E \& 4$ allele moderates the relationship between lifestyle factors and biomarkers of preclinical AD. However, no study has examined the interaction between $A P O E$ e4 and sleep on markers of neurodegeneration or synaptic dysfunction.

The specific aim of Study IV was to investigate the associations between subjective sleep disturbance and CSF markers of amyloid plaque accumulation (A $\beta 42)$, AD-type neurodegeneration (t-tau, p-tau), neuronal injury (NfL), and synaptic dysfunction (neurogranin) in a large population-based sample of 70 -years-olds free from dementia. In addition, we tested possible moderating effects of the $A P O E \varepsilon 4$-allele. 


\section{Methods}

\section{Participants}

All data, except for the multicenter Study III, were derived from the Gothenburg H70 Birth Cohort Studies. Study III also comprised data from studies in Stockholm and Finland.

The Gothenburg H70 Birth Cohort Studies (H70 studies) are an ongoing multidisciplinary epidemiological study examining representative birth cohorts of older populations in Gothenburg, Sweden. The first study started in 1971, with those born 1901-02 (Studies I and III), and the latest cohort born 1944 is currently examined at age 75 (Study IV). The examinations have been nearly identical across studies to enable comparisons between cohorts. Samples were drawn systematically, based on birth dates, from the Swedish Population Register, which contains names and addresses of all people living in Sweden. Samples were 70-years-olds in Gothenburg and included both those living at home and in institutions. The $\mathrm{H} 70$-studies have been previously described in detail (see Rydberg Sterner, Ahlner, Blennow, Dahlin-Ivanoff, Falk, Havstam Johansson, Hoff, Holm, Hörder, et al., 2019).

\section{Examinations and interviews}

Psychiatric examinations were carried out by psychiatrists in the 1970s, and by psychiatric nurses at the examinations in the 2000s. The examinations included ratings of psychiatric symptoms and signs, tests of mental functioning, aphasia, apraxia, agnosia, executive functioning, and personality changes. Key-informant interviews were performed by psychiatric research nurses as previously described (see Rydberg Sterner, Ahlner, Blennow, DahlinIvanoff, Falk, Havstam Johansson, Hoff, Holm, Hörder, et al., 2019).

\section{Primary outcomes}

\section{Sleep}

Measures of sleep were derived from questions during the psychiatric examinations, and reduced sleep and increased sleep was derived from the Comprehensive Psychopathological Rating Scale (CPRS). The CPRS has been shown to have good reliability among older people (van der Laan et al., 2005).

Reduced sleep (Studies I, III, IV) was assessed with the question "Do you experience reduced sleep duration or lighter sleep than usual?" Responses included "normal sleep, difficulty initiating sleep, difficulty maintaining sleep, lighter or disturbed sleep without external influence, and less than three 
hours sleep per night." This question was dichotomized into normal sleep versus insomnia symptoms. This question was also assessed in both $\mathrm{H} 70$ and the Kungsholmen Project (KP) in Study III.

Increased sleep (Study IV) was assessed with the question "Do you experience increased sleep or heavier sleep than usual?" Responses included "longer sleep duration or heavier sleep than normal, considerably earlier initiating sleep, waking up considerably later (several hours) than normal, or spending most of the day sleeping." This question was dichotomized as increased sleep or no increased sleep.

Sleep medication (Studies I, III, IV) was addressed with the question "Do you use sleep medication?" Responses included "no, less than once a week, 1-2 times a week, 3-5 times a week, and almost every night or every night." This question was dichotomized as no sleep medication (no medication, less than one times a week), and sleep medication (1-2 times a week, 3-5 times a week and almost every night or every night).

Sleep satisfaction (Study I) during the past month was addressed with the question "Are you satisfied with your sleep?" Responses included "satisfied, not entirely satisfied, or not at all satisfied with sleep with or without sleep medication". This question was dichotomized into satisfied with sleep (with or without sleep medication) or dissatisfied with sleep (not entirely, not at all, with or without sleep medication).

Sleep duration (Studies I, III) was addressed with a question on average hours of sleep per night.

Initial insomnia (Study III) was addressed with the question "Do you have trouble initiating sleep?". Responses included yes or no.

Terminal insomnia (Study III) was addressed with the question "Do you wake up early in the morning?" Responses included yes or no.

The criteria for insomnia in Study I were based on insomnia disorder described in the Diagnostic and Statistical Manual of Mental Disorder 5th edition (DSM-5) (American Psychiatric Association, 2013). Insomnia disorder, according to DSM-5, includes measures on clinically significant distress and impairment in important areas of functioning but this information was missing in the H70 study. The insomnia diagnosis required the subject to meet the criteria for both dissatisfied with sleep and reduced sleep.

\section{Cognitive status}

In Study II, MMSE (Folstein et al., 1975) was used to assess cognitive status. The MMSE is the most widely used screening tool for cognitive status in older ages (Tombaugh, 2005). Both the serial sevens and backwards spelling of the word "Konst" (Swedish word for art) was included in the test, but only 
the higher of these sub-scores was counted in the total score. The maximum score was 30 points. Zero scores were given if individual items were refused.

\section{Dementia}

Dementia was diagnosed by geriatrics specialist psychiatrists based on data from the psychiatric examination and the key-informant interview. The final diagnosis was made if the participant had dementia according to both sources of information or if there was clear evidence of dementia from one source and sub-threshold symptoms in the other.

In Studies II and IV, dementia was diagnosed according to the DSM-III-R (American Psychiatric Association, 1987) and in Study I, dementia was diagnosed according to old Roth-criteria (Kay et al., 1964), which were commonly used in the 1970s. Dementia, according to Roth's, is defined as "impairment of short-term or long-term memory or impaired orientation, when no clouding of consciousness can be observed," and has been described elsewhere (Wancata et al., 2007). In 2000, it was possible to compare old Rothcriteria with dementia diagnoses based on the DSM-III-R (American Psychiatric Association, 1987). The kappa-value for the agreement between Roth- and DSM-III-R-criteria was K=0.81 (Wancata et al., 2007).

For Study III, dementia was diagnosed according to DSM-IV in The Cardiovascular Risk Factors, Aging and Dementia Study (CAIDE) and DSM-III$\mathrm{R}$ in $\mathrm{H} 70$ and Kungsholmen Project (KP).

\section{CSF-measures}

For the CSF data in Study IV, a lumbar puncture was performed. All assays were included in the clinical routines at the Mölndal Clinical Neurochemistry Laboratory. Analytic runs had to pass quality control criteria for the calibrators, and internal quality control samples had to be approved. This procedure has been previously described in more detail (see Kern et al., 2018). In Study IV, $A \beta 42$ was analyzed in ratio to $A \beta 40$ as it has been shown that $\mathrm{A} \beta 42 / \mathrm{A} \beta 40$ are better than $\mathrm{A} \beta 42$ alone to identify brain amyloid deposition in preclinical AD (Janelidze et al., 2016). This ratio also accounts for individual differences in production of amyloid.

\section{Control variables}

\section{Apolipoprotein $\mathrm{E}$}

In Studies III and VI, the single nucleotide polymorphisms (SNPs) rs7412 and rs429358 in APOE (gene map locus 19q13.2) were genotyped with the KASPar PCR SNP genotyping system (LGC Genomics, Hoddesdon, Herts, 
UK). Genotype data for these two SNPs were used to define the $\varepsilon 2$, $\varepsilon 3$, and $\varepsilon 4$ alleles, as described previously (see Kern et al., 2018).

\section{Depression}

In Study I, diagnoses of major depression was made according to DSM-5 (American Psychiatric Association, 2013), and in Study IV, minor depression were diagnosed according to DSM-IV-TR criteria (American Psychiatric Association, 2000), using an algorithm, as described previously (Wiberg et al., 2013). The diagnoses were based on symptoms during the month preceding the examination.

\section{Diabetes}

In Study IV, Diabetes mellitus was defined as past or present treatment with insulin or oral antidiabetic drugs.

\section{Education}

In Studies I and II, level of education was dichotomized as compulsory (six years if born 1901-07, and seven years if born in 1930 and 1944) versus more than compulsory education. Years in education was used in Study III and IV.

\section{Health indicators}

In Study I, we used a variable of 13 health indicators: self-rated health, physical inactivity during the last year, current angina pectoris, bronchitis, smoking, intermittent claudication, history of myocardial infarction, stroke, asthma, cancer, diabetes mellitus, and osteoarthritis. All items were summed up and were then divided by the number of items with complete answers. It was necessary to have complete answers in at least seven out of 13 items to be included in the analyses.

\section{History of cardiovascular events}

In Study IV, heart diseases included present or past heart failure, myocardial infarction or angina pectoris. The diagnosis of myocardial infarction was based on a self-report or the presence of major or moderate Q-waves on ECG (MC $1-1-1$ to $1-2-5$ or $1-2-7$ ). The diagnosis of angina pectoris was based on self-report or chest pain according to the ROSE questionnaire (Rose, 1962). The diagnosis of heart failure was based on a self-report.

\section{Hypertension}

In Studies I, III, and IV, blood pressure was measured in the right arm after five minutes rest in the seated position with a manual sphygmomanometer. A 12-lead ECG was performed and coded according to the Minnesota Code 
(MC). Hypertension was defined as systolic blood pressure $\geq 140$ or diastolic blood pressure $\geq 90$ or present treatment with antihypertensive medication, as described previously (see Rydberg Sterner, Ahlner, Blennow, Dahlin-Ivanoff, Falk, Havstam Johansson, Hoff, Holm, Hörder, et al., 2019).

Years to death

In Study I, years to death was defined as the number of years between examination and death. To allow comparison between the cohorts, the maximum years for subsequent death was set to five years.

\section{Statistical analyses}

For Studies I, II and III, the statistical analyses were carried out using a frequentist approach and the analyses in Study IV was based on a Bayesian framework. Since this is a single age cohort, age is approximately the same as time in study and was centered at the baseline age for Studies I, II.

For studies I and II, growth curve models were fitted to the data to test the relationship between the outcome variable and predictors. Laird and Ware first introduced multilevel models on longitudinal data in their paper Random-Effects Models for Longitudinal Data (1982). They analyzed the data using measurements occasions as level-one units and individual subjects as level-two units (Snijders \& Bosker, 2012). In these models, every subject has their own growth curve and these models are therefore often called growth curve models. Growth curve models are flexible and can be assessed both on datasets where data are measured at different sets of time points, or when data on some individuals are missing. There are several types of reasons for missing data and missing data is commonly classified as: missing completely at random (MCAR), missing at random (MAR), and missing not at random (MNAR). Sterne et al. (2009) defined MCAR as no systematic differences between missing and observed values, MAR as when differences between observed and missing values can be explained by differences in the observed data, while MNAR occurs when the differences between observed and missing data remain even after the observed data is taken into consideration

In this thesis, the models were run under the assumption that the missing data points were MAR. Any incomplete data were analyzed using maximum likelihood estimation. In this method, the estimated value is the parameter that is most likely to have resulted in the observed data (Cham et al., 2017).

\section{Study I}

Logistic growth curve models were fitted to the data to test the relationship between the outcome variable insomnia and predictors. All predictors were modeled as fixed effects and all models included a random intercept. The earlier-born birth cohort (1901-07) and male sex were coded as reference 
categories in all models. The first model had insomnia (yes or no) as outcome variable, and sex, age, birth cohort as predictors. Interactions between age and sex, age and birth cohort, and birth cohort and sex were tested. Education and major depression were controlled for in a second model, and years to death and health indicators were added in the last model. Major depression, years to death and health indicators were modeled as time-varying covariates.

\section{Study II}

Growth curve models were fitted to the data to model the linear relationship between MMSE score and predictors. All predictors were modeled as fixed effects, and all models included a random intercept and slope. Interactions between predictors were tested during model building and were kept in the model if significant. Dementia groups were defined according to dummy coding using participants free from dementia at age 100 as the reference group and dementia status at each examination was modeled as a timevarying covariate. The score for MMSE from age 97 to 100 was used as the outcome variable. In Model 1, the predictors were age, dementia status, alive or dead at age 100, while controlling for sex and education, and interactions between predictors and age were tested. In Model 2, the predictors were age, and dementia status while controlling for sex, education, and the interactions between predictors and age.

\section{Study III}

Hazard regression models were fitted to the data using Gompertz distributed baseline intensity for the long follow-up analyses. Ending time was time of event or time of censoring. Censoring was defined as time of death or end of follow-up while ending time was specified as age in days. In the short followup analyses logistic regressions were used to analyze the associations between the predictor baseline sleep disturbances and the outcome variable dementia. In Model 1, age, sex, education, follow-up time, and study were adjusted for. However, since age and follow-up time are included in the basic specification of time for the hazard regression model, this model was only adjusted for sex and education. Model 2 was additionally adjusted for alcohol consumption, smoking, physical activity, and cohabitant status. Model 3 was additionally adjusted for cardio and cerebrovascular conditions and hypnotics, and Model 4 was additionally adjusted for hopelessness while Model 5 was additionally adjusted for $A P O E \varepsilon 4$. Model 5 was not fitted to the CAIDE data as information about the APOE genotype was not available. 


\section{Study IV}

Linear multiple regression models were fitted to the data using the Bayesian framework. Bayesian statistics is a method that uses Bayes' theorem, which is often described as the probability of an event, based on previous knowledge that is associated with the event, the so-called prior probability (van de Schoot et al., 2014). In this study, low-informative prior distributions were used.

In the first set of models, CSF data were modelled as the outcome variable and sleep measures were modelled as predictors while controlling for sex, education, time between psychiatric interview and lumbar puncture, major depression, history of cardiovascular events, stroke, BMI, and diabetes. The parameter estimates were derived through a numerical approximation using a Markov Chain Monte Carlo (MCMC) using Gibbs sampling in JAGS (Plummer, 2003). In the next set of models, the interaction between each sleep measure and $A P O E \varepsilon 4$-status were included. Sleep measures and $A P O-$ $E \varepsilon 4$-status were dummy coded using non-APOE\&4-carriers without sleep disturbances as the reference group. The $95 \%$ highest density intervals (HDI), defined as the interval enclosing $95 \%$ of the highest probability density of the marginal posterior distributions, were included. 


\section{Study samples}

\section{Study I}

1901-07-cohort

In 1976-77, a sample of all 70- and 75-year-olds from Gothenburg born in 1906-07 or 1901-07 from July 1 to June 30 on dates ending with 2, 5, or 8 were examined. Participants were randomly numbered consecutively from one to five. Those with numbers 1 and 2 were selected to take part in a psychiatric examination $(n=901)$. Among those, 724 were examined at baseline (response rate $80.4 \%$ ). These comprised 42170 -year-olds (241 women and 180 men) and 303 75-year-olds (117 men and 186 women) (see Nilsson \& Persson, 1984; Persson, 1980). Individuals with dementia $(n=8$ at age 70 and 15 at age 75) or with missing data on sleep variables $(n=22$ at age 70 and 5 at age 75 ) were excluded leaving 39170 -year-olds ( 217 women and 174 men), and 28375 -year-olds (175 women and 108 men). The 70- and 75-yearolds were re-examined at age $79(n=421,267$ women and 154 men). Individuals with dementia $(n=21)$ or missing data on sleep variables $(n=11)$ at follow-up were omitted from the analyses, leaving 389 individuals (148 women, 141 men).

\section{0-cohort}

In 2000-01, a sample of all 70-year-olds from Gothenburg born 1930 on days $3,6,12,18,21,24$ or 30 of each month were invited $(n=896)$. Five people were excluded as they could not be traced, 12 could not speak Swedish, 14 had emigrated from Sweden, and 13 died before participating; leaving an effective sample of 852 individuals. Among those, 604 individuals (361 women and 243 men) agreed to participate in the study (response rate $71.1 \%)$. At follow-up at age 75, this birth cohort was further extended to also include individuals born on days $2,5,11,16,20$, and $27(n=1,250)$. Among those, 851 individuals (528 women and 323 men) agreed to participate in the study (response rate 68\%) (see Beckman et al., 2008; Thorvaldsson et al., 2017). Individuals with dementia at age $75(n=50)$ or with missing data on sleep variables $(n=95)$ were omitted from the analyses, leaving 706 individuals (354 women and 271 men). This birth cohort was also examined at age $79(n=662,404$ women, 258 men). Individuals with dementia $(n=40)$ or missing data on sleep variables $(n=19)$ were omitted from the analyses, leaving 603 individuals ( 363 women and 240 men). 
Study II

All 97-year-olds living in Gothenburg, Sweden and born between July 1, 1901 and December 31, 1909 were invited ( $n=973,156$ men and 817 women). Of those, eight individuals were excluded as they could not speak Swedish, four had emigrated, two could not be traced and 48 died before they could be contacted, leaving 911 (147 men and 764 women) eligible for the study (see Andersson et al., 2012). Among those, 591 (107 men and 484 women, response rate $65 \%$ ) participated at baseline. Participants were reexamined at ages 99 and 100 years.

More than two thirds of the baseline sample died during the study period. Loss to death was especially frequent among men and among those with dementia. Of the 270 individuals without dementia at baseline, one fourth were free from dementia, $12 \%$ had developed dementia, and more than half of the sample had died at age 100 .

Study III

$\mathrm{H} 70$

In this study, we used data from the cohort born in 1930, examined at ages 70,75 , and 79 years and described above. At baseline, 875 individuals were invited. After excluding individuals who died, could not be traced, could not speak Swedish, or had emigrated, an effective sample of 827 individuals remained. Among those, 579 agreed to participate in a psychiatric examination (response rate $70.0 \%$ ). We excluded 16 individuals who either were diagnosed with dementia at baseline or had missing information on independent variables. Of the 563 individuals examined at baseline, 405 were re-examined at age 75 years (in 2005-2006) and 332 at age 79 years (in 2009-2010). In total, 437 participants were included in the longitudinal analyses.

\section{The Kungsholmen Project}

The Kungsholmen Project (KP) was carried out among older adults aged 75 years living in the Kungsholmen district of Stockholm, Sweden. Individuals born before 1913 were invited to participate in the initial examination, which was conducted between 1987 and 1989. At baseline a total of 2,368 individuals were invited and 1,810 participated. Three follow-up examinations were conducted approximately every three years until 1998, providing up to nine years of follow-up (see Fratiglioni et al., 1992).

The initial sample comprised 1,810 individuals, and 668 performed the clinical examinations. We excluded 220 individuals due to dementia, 24 subjects refused participation at baseline and 188 individuals had missing information on covariates leaving 306 individuals. 


\section{CAIDE}

CAIDE was carried out in Finland and participants were first examined at midlife within the North Karelia Project and the FINMONICA study. Baseline assessments took place in: 1972, 1977, 1982, or 1987 (see Puska, 2010). Baseline participation rates ranged between $82 \%$ and $90 \%$. In 1998, a random sample of 2000 survivors, aged 65 to 79 years, living in the cities of Kuopio and Joensuu, were invited for the first re-examination. In total, 1,449 individuals participated, and 1,409 completed the cognitive assessments. The mean follow-up time was 21 years. A total of 1,409 individuals completed the cognitive assessments at baseline. Participants returned for a second reexamination between 2005 and 2008, on average 10 years after the first reexamination. When invited, 909 of them accepted to participate, and $852 \mathrm{com}-$ pleted the cognitive assessment. In total, 1,511 individuals participated in at least one re-examination, and 750 participated in both. After excluding participants with missing data on sleep or other independent variables, 1,407 were included in the analyses with baseline in midlife, and 703 participants were included in the analyses with baseline in late life.

\section{Study IV}

All men and women born 1944 on dates ending with $0,2,5$, or 8, and registered as residents in Gothenburg were eligible for participation. Among those eligible, 29 individuals died before the examination, 32 had moved from Gothenburg, 53 could not speak Swedish, and 58 could not be traced, leaving an effective sample of 1,667 individuals who were invited to participate in the study. A total of 1,203 (response rate $72.2 \%$; 559 men and 644 women; mean age 70.5 years) agreed to participate in the study (see Rydberg Sterner, Ahlner, Blennow, Dahlin-Ivanoff, Falk, Havstam Johansson, Hoff, Holm, Horder, et al., 2019).

Of the total 1,203 participants, 430 (35.8\%) consented to a lumbar puncture. 108 had contraindications, seven individuals were excluded due to dementia leaving 315 for the analyses. 


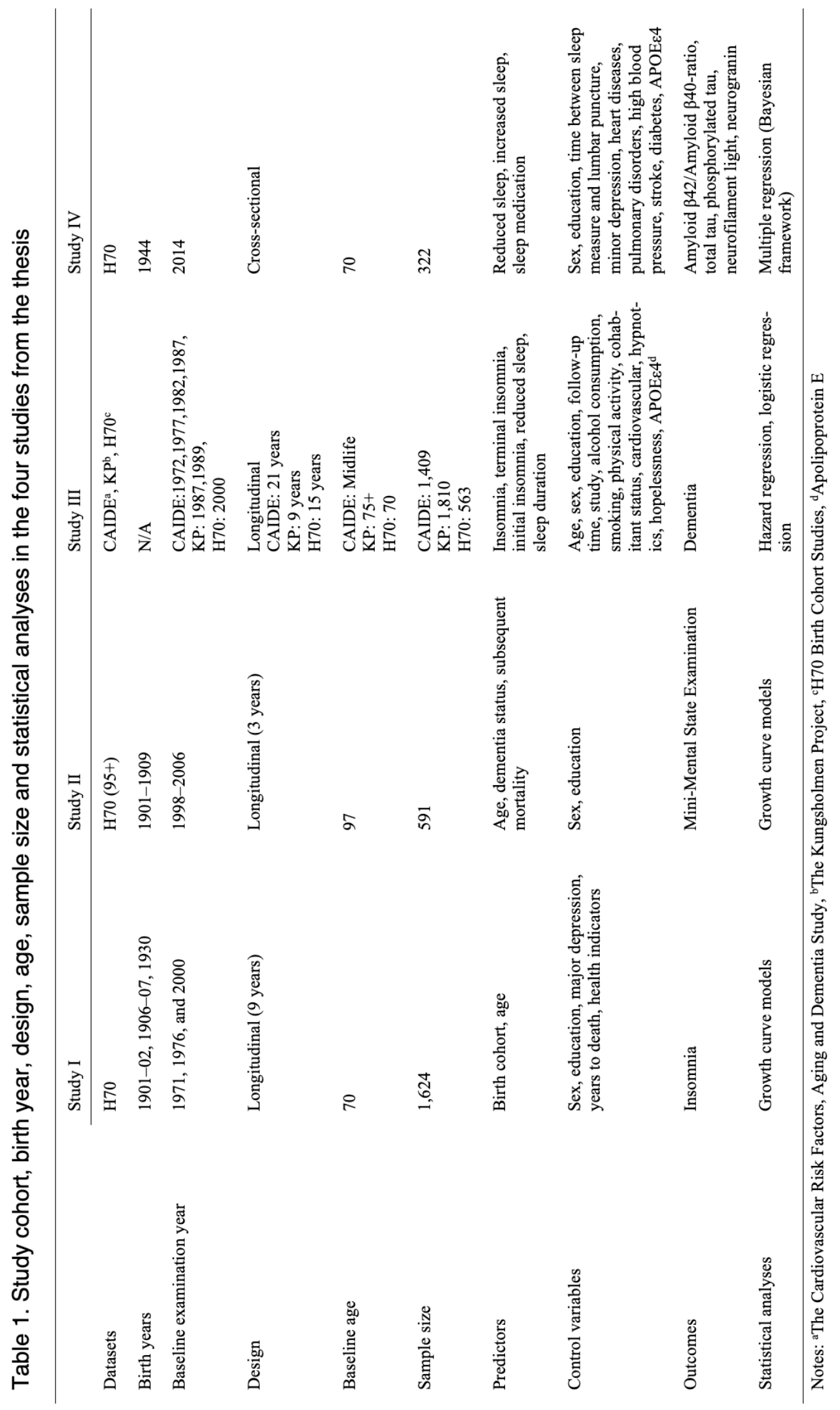




\section{Main results}

The main results from the four papers in the thesis are presented below. See also reprinted publications in the appendix at the end of this thesis for detailed results.

\section{Study I}

\section{Prevalence}

Results from the growth curve models revealed that the later-born cohort had lower odds for insomnia at age $70, \mathrm{OR}=0.52,95 \%$ CI [0.31, 0.88], but the prevalence of insomnia increased with age in the later but not in the earlierborn birth cohort, $\mathrm{OR}=1.14,95 \% \mathrm{CI}[1.08,1.21]$. Adding explanatory variables did not largely affect any of the main findings from the first model (see appendix I). The prevalence of insomnia in the two birth cohorts at ages 70 , 75 and 79 is also shown in Figure 6.

Figure 6. Prevalence of insomnia in two birth cohorts of 70-year-olds followed until age 79

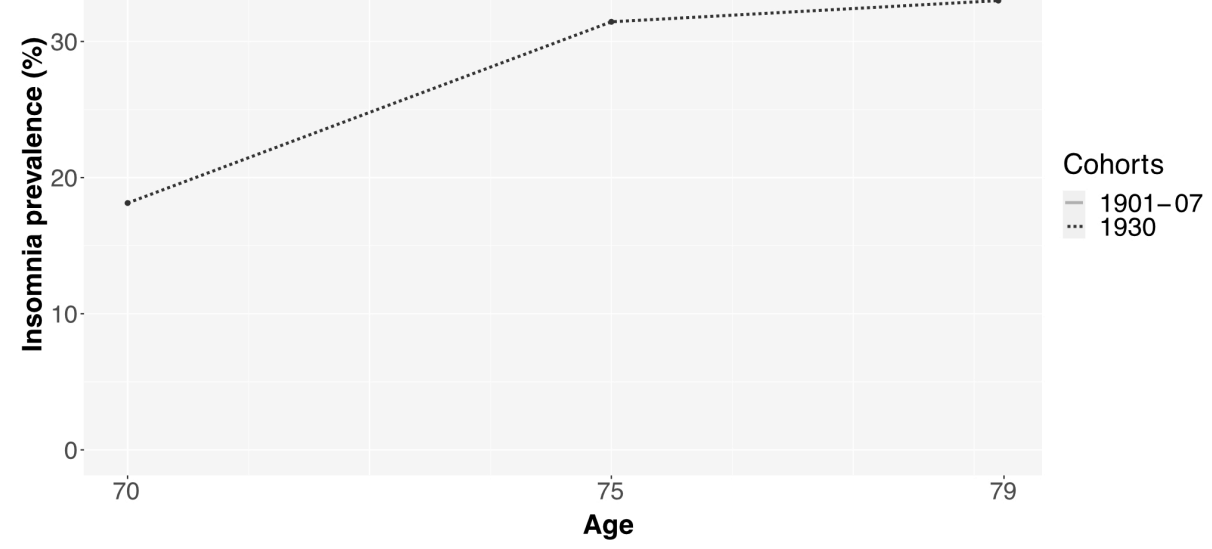




\section{Sex differences}

Women had higher odds ratio for insomnia compared to men, $\mathrm{OR}=2.95$, 95\% CI [1.92, 4.54]. There was also an interaction between sex and birth cohort, OR $=0.55,95 \%$ CI $[0.32,0.95]$. This finding may be interpreted in two ways; a larger cohort difference among women than among men and that sex differences were less pronounced in the later-born birth cohort. The prevalence of insomnia as stratified by sex is shown in Figure 7.

Figure 7. Prevalence of insomnia in two birth cohorts of 70-year-olds followed until age 79 as stratified by sex.

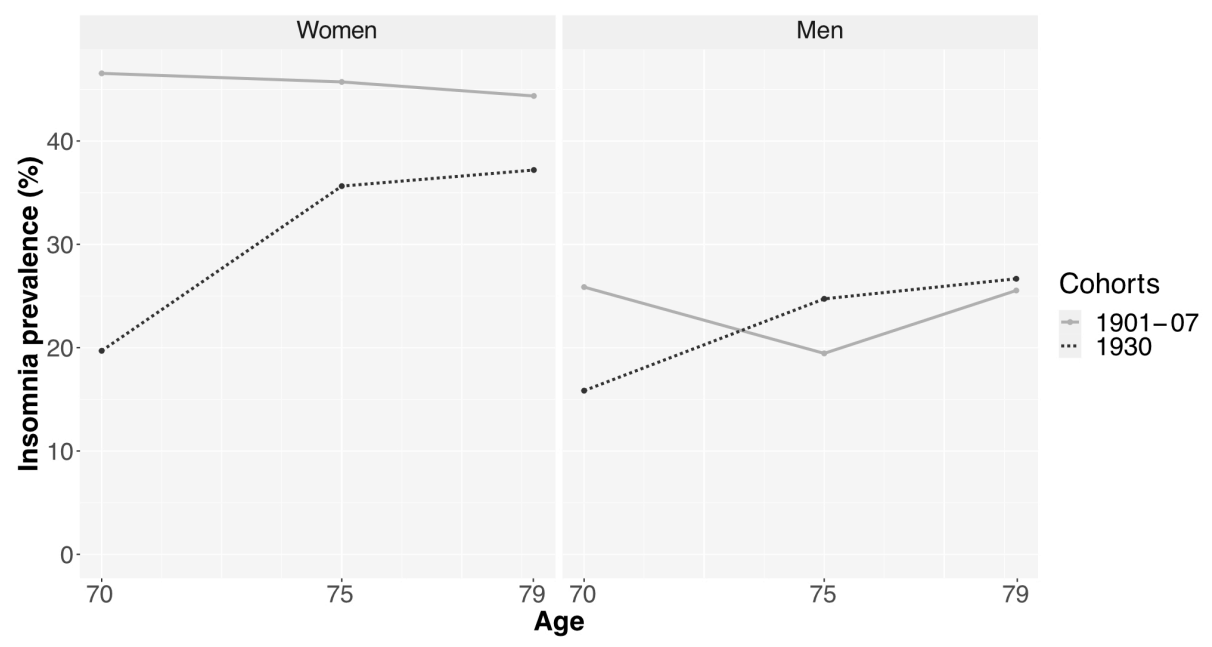




\section{Study II}

Dementia prevalence

The prevalence of dementia was $54.3 \%$ at age 97 (32.7\% in men, $59.1 \%$ in women), $60.9 \%$ at age 99 (45.3\% in men, $63.7 \%$ in women) and $55.7 \%$ at age $100(34.6 \%$ in men, $58.9 \%$ in women).

MMSE score from age 97 to 100 years in relation to dementia and mortality. Those with dementia between ages 97 and 100 years had lower MMSE score compared to those without dementia, -11.02 , 95\% CI [-11.96, -10.09$]$. Those who died between age 97 and 100 years had lower MMSE score compared to those who survived, $-2.75,95 \%$ CI $[-3.90,-1.60]$. Men, $2.16,95 \%$ CI $[0.76,-3.55]$ and those with higher level of education, $-2.08,95 \%$ CI $[1.03,3.13]$ had higher MMSE scores. There was no interaction between age and any of the predictors. 
MMSE score from age 97 to 100 years in survivors to age 100 in relation to age at onset of dementia

Figure 8 shows estimated mean MMSE scores in survivors at age 100 in relation to age at onset of dementia. The group with dementia at baseline had lowest MMSE scores, $-14.10,95 \%$ CI $[-16.14,-12.06]$. However, MMSE score at baseline did not significantly differ between those free from dementia during the three-year follow-up compared to those who developed dementia, $-1.4795 \%$ CI $[-3.7,0.8]$. All groups declined over time but the group with dementia at baseline, $-1.15,95 \%$ CI $[-1.94,-0.42]$, and those who developed dementia, $-1.94,95 \%$ CI $[-2.75,-1.13]$ had steeper slopes compared to those who were free from dementia during the study period.

Figure 8. Estimated mean MMSE score from age 97 to 100 in relation to age at onset of dementia

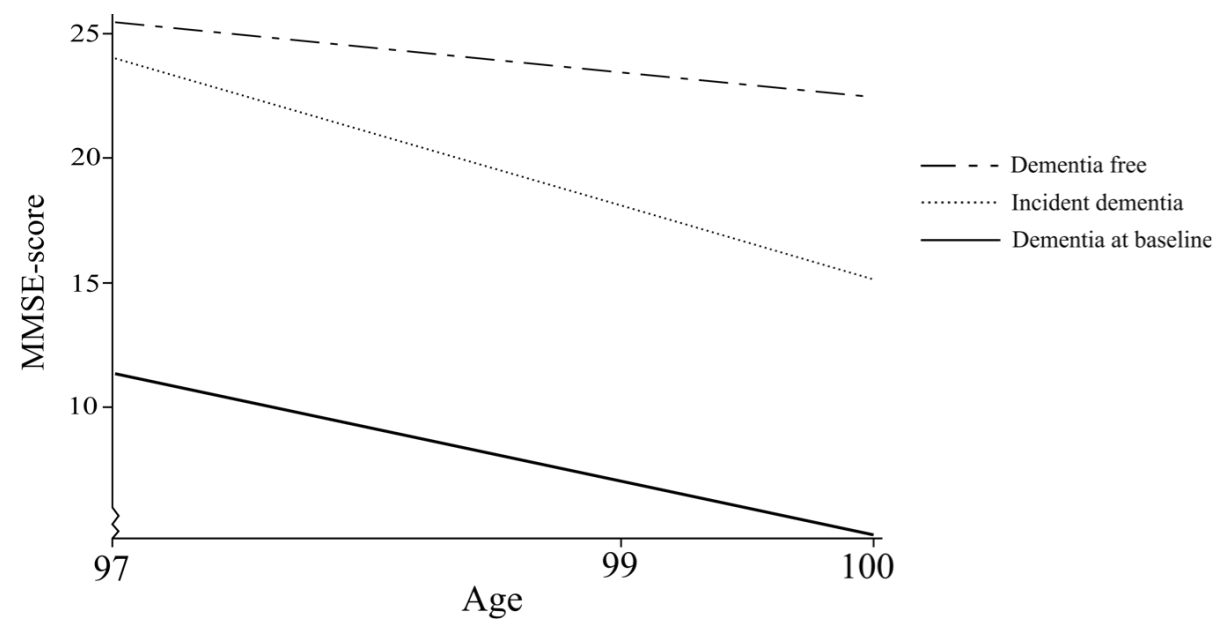




\section{Study III}

Midlife insomnia

Parameter estimates from the final models in the hazard and logistic regression are shown in Table 2. The long follow-up analysis using the CAIDE dataset showed that insomnia in midlife was related to an increased risk of developing dementia later in life, $\mathrm{HR}=1.24,95 \% \mathrm{CI}[1.02,1.50]$.

Terminal insomnia and sleep duration in late life

The analyses combining both the CAIDE and H70 datasets revealed that terminal insomnia, OR $=1.94,95 \%$ CI $[1.08,3.49]$ and long sleep duration, OR $=3.98,95 \%$ CI $[1.87,8.48]$ were related to an increased risk of developing dementia. Short sleep duration was not associated with an increased risk of developing dementia, $\mathrm{OR}=0.74,95 \% \mathrm{CI}[0.36,1.53]$.

Table 2. Associations between sleep parameters and dementia risk in final models

\begin{tabular}{lll}
\hline Parameter & Studies & Estimates \\
\hline Midlife insomnia & CAIDE & $1.24[1.02-1.50]^{\mathrm{a}}$ \\
Initial insomnia in late life & $\mathrm{H} 70$ & $0.53[0.15-1.90]^{\mathrm{b}}$ \\
Terminal insomnia in late life & CAIDE, H70 & $1.94[1.08-3.49]^{\mathrm{b}}$ \\
Reduced sleep in late life & $\mathrm{KP}, \mathrm{H70}$ & $0.93[0.81-1.07]^{\mathrm{b}}$ \\
Short sleep duration & $\mathrm{H} 70$ & $0.74[0.36-1.53]^{\mathrm{b}}$ \\
Long sleep duration & $\mathrm{H} 70$ & $3.98[1.87-8.48]^{\mathrm{b}}$ \\
\hline
\end{tabular}

Notes: ${ }^{a}$ Hazard Ratio from hazard regression models, ${ }^{b}$ Odds ratio from logistic regression models 


\section{Study IV}

Since this contains unpublished results this section has been condensed. For more information see appendix IV.

Associations between sleep measures and $A B 42 / A B 40$-ratio

Associations between increased sleep, reduced sleep and sleep medication with the CSF markers are shown in Table 3. Both increased and reduced sleep and sleep medication were associated with lower A $\beta 42 / \mathrm{A} \beta 40$-ratio. The associations between sleep variables and the other CSF markers were smaller (see appendix IV).

Table 3. Estimated associations between subjective sleep measures and $A B 42 / A ß 40$ ratio as derived from the linear multiple regression models

\begin{tabular}{lclc}
\hline Parameters & $\mathrm{n}$ & Standardized effect size & $95 \% \mathrm{HDI}^{\mathrm{a}}$ \\
\hline Aß42/Aß30 & & & \\
Increased sleep & 204 & -0.18 & {$[-0.33 ;-0.01]$} \\
Reduced sleep & 268 & -0.14 & {$[-0.25 ;-0.03]$} \\
Sleep medication & 283 & -0.15 & {$[-0.27 ;-0.04]$} \\
\hline
\end{tabular}


Associations between sleep measures and CSF markers by APOE\&4-status Figure 9 shows the relationship between reduced sleep and CSF markers stratified by $A P O E \varepsilon 4$-status. Reduced sleep was associated with lower A $342 / \mathrm{A} \beta 40$-ratio and higher t-tau, p-tau, and neurogranin among APOE\&4carriers, but not among non-carriers.

Figure 9. Reduced sleep in relation to A $342 / A \beta 40$-ratio, t-tau, $p$-tau, and neurogranin and stratified by APOE $\varepsilon 4$-status
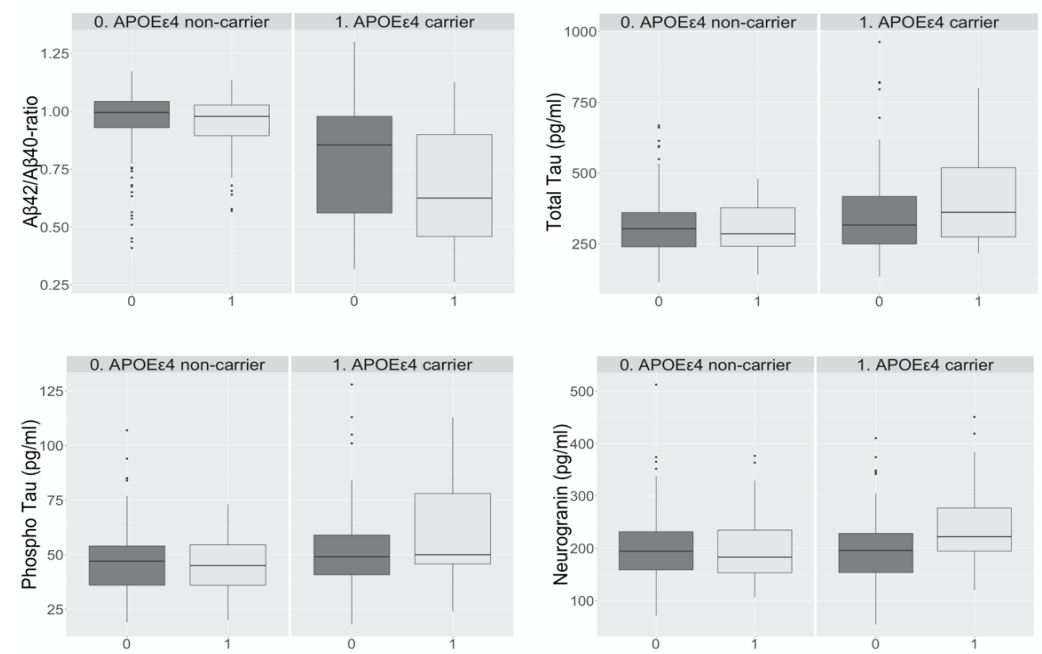

Reduced Sleep 章 0 自 1 


\section{General Discussion}

\section{Summary of main findings}

The overall aim of this thesis was to increase our understanding of subjective sleep disturbance, cognition, and dementia in old age and to investigate the relationship between sleep disturbances and dementia and biomarkers of AD.

Study I was a longitudinal birth-cohort study investigating differences in insomnia prevalence between two birth cohorts examined three decades apart. We found that the prevalence of insomnia was lower among 70-yearolds examined in the later compared to the earlier-born birth cohort. The prevalence of insomnia increased with age in the later but not in the earlierborn cohort. In addition, insomnia was more common in women than in men, but the sex difference was less pronounced in the later-born birth cohort.

Study II was a longitudinal study evaluation level and change in cognitive status measured by the MMSE. We found that the MMSE score at baseline was related to dementia at baseline, but not to development of dementia. While both dementia and subsequent mortality were related to the MMSE score it declined with age in all groups, including those who stayed free from dementia during the whole study period. In addition, higher level of education was associated with higher MMSE scores, but not with cognitive change. Also, the prevalence of dementia was stable from age 97 to 100 .

Study III was a multicenter study investigating the associations between sleep disturbances in mid- and late-life and risk of dementia. We found that midlife insomnia was associated with an increased risk of developing dementia later in life. Terminal insomnia and longer sleep duration in late life was associated with an increased risk for dementia.

Study IV was a cross-sectional study investigating the associations between sleep disturbances and CSF markers of AD and the moderating effect of the APOE4 allele. We found that reduced sleep, increased sleep, and taking sleep medication were associated with markers of amyloid plaque accumulation (A $342 / 40$-ratio). Among APOE 4 -carriers, reduced sleep was associated with markers of AD-type neurodegeneration ( $\mathrm{t}$-tau, phosphorylated tau) and synaptic dysfunction (neurogranin).

\section{Interpretation of the main findings}

Time trends in sleep

Our finding from Study I that later-born birth cohorts showed a lower prevalence of insomnia at age 70 in comparison to earlier-born cohorts may seem 
unexpected when compared to studies of time trends in younger ages. In fact, previous studies in younger populations have reported that the prevalence of insomnia (Calem et al., 2012), sleep complaints, and sleeping problems (Santos-Silva et al., 2010) were higher and sleep duration shorter (Kronholm et al., 2008) in cohorts examined more recently and during later time periods. Most previous studies on time trends of sleep problems are conducted through surveys with large age ranges for the whole population during a specific time period. These studies may be highly influenced by period effects besides the effect of birth cohort and may not reveal changes that are specific for a birth cohort in older age groups. Birth cohort effects in older people may, therefore, be hidden due to the fact that people slept worse during that particular time period. Interestingly, both Calum (2012) and Pallesson (2014) have found time trends that suggests that older age was related to more sleep problems. It is likely that this reflects an age effect and that sleep problems are more common in older ages, rather than that later-born cohorts of older people slept worse. An age effect in our study was that insomnia increased with age in the later-born cohort. The pattern of time trends found in previous studies could indicate an increase in work-related stress, or shiftwork, during later time periods affecting sleep more in younger adults compared to in older ages, where a larger proportion are retired.

We also found that the cohort differences in insomnia prevalence at age 70 had disappeared by age 79 years. This is similar to studies on cognition, where later-born cohorts performed better at age 70, but had a greater cognitive decline with age (Karlsson et al., 2015; Thorvaldsson et al., 2017). One possible explanation of these findings relates to survival effects, where it could be assumed that those who survived to age 70 in the earlier-born cohorts was a more selected group of survivors in comparison to survivors from later-born birth cohorts. In Sweden, the proportion who lived to age 70 increased from $60 \%$ of men and $80 \%$ of women in the earlier-born cohort to $78 \%$ of men and $86 \%$ of women in the later-born cohort (Statistics Sweden, 2018). The later-born cohort could, therefore, be more sensitive to age-related disorders associated with insomnia between age 70-79 and could, therefore, have experienced more sleep problems during this period.

Another possible explanation is that later-born cohorts simply develops insomnia at a later age compared to earlier born cohorts. This could be explained in relation to the compression of morbidity hypothesis (Fries, 1980; Fries et al., 2011), which propose that age at onset of chronic diseases is postponed in later-born cohorts. The period of morbidity is, therefore, likely compressed to a shorter time period. Thus, the age-related increase of insomnia may be postponed in later-born cohorts and then compressed into a shorter time period. 
Cognitive status - Dementia, cognitive reserve and terminal decline The finding that MMSE score at baseline was related to dementia at baseline, but not to development of dementia is in line with a previous study, that found that cognitive impairment in the preclinical phase of dementia may be more severe in younger old compared to older old ages (Backman et al., 2005). Kliegel and Sliwinski (2004) have suggested that intraindividual variability in the different subscales of MMSE is a better predictor of subsequent cognitive decline, in comparison to mean level of performance. We did not, however, test the intraindividual differences across the domains of MMSE in this thesis.

A common question is whether or not dementia is an inevitable effect of aging. We found that the prevalence of dementia among 97-year-olds was $54.3 \%$ (59\% in women and 33\% in men), with no major changes over three years. This is in line with previous studies that have suggested that the prevalence of dementia levels off and reaches a plateau in very old age (Kliegel et al., 2004; Ritchie \& Kildea, 1995). Our finding may also be explained by the high mortality rates among older people with dementia (Aevarsson et al., 1998; Börjesson-Hanson et al., 2007; Yang et al., 2013), which could result in the prevalence levelling off. According to Johansson and Zarit (1995), the high mortality rates in individuals with dementia in the oldest ages counterbalances the high incidence rates, resulting in a lower prevalence than otherwise would be the case. Moreover, studies of supercentenarians, aged 110 years and above, have suggested that normal aging without progressive cognitive decline is indeed possible (den Dunnen et al., 2008). In fact, the person with the longest documented lifespan, Jeanne Calment (1875-1997) of France, lived to the age of 122 years. She was psychometrically assessed at age 118 where it was found that she performed comparable to a similarly educated person aged 80 years (Ritchie, 1995). Ritchie and Kildea (1995) stated that dementia may be better conceptualized as an "age-related" (i.e., occurring within a specific age range) rather than as an "aging-related" disorder (i.e., caused by the aging process itself).

Perhaps not surprising, but still remarkable, is the finding in Study II, that level of education affected MMSE score also in these old ages, more than eight decades after it was achieved. We found that higher education was associated with increased overall MMSE scores in all models. One possible explanation could be related to the cognitive reserve hypothesis, according to which individuals with higher education are assumed to be able to cope better with brain pathologies and, therefore, experience a more intact cognition later in life (Stern, 2002, 2009). However, we did not find any association between education and cognitive change. It is possible that once an individual with a 
higher reserve capacity starts to decline, they may already have developed more severe brain pathology than those with less reserve capacity and may, therefore, have proceeded further along the disease process. In contrast, individuals with less reserve capacity may have started their decline earlier during the process. It is, therefore, possible that individuals with a higher reserve capacity also experience steeper decline once they begin to decline (Thorvaldsson et al., 2017). Higher education has been suggested as protecting against cognitive decline in some studies (Christensen et al., 2009; Stern, 2002), but several recent studies have suggested that education increases cognitive performance, but does not protect against cognitive decline thereafter (Cadar et al., 2017; Lovden et al., 2020; Piccinin et al., 2013; Seblova et al., 2020).

In relation to the birth-cohort effects found in Study I, it is possible that later-born cohorts have gained a larger reserve capacity due to multiple environmental and societal improvements during the last decades. Several studies have suggested that later-born cohorts perform better on cognitive tests, the so-called "Flynn Effects" (Flynn, 1984), which have also been seen in older age groups (Karlsson et al., 2015; Sacuiu et al., 2010; Thorvaldsson et al., 2017). In addition, other factors that are strongly related to sleep, such as depressive burden and neuroticism have decreased in later-born cohorts (Rydberg Sterner, Gudmundsson, et al., 2019). A plausible explanation is therefore that the general improvement in living conditions has led to improved overall health, which may contribute to the observed cohort differences concerning sleep.

A decrease in function during the last years of life is common and may occur in several domains, including cognition (Hulur et al., 2016), and this phenomenon is commonly referred to as terminal decline (Kleemeier, 1963; Palmore \& Cleveland, 1976; Riegel \& Riegel, 1972; Siegler, 1975). Riegel and Riegel (1972) have suggested that death may strike more randomly at older ages and that the differences in cognition between survivors and nonsurvivors, therefore, are less pronounced in the oldest-old ages. However, other studies have reported limited evidence for this claim (Thorvaldsson et al., 2006). Kliegel et al. (2004) found an accelerated cognitive decline prior to death in their study on centenarians, but this effect was rather small. This is similar to our results in Study II, where the group who died within the study period had lower MMSE-scores and a somewhat (although not statistically significant) steeper slope.

It has also been discussed whether birth-cohort effects could affect the period of terminal decline. Hülur et al. (2016) have listed three possible scenarios of terminal decline in relation to birth cohort effects, as shown in Figure 10. The first scenario is that cohorts do not differ in onset of decline, but that 
later cohort shows slower declines over time. The second scenario is that cohorts do not differ in rate of decline, but that later cohorts show a later onset of decline. The third scenario is that later cohorts experience a later onset of decline and show steeper declines thereafter. The latter is in line with the findings from Study I, where later-born birth cohorts had lower prevalence of insomnia at age 70, but where no differences between the cohorts were found nine years later.

Figure 10. Three scenarios for cohort differences late in life.
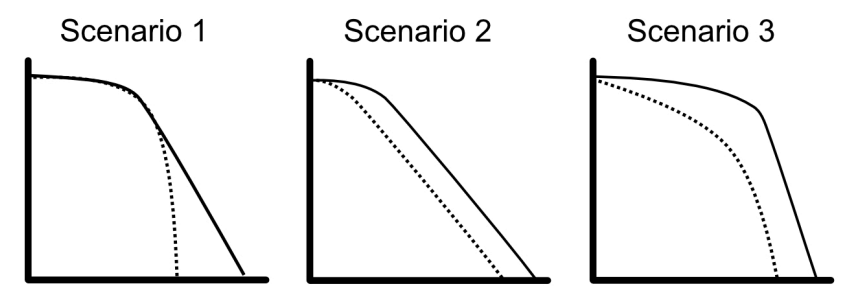

Notes: Adapted and illustrated by the author from Handbook of Theories of Ageing, Chapter Terminal Decline (Hulur et al., 2016)

Sleep, biomarkers and dementia associations

The results from Study III and IV give additional support to the now growing number of studies that have found an association between sleep disturbances and the early processes of AD or manifest dementia (Kang et al., 2009; Mander et al., 2015; Spira et al., 2013; Spira et al., 2014; Sprecher et al., 2015; Sprecher et al., 2017; Xie et al., 2013). There are several possible explanations for these findings. First, poor sleep could be an early risk factor for development of dementia later in life, which has been suggested in some studies (Benedict et al., 2015; Bokenberger et al., 2017). Secondly, poor sleep could also be an early symptom of a dementia disorder (Prinz et al., 1982; Westerberg et al., 2012). The design of Study III and IV limits such causal inferences. However, although the preclinical phase of dementia is long, it is not likely that the finding in Study III, that insomnia in midlife was associated with development of dementia in late life is due to early processes or of being a symptom of AD. It is possible that poor sleep in midlife is one of the so-called modifiable lifestyle risk factors for dementia (Edwards III et al., 2019). This may turn up to be a promising finding since this implies that prevention may be possible. It is, however, possible that the finding in Study III 
shows that terminal insomnia later in life and long sleep duration may be an early symptom of the disease. This could indicate that different types of sleep problems play different roles in relation to the dementia process during the life course.

The findings in Study IV, that reduced sleep and increased sleep were associated with lower levels of $A \beta$ in participants without dementia, is similar to findings from a convenience sample (Sprecher et al., 2017), and with findings on PET scans, where poor sleep, measured objectively and subjectively have been associated with markers of amyloid burden (Spira et al., 2013; Spira et al., 2014; Sprecher et al., 2015). This might indicate that poor sleep plays a role in the early processes of $\mathrm{AD}$ by decreased clearance of $\mathrm{A} \beta$ (Shokri-Kojori et al., 2018; Xie et al., 2013), but also by an increased production of $A \beta$ during sleep deprivation (Lucey et al., 2017). Both these processes could lead to an accumulation of $A \beta$ and formation of amyloid plaques that eventually leads to AD. Given the long preclinical phase of AD, it is difficult to draw conclusions as to whether these are symptoms of the disease or related to the early processes. Even though we excluded participatns with dementia in Study IV, it is likely that some may already have started their pathological processes. Moreover, we already know that as much as one fourth of the cognitively intact participatns of the sample had amyloid pathology and one third tau pathology in CSF (Kern et al., 2018).

Lastly, a novel finding is that reduced sleep was related to markers of neurodegeneration and synaptic dysfunction only in $A P O E \varepsilon 4$ carriers. One explanation is that $A P O E \varepsilon 4$ carriers had lower $A \beta 42 / 40$ ratio than non-carriers. It is, therefore, possible that these participants were further along in the dementia process than non-carriers. Thus, they may show signs of pathology also on markers of neurodegeneration or synaptic dysfunction. Another explanation could be that carriership of the APOE\&4 could directly increase the risk for sleep disturbance, as shown in another study (Wang \& Lung, 2012). However, in our study, the carriers and non-carrier groups where almost identical with regard to their sleep.

\section{Methodological considerations}

\section{Subjective sleep measures}

A limitation of the studies presented as part of this thesis is the lack of objective measures of sleep. Studies have shown that subjective sleep questions may be more unreliable in the oldest ages (O'Donnell et al., 2009), and may also be even worse in populations with preclinical dementia, due to the difficulties in subjectively reporting sleep problems (Hita-Yanez et al., 2013). However, as relating to Studies I and III, it is important to remember that 
there were very few, if any, population-based studies with comprehensive examinations using objective measures of sleep in the 1970s.

Although the criteria for insomnia in Study I included most features of the DSM-5-criteria for insomnia disorder (i.e., sleep satisfaction, difficulty initiating or maintaining sleep, lighter or disturbed sleep without external influence), information concerning certain symptoms, such as clinically significant distress and impairment in important areas of functioning are missing. However, questions about impairment due to sleep problems may have poor validity as a measure of insomnia in older populations, where most people are retired, and typically no longer engaged in demanding occupational, educational, or academic activities. For example, one study reported that only one third of older people with insomnia had day-time consequences of their sleep problems compared to over a half in younger populations (Ohayon \& Reynolds, 2009). Furthermore, this limitation probably concerns both cohorts in Study I equally, and it is, therefore, not likely that this limitation would have considerably influenced the comparisons.

\section{Measures of cognitive status}

Although the MMSE test used in Study II is the most widely used test for cognitive status in older ages it is also known for its many limitations. It typically has ceiling effects and the earliest stages of dementia may, therefore, be concealed in high-performing participants. Thus, by the time MMSE becomes indicative of cognitive decline, these participants may already be further along in the dementia process. This could also be one explanation for the lack of association between education and cognitive change. It is of note that only $2 \%$ scored the maximum point at age 97 years compared to nearly $7 \%$ in a previous study of 85-year-olds born 1901-02 (Aevarsson \& Skoog, 2000).

\section{Response rates}

Although the response rates were within acceptable ranges in all studies in this thesis (between $65 \%$ and 91\%) we found that participants in Study II more often had a diagnosis of dementia according to the hospital discharge register in comparison to non-participants (16\% vs. $11 \%$ in 97-years-olds). The findings from this study, where the prevalence rates of dementia were about $50 \%$ using clinical diagnoses, suggests, however, that the hospital discharge register only covers a minority of those with dementia.

In Study I, response rates were higher in the cohort born 1906-07 compared to the cohort born 1930 ( $80 \%$ vs. 68\%). It is possible that nonresponders had a higher prevalence of insomnia than responders, but the differences in insomnia prevalence between the cohorts at baseline were so pronounced that it is not likely that this could be fully explained by declining 
response rates. In Study IV, the general study response rate was fairly high in the original sample (72\%), but only one fourth of the sample performed a lumbar puncture. Even though the CSF-sample was similar to the total sample regarding factors such as education and cognitive status, more men than women had a lumbar puncture.

\section{Statistical considerations}

In Studies I and II, missing values were handled using maximum likelihood estimations, and the missing data were required to be either MCAR or MAR. One common problem with longitudinal study designs is the risk of dropouts, and that these dropouts are not random (e.g., missing due to worsened somatic health or morbidity). Li et al. (2017) have suggested that the level of dropouts was the strongest factor for affecting the parameter estimates using the maximum likelihood estimation. In their analyses, level of dropouts could only be ignored if the dropout rate falls below $10 \%$. For Study I, the missing values for the earlier-born cohort was low at age $79(<1 \%)$. For the laterborn cohort, the missing values for insomnia was slightly higher in comparison to the earlier-born cohort at age $75(11 \%)$. However, since this was the extended sample, most of these subjects had this study occasion as their baseline. These subjects were therefore not included in the longitudinal analyses.

In Study II, only about one fifth to one third provided data for the longitudinal analyses, but this was mainly due to death during follow-up (which was included as covariate in Model II). It was only $6 \%$ who refused participation at the age of 99 , and $5 \%$ at the age of 100 . In addition, most participants had data on both the outcome variable MMSE score and the predictors. It is not possible to completely guarantee that the results were unaffected by missing values, but it is not likely that this would have largely affected the main conconclusions.

\section{Clinical implications}

With the large increase in the number of people living with $\mathrm{AD}$, which will continue to increase during the forthcoming decades, it is important to find potentially modifiable risk factors. Given our findings, improving sleep could be one potential candidate for AD prevention (Mander et al., 2016). This research is even more urgent now due to the many failed clinical trials for $\mathrm{AD}$ and the fact that there are currently no effective or disease-modifying drugs for AD (Huang et al., 2020). The findings from Study III suggests that different types of sleep problems may play different roles for the progression of dementia during different disease periods. In Study III, we found that insomnia in midlife and terminal insomnia in late life was related to incidence of dementia. Therefore, treatment for insomnia might be more important 
during midlife compared to later in life, while treatments for terminal insomnia or long sleep duration is more important in older ages. Furthermore, in Study IV, we found that sleep medication was associated with CSF markers of AD. We emphasize that this finding should be interpreted with caution, as this group may be the group with most severe insomnia. The effects of sleep medication usage and insomnia severity on CSF markers of AD are, therefore, confounded in these comparisons. However, these finding could indicate that medical treatments for insomnia do not protect from developing dementia. Therefore, other treatments for insomnia may be recommended. Cognitive-behavioral therapy for insomnia (CBT-I) can be applied both when a patient is suffering from insomnia alone or when comorbidities are present (Pigeon, 2010), which is common in older adults. The CBT-I treatment is cost effective, has very few side effects (Spira \& Gottesman, 2017), and is easy to implement in both primary care and even through internet-based therapy.

\section{Future directions}

Future studies should investigate if birth cohort changes in insomnia continues in a new cohort of older people. In fact, the later-born cohort in Study I was examined in the early 2000s, which is now more than a decade ago. Preliminary results from the H70-studies indicate that the cohort assessed in Study IV, born 1944, performs even better on a number of health-related factors.

Most studies focusing on very old people, including Study II, have investigated longitudinal change in global measures of cognition. Future research should investigate longitudinal change also in different cognitive domains to find out if specific domains are more sensitive for dementia or mortality in this age group. This could be prospective memory tasks (Kliegel \& Martin, 2003), AD-related cognitive markers, such as delayed recall and naming, or vascular cognitive markers such as perceptual speed, executive functioning, and attention. Also, studies have shown that the prevalence of $A \beta$-pathology increases with age (Jansen et al., 2015). It will thus be important to include biomarkers on CSF or PET scans in studies of the oldest-old. It is possible that the relationship between the most common pathologies and cognition is stronger in younger old than in older old populations. Some studies even suggests that $\mathrm{AD}$ or vascular dementia may not have the same relevance on cognition after age 90 years (Andersson et al., 2012; Savva et al., 2009).

Several studies have investigated the cross-sectional effect of sleep problems using objective measures of sleep (e.g., polysomnography, actigraphy). Polysomnography adds the possibility of investigating whether different stages of sleep may be specifically related to different markers of AD. For 
example, recent cross-sectional studies suggest that SWS may be more related to $A \beta$ (Mander et al., 2015), while spindle coupling may be more related to tau pathology (Winer et al., 2019). Therefore, it has been suggested that sleep itself could be used as an early marker of preclinical AD (Hita-Yanez et al., 2013; Jelicic et al., 2002; Ju et al., 2013; Lloret et al., 2020; Winer et al., 2019). Assessing sleep is a relatively non-invasive method in comparison with CSF or PET scans.

\section{Conclusions}

This thesis challenges the current knowledge of time trends in insomnia, where it has been suggested that later-born cohorts sleep worse, by showing that the large environmental changes that have occurred during the last decades may in fact have positively influenced the prevalence of insomnia in older people. The findings also indicate that an age-related increase in insomnia is postponed to a higher age in later-born cohorts. We have also highlighted the many challenges when conducting longitudinal studies in the oldest old, where only one third of the sample survived the three-year follow-up and half of the survivors developed dementia. In addition, education can still account for individual differences in cognitive performance even at the oldest-old ages but might not protect against cognitive decline.

The findings from this thesis also suggests that different stages in the life course may be more critical for the relationship between sleep and dementia and that poor sleep may play a role in the early processes of $\mathrm{AD}$, potentially by decreasing clearance or increasing production of $A \beta$. Further, it adds to current research by showing that poor sleep may also affect other markers of neurodegeneration and synaptic dysfunction, and that these associations are influenced by the $A P O E \varepsilon 4$ allele. Taken together, these findings suggest that improving sleep could be one potential candidate for dementia prevention. Future research needs to elucidate whether poor sleep is a consequence or cause of cognitive disorders in old age. A better understanding of the associations between sleep disturbances and age-related cognitive decline may guide clinicians in making health care decisions and designing person-oriented interventions that improve health and wellbeing in future older generations. 



\section{Acknowledgments}

This project is really a joint collaboration and would not have been possible without the help and support from others. This includes supervisors, coauthors, research and clinical colleagues, administrative staff, my friends and my family. I especially want to thank:

First and foremost, all the study participants who contributed with their data and made this project possible. I have met some of you during psychological testing and when we almost bump into each other during gait speed tests in the corridor outside my room. I am looking forward to more meetings in future examinations!

My main supervisor, Valgeir Thorvaldsson. I am sincerely grateful for all your patience with me and that you always find time to answer my endless amount of questions. Thanks for your scientific vision, the statistical guidance, but also for always supporting me during my entire PhD-period. I also appreciate your Icelandic humor, the way you say "einmitt" when you agree with me, and all the fun times after dissertations and conferences. Without you this thesis would surely not have been possible.

My co-supervisor, Boo Johansson. You were the first to suggest that I should start this project and you were the one that welcomed me to your research group. I am forever grateful for this. You are certainly a role model, not only in research, but also how to dress properly, drink beer, and how to socialize with different people no matter the context. I will never forget all the fun times at conferences all over the world, especially the "bar-runda" in New Orleans.

My co-authors. Helena Jönsson for your collaboration on our master thesis at the University library in Örebro. All our hard work really laid the ground for Study I. My other co-authors, Kaj Blennow, Henrik Zetterberg, Silke Kern, Lina Rydén, Anna Zettergren, Pia Gudmundsson, Hanna Falk Erhag, Margda Waern, Robert Sigström, Anne Börjesson-Hanson for all your suggestions, discussions, and corrections. I especially want to thank Kristoffer Bäckman for helping me with the statistics in Study I. I also want to mention my dear colleague Svante Östling, who passed away too early. You were truly an inspiration in the way you enjoyed life and I miss your humor and all the discussions both on and off work. 
The Sleep Project in NEAR. Thank you, Lena Johansson, Linnea Sjöberg, Erika Jonsson Laukka, Hui-Xin Wang, Miia Kivipelto, and Laura Fratiglioni. I especially want to thank Shireen Sindi and Ingemar "Pingo" Kåreholt for all your hard work on Study III in this thesis. I have really enjoyed our analysis at ARC but maybe even more the dinners and partying afterwards. You really showed me what a research collaboration should be like. I am looking forward to finalizing our paper on sleep and cognition after my dissertation!

My research colleagues in the Life-Lab research group for all the discussions and good times during my years as PhD-student. Thank you, Anne Ingeborg Berg, Magnus Lindwall, Marie Kiwi, Stefanie König, Marcus Praetorius, Linn Elena Zulka, Sandra Buratti, Pär Bjälkebring, Sindre Rolstad, and Martin Lövdén.

My friends at the Department of Psychology for sharing this journey with me as $\mathrm{PhD}$-candidates. Thank you, Joel, Sofia, Patrik, Isabelle, Georg, Malin, Emma, Jonas, Gro, Isak, Magnus, Py, and all other colleagues at the department. Thank you, Ann, Jenny, Anna and Ann-Sofie for your administrative support. My examinator Karl Ask, and also Stefan Hansen, Arne Lowden and Daniel Zimprich for the excellent feedback and advices on earlier versions of this thesis.

Scott Hofer and Graciela Muniz Terrera for inviting me to the IALSAnetwork and that you believed in me as a young researcher. I also want to thank Ardo van den Hout and Andriy Koval for introducing me to R. Things have not been the same since then.

My colleagues and now long-time friends from the EPINEP-research group. I just realized that I have been part of this group for two decades now! I especially want to thank Tina Jacobsson, for all your support on my projects, the fun discussions at lunches and dinners, and for the excellent tips on which TV-shows to watch. Thank you, Therese, Cecilia, Elin, Ragnhild, Kerstin, Xinxin, Deb, Tore, Elisabet, Michael, Thorsteinn, Daniel, Jürgen,

Simona, Stefan, Felicia, Maya, Isak, Erik, Mattias, Tobias, Jenna, Mats, Irma, Jessica, Hanna W, Yadi, Nazib, Valter, Isabell, and Karolina for all "frukostmöten", "julbord", and the other adventures during all these years. I especially want to thank Madeleine Mellqvist Fässberg for still being my friend after all our work with "inmatning" and searching for data in dark archives all over Västra Götaland. Thank you, Johan Nilsson for all the times 
we have been roommates at different conferences all over the world. You are not always right (i.e., "så e' det"), but I have to admit that you are the king of playing pool in our research group.

The research nurses in the H70 Birth Cohort Studies. I have really enjoyed working with you on the cognitive testing, especially when working with the iPads during the last examinations. Thank you, Maggan, Nils, Chia, Carina, Malin, Fredrika, Kerstin, Anna, Katarina, Paula, Helen, Louise, Annie, Gunnel, and all former research nurses. I especially want to mention Birgitta for all your hard work with the 95+ studies. The credit is all yours for the high response rates and that the dropout rates were so low!

The Swedish National Graduate School for Competitive Science on Ageing and Health (SWEAH). Thank you, Susanne Iwarsson, and Stina

Elfversson. I also want to thank my friend Alexander Darin Mattsson for our talks on "Whatsapp" and for the great times in Stockholm and at conferences, and MarieClaire Overton, Stina Ek, Anna Marseglia, and Malin Ericsson for all the discussions on how we should take over the world in pubs at $3 \mathrm{am}$, and all the other fun times both in and outside of research!

My co-workers at the Memory Clinic in Mölndal. Thank you, Camilla, Johan, Malin, Maria and my colleagues in Team Ulla-Britt, Helene, Helena, Michael, Samih, and Anna and Anki for keeping things in order, and of course all other colleagues at the clinic. I have really enjoyed working with you all. To my neighbors in the corridor, Annika, Yvonne, Paulina, Sara, Ann-Katrin, Mona, Jannike and Angelica.

The psychologists at the clinic, thank you Elsa, Sara G, Jacob, Jonas, Nora, Sara H, and also Olena and Kaan. My clinical supervisor, Marie

Eckerström for guiding me through my first clinical year. Thank you for all your encouragement and advices. I hope that we will work together again in the future both clinically and in research. My clinical (and in research) partners in crime, Timothy and Fredrik. You are really lighting up my everyday work and my two years at the clinic would not have been the same without you! I also want to thank Timothy for your great collaboration on the cognitive test battery and for your invaluable input on the cover page and other figures in this thesis.

My friends, Johan, Fredrik, Oscar, Martin, Mikael, Henric, Viktor, Jonathan, Anders, and Antoine. Thank you for all our great adventures and that you always keep me grounded. My dear friend Mats, thank you for not being tired of me all the times I have interrupted your work for coffee breaks, 
for your endless encouragement during all these years and for our epic workouts!

My family, Kristoffer, Melker, Holger, Harry, Elsy, Inge, Kristina, Johanna, Bengt, Lotta, Paulina, Emil and Anders. My mom Christina for supporting and believing in me and that you always find time to listen and give advice when I need it. My sister Helena, for the encouragement and support, the unforgettable Skoog-sibling's nights out all over the world, and not least, for all the help with my Swedish writing! To my dad, Ingmar. It has been a privilege to work with you during all these years. I sincerely want to thank you for all the talks outside of research, your never-ending support, the Michelin star dinners all over the world, and for showing me that research should be fun, and sometimes, even Rock 'n' Roll.

My beloved Sven-Edvin, Gunnar and Anna-Lisa, I truly miss our philosophical discussions, the art of being minimalistic and that Metallica, Sartre and Freud can always be discussed in the same context.

Lastly, I want to give a big "un-thank you" to the coronavirus.

This thesis was supported by grants from the Swedish state under the agreement between the Swedish government and the County Councils, the ALFagreement (ALFGBG 716681, ALFGBG-715986), the Swedish Research Council (825-2012-5041, 2012-5041, 2013-8717, 2013-61X-14002, 201502830, 2017-00639, 2019-01096), Swedish Research Council for Health, Working Life and Wellfare (AGECAP 2013-2300, 2013-2496, 2013-1202, 2018-00471), the Alzheimer's Drug Discovery Foundation (ADDF), USA (\#RDAPB-201809-2016615), The Alzheimer's Association (ZEN-01-3151, IIRG-03-6168), the Torsten Söderbergs Stiftelse at the Royal Swedish Academy of Sciences, Alzheimerfonden, Hjärnfonden, the Knut and Alice Wallenberg Foundation, the European Research Council (\#681712), Konung Gustaf V:s och Drottning Victorias Frimurarestiftelse, Eivind och Elsa K:son Sylvans stiftelse, Stiftelsen för Gamla Tjänarinnor, Handlanden Hjalmar Svenssons Forskningsfond, Stiftelsen Längmanska Kulturfonden, Stiftelsen Demensfonden, Stiftelsen Wilhelm and Martina Lundgrens Vetenskapsfond, the Emil and Maria Palm Foundation, and Swedish National Graduate School for Competive Science on Ageing and Health (SWEAH) funded by the Swedish Research Council. 


\section{Scientific papers not included in the thesis}

I. Thorvaldsson, V., Karlsson, P., Skoog, J., Skoog, I., \& Johansson, B. (2017). Better Cognition in New Birth Cohorts of 70 Year Olds, But Greater Decline Thereafter. J Gerontol B Psychological Science Social Science, 72(1), 16-24.

II. Robitaille, A., van den Hout, A., Machado, R. J. M., Bennett, D. A., Cukic, I., Deary, I. J., Skoog, J . . Muniz Terrera, G. (2018). Transitions across cognitive states and death among older adults in relation to education: A multistate survival model using data from six longitudinal studies. Alzheimer's \& Dementia, 14(4),

III. Sindi, S., Johansson, L., Skoog, J., Mattsson, A. D., Sjoberg, L., Wang, H. X., Fratiglioni, L., Kulmala, J., Soininen, H., Solomon, A., Johansson, B., Skoog, I., Kivipelto, M., \& Kareholt, I. (2018). Sleep disturbances and later cognitive status: a multicentre study. Sleep Medicine, 52, 26-33.

IV. Karlsson, P., Johansson, B., Skoog, I., Skoog, J., Ryden, L., \& Thorvaldsson, V. (2018). Cohort Differences in the Association of Cardiovascular Risk and Cognitive Aging. Geropsych-the Journal of Gerontopsychology and Geriatric Psychiatry, 31(4), 195-203.

V. Rydberg Sterner, T., Ahlner, F., Blennow, K., Dahlin-Ivanoff, S., Falk, H., Havstam Johansson, L., Hoff, M., Holm, M., Horder, H., Jacobsson, T., Johansson, B., Johansson, L., Kern, J., Kern, S., Machado, A., Mellqvist Fassberg, M., Nilsson, J., Ribbe, M., Rothenberg, E., Ryden, L., Sadeghi, A., Sacuiu, S., Samuelsson, J., Sigstrom, R., Skoog, J., Thorvaldsson, V., Waern, M., Westman, E., Wetterberg, H., Zetterberg, H., Zetterberg, M., Zettergren, A., Ostling, S., \& Skoog, I. (2019). The Gothenburg H70 Birth cohort study 2014-16: design, methods and study population. European Journal of Epidemiology, 34(2), 191-209. 
VI. Zettergren, A., Höglund, K., Kern, S., Thorvaldsson, V., Skoog, J., M., Hansson, O., Andreasen, N., Bogdanovic, N., Blennow, K., Skoog, I., \& Zetterberg, H. (2019). Association of IL1RAPrelated genetic variation with cerebrospinal fluid concentration of Alzheimer-associated tau protein. Scientific Reports, 9(1), 2460.

VII. Hoogendijk, E., Rijnhart, JJM., Skoog, J., Robitaille, A., van den Hout, A., Ferrucci, L., Huisman, M., Skoog, I., Piccinin, AM., Hofer, SM. and Muniz Terrera, G. (2020). Gait speed as predictor of transition into cognitive impairment: Findings from three longitudinal studies on aging. Experimental Gerontology, Volume 129, 110783

VIII. Peters, R., Yasar, S., Anderson, C. S., Andrews, S., Antikainen, R., Arima, H., Beckett, N., Beer, J. C., Bertens, A. S., Booth, A., van Boxtel, M., Brayne, C., Brodaty, H., Carlson, M. C., Chalmers, J., Corrada, M., DeKosky, S., Derby, C., Dixon, R. A., Forette, F., Ganguli, M., van Gool, W. A., Guaita, A., Hever, A. M., Hogan, D. B., Jagger, C., Katz, M., Kawas, C., Kehoe, P. G., Keinanen-Kiukaanniemi, S., Kenny, R. A., Kohler, S., Kunutsor, S. K., Laukkanen, J., Maxwell, C., McFall, G. P., van Middelaar, T., Moll van Charante, E. P., Ng, T. P., Peters, J., Rawtaer, I., Richard, E., Rockwood, K., Ryden, L., Sachdev, P. S., Skoog, I., Skoog, J., Staessen, J. A., Stephan, B. C. M., Sebert, S., Thijs, L., Trompet, S., Tully, P. J., Tzourio, C., Vaccaro, R., Vaaramo, E., Walsh, E., Warwick, J., \& Anstey, K. J. (2020). Investigation of antihypertensive class, dementia, and cognitive decline: A meta-analysis. Neurology, 94(3), e267-e281.

IX. Lindberg, O., Kern, S., Skoog, J., Machado, A., Pereira, J., Sacuiu, S., Wahlund, L-O., Blennow, K., Zetterberg, H., Zettergren, A., Westman. and Skoog, I. (in press). Effects of amyloid pathology and the APOE 4 allele on the associations between cerebrospinal fluid $A \beta 38$ and $A \beta 40$ with brain morphology in cognitively normal 70 -years-olds. Neurobiology of Aging.

X. $\quad$ Arvidsson Rådestig, M., Skoog, J., Zetterberg, H., Kern, J., Zettergren, A., Sacuiu, S., Waern, M., Wetterberg, H., Blennow, K., Skoog, I., \& Kern, S. (in press). Cognitive performance in cognitively unimpaired older adults with preclinical Alzheimer's disease on CSF - Results from the Gothenburg H70 Birth Cohort Studies. Journal of Alzheimer's Disease 


\section{References}

Aevarsson, O., \& Skoog, I. (2000). A longitudinal population study of the mini-mental state examination in the very old: relation to dementia and education. Dementia and Geriatric Cognive Disorders, 11(3), 166-175. https://doi.org/10.1159/000017231

Aevarsson, Ó., Svanborg, A., \& Skoog, I. (1998). Seven-Year Survival Rate After Age 85 Years: Relation to Alzheimer Disease and Vascular Dementia. Archives of Neurology, 55(9), 1226-1232. https://doi.org/10-1001/pubs.Arch Neurol.-ISSN-0003-9942-55-9noc 7310

Aisen, P. S., Cummings, J., Jack, C. R., Morris, J. C., Sperling, R., Frölich, L., Jones, R. W., Dowsett, S. A., Matthews, B. R., Raskin, J., Scheltens, P., \& Dubois, B. (2017). On the path to 2025: understanding the Alzheimer's disease continuum. Alzheimer's Research \& Therapy, 9(1), 60. https://doi.org/10.1186/s13195-017$0283-5$

Alzheimer's Disease International. (2019). World Alzheimer Report 2019. A. s. D. International.

American Academy of Sleep Medicine. (2007). The AASM manual for the scoring of sleep and associated events : rules, terminology, and technical specifications. American Academy of Sleep Medicine.

American Psychiatric Association. (1987). Diagnostic and Statistical Manual of Mental Disorders: DSM-III-R. $A P A, 3$.

American Psychiatric Association. (2000). Diagnostic and statistical manual of mental disorders : DSM-IV-TR. American Psychiatric Association.

American Psychiatric Association. (2013). Diagnostic and statistical manual of mental disorders : DSM-5. http://dsm.psychiatryonline.org/book.aspx?bookid=556

Ancoli-Israel, S. (2009). Sleep and its disorders in aging populations. Sleep Medicine, 10 Suppl 1, S7-11. https://doi.org/10.1016/j.sleep.2009.07.004

Andersson, M., Guo, X., Borjesson-Hanson, A., Liebetrau, M., Ostling, S., \& Skoog, I. (2012). A population-based study on dementia and stroke in 97 year olds. Age and Ageing, 41(4), 529-533. https://doi.org/10.1093/ageing/afs040

Aserinsky, E., \& Kleitman, N. (1953). Regularly Occurring Periods of Eye Motility, and Concomitant Phenomena, during Sleep. Science, 118(3062), 273-274. https://doi.org/DOI $10.1126 /$ science. 118.3062 .273 
Backman, L., Jones, S., Berger, A. K., Laukka, E. J., \& Small, B. J. (2005). Cognitive impairment in preclinical Alzheimer's disease: a metaanalysis. Neuropsychology, 19(4), 520-531. https://doi.org/10.1037/0894-4105.19.4.520

Baumgart, M., Snyder, H. M., Carrillo, M. C., Fazio, S., Kim, H., \& Johns, H. (2015). Summary of the evidence on modifiable risk factors for cognitive decline and dementia: a population-based perspective. Alzheimer's \& Dementia, 11(6), 718-726.

Beckman, N., Waern, M., Gustafson, D., \& Skoog, I. (2008). Secular trends in self reported sexual activity and satisfaction in Swedish 70 year olds: cross sectional survey of four populations, 1971-2001. BMJ, 337, a279. https://doi.org/10.1136/bmj.a279

Benedict, C., Blennow, K., Zetterberg, H., \& Cedernaes, J. (2020). Effects of acute sleep loss on diurnal plasma dynamics of CNS health biomarkers in young men. Neurology. https://doi.org/10.1212/WNL.0000000000008866

Benedict, C., Byberg, L., Cedernaes, J., Hogenkamp, P. S., Giedratis, V., Kilander, L., Lind, L., Lannfelt, L., \& Schioth, H. B. (2015). Selfreported sleep disturbance is associated with Alzheimer's disease risk in men. Alzheimer's \& Dementia, 11(9), 1090-1097.

https://doi.org/10.1016/j.jalz.2014.08.104

Berger, H., \& Gloor, P. (1969). Hans Berger on the electroencephalogram of man : the fourteen original reports on the human electroencephalogram. Elsevier Pub. Co.

Bjorkelund, C., Bengtsson, C., Lissner, L., \& Rodstrom, K. (2002). Women's sleep: longitudinal changes and secular trends in a 24-year perspective. Results of the population study of women in Gothenburg, Sweden. Sleep, 25(8), 894-896.

Blanchard, R. D., Bunker, J. B., \& Wachs, M. (1977). Distinguishing aging, period and cohort effects in longitudinal studies of elderly populations. Socio-Economic Planning Sciences, 11(3), 137-146. https://doi.org/https://doi.org/10.1016/0038-0121(77)90032-5

Blennow, K., Vanmechelen, E., \& Hampel, H. (2001). CSF total tau, Abeta42 and phosphorylated tau protein as biomarkers for Alzheimer's disease. Molecular Neurobiology, 24(1-3), 87-97. https://doi.org/10.1385/MN:24:1-3:087

Bokenberger, K., Strom, P., Dahl Aslan, A. K., Johansson, A. L., Gatz, M., Pedersen, N. L., \& Akerstedt, T. (2017). Association Between Sleep Characteristics and Incident Dementia Accounting for Baseline Cognitive Status: A Prospective Population-Based Study. The Journals of Gerontology Series A: Medical and Biological Science, 72(1), 134-139. https://doi.org/10.1093/gerona/glw127

Borbely, A. A. (1982). A two process model of sleep regulation. Human Neurobiology, 1(3), 195-204. 
Borbely, A. A., Daan, S., Wirz-Justice, A., \& Deboer, T. (2016). The twoprocess model of sleep regulation: a reappraisal. Journal of Sleep Research, 25(2), 131-143. https://doi.org/10.1111/jsr.12371

Brown, B. M., Peiffer, J. J., Taddei, K., Lui, J. K., Laws, S. M., Gupta, V. B., Taddei, T., Ward, V. K., Rodrigues, M. A., Burnham, S., RaineySmith, S. R., Villemagne, V. L., Bush, A., Ellis, K. A., Masters, C. L., Ames, D., Macaulay, S. L., Szoeke, C., Rowe, C. C., \& Martins, R. N. (2013). Physical activity and amyloid-beta plasma and brain levels: results from the Australian Imaging, Biomarkers and Lifestyle Study of Ageing. Molecular Psychiatry, 18(8), 875-881. https://doi.org/10.1038/mp.2012.107

Brown, B. M., Rainey-Smith, S. R., Villemagne, V. L., Weinborn, M., Bucks, R. S., Sohrabi, H. R., Laws, S. M., Taddei, K., Macaulay, S. L., Ames, D., Fowler, C., Maruff, P., Masters, C. L., Rowe, C. C., Martins, R. N., \& Group, A. R. (2016). The Relationship between Sleep Quality and Brain Amyloid Burden. Sleep, 39(5), 1063-1068. https://doi.org/10.5665/sleep.5756

Börjesson-Hanson, A., Gustafson, D., \& Skoog, I. (2007). Five-year mortality in relation to dementia and cognitive function in 95-yearolds. Neurology, 69(22), 2069-2075. https://doi.org/10.1212/01.wnl.0000280464.59322.af

Cadar, D., Robitaille, A., Clouston, S., Hofer, S. M., Piccinin, A. M., \& Muniz-Terrera, G. (2017). An International Evaluation of Cognitive Reserve and Memory Changes in Early Old Age in 10 European Countries. Neuroepidemiology, 48(1-2), 9-20. https://doi.org/10.1159/000452276

Cajochen, C., Munch, M., Knoblauch, V., Blatter, K., \& Wirz-Justice, A. (2006). Age-related changes in the circadian and homeostatic regulation of human sleep. Chronobiology International, 23(1-2), 461-474. https://doi.org/10.1080/07420520500545813

Calem, M., Bisla, J., Begum, A., Dewey, M., Bebbington, P. E., Brugha, T., Cooper, C., Jenkins, R., Lindesay, J., McManus, S., Meltzer, H., Spiers, N., Weich, S., \& Stewart, R. (2012). Increased prevalence of insomnia and changes in hypnotics use in England over 15 years: analysis of the 1993, 2000, and 2007 National Psychiatric Morbidity Surveys. Sleep, 35(3), 377-384. https://doi.org/10.5665/sleep.1700

Cash, S. S., Halgren, E., Dehghani, N., Rossetti, A. O., Thesen, T., Wang, C., Devinsky, O., Kuzniecky, R., Doyle, W., Madsen, J. R., Bromfield, E., Eross, L., Halasz, P., Karmos, G., Csercsa, R., Wittner, L., \& Ulbert, I. (2009). The human K-complex represents an isolated cortical down-state. Science, 324(5930), 1084-1087. https://doi.org/10.1126/science.1169626

Caton, R. (1875). Electrical Currents of the Brain. The Journal of Nervous and Mental Disease, 2(4), 610. 
Cham, H., Reshetnyak, E., Rosenfeld, B., \& Breitbart, W. (2017). Full Information Maximum Likelihood Estimation for Latent Variable Interactions With Incomplete Indicators. Multivariate Behavioral Research, 52(1), 12-30. https://doi.org/10.1080/00273171.2016.1245600

Chiu, H. F., Leung, T., Lam, L. C., Wing, Y. K., Chung, D. W., Li, S. W., Chi, I., Law, W. T., \& Boey, K. W. (1999). Sleep problems in Chinese elderly in Hong Kong. Sleep, 22(6), 717-726.

Chopra, D., \& Tanzi, R. E. (2015). Super Genes: The hidden key to total well-being. Ebury Publishing.

Christensen, K., Doblhammer, G., Rau, R., \& Vaupel, J. W. (2009). Ageing populations: the challenges ahead. Lancet, 374(9696), 1196-1208. https://doi.org/10.1016/S0140-6736(09)61460-4

Christensen, K., Thinggaard, M., Oksuzyan, A., Steenstrup, T., AndersenRanberg, K., Jeune, B., McGue, M., \& Vaupel, J. W. (2013). Physical and cognitive functioning of people older than 90 years: a comparison of two Danish cohorts born 10 years apart. Lancet. https://doi.org/S0140-6736(13)60777-1 [pii]

10.1016/S0140-6736(13)60777-1

Corrada, M. M., Brookmeyer, R., Paganini-Hill, A., Berlau, D., \& Kawas, C. H. (2010). Dementia incidence continues to increase with age in the oldest old: the 90+ study. Annals of neurology, 67(1), 114-121. https://doi.org/10.1002/ana.21915

Cox, R., Hofman, W. F., \& Talamini, L. M. (2012). Involvement of spindles in memory consolidation is slow wave sleep-specific. Learning \& Memory, 19(7), 264-267. https://doi.org/10.1101/lm.026252.112

Crimmins, E. M., Hayward, M. D., \& Saito, Y. (1996). Differentials in active life expectancy in the older population of the United States. The Journals of Gerontology Series B: Psychological Sciences and Social Sciences, 51(3), S111-S120.

Crowley, K., Trinder, J., Kim, Y., Carrington, M., \& Colrain, I. M. (2002). The effects of normal aging on sleep spindle and K-complex production. Clinical Neurophysiology, 113(10), 1615-1622.

De Vos, A., Struyfs, H., Jacobs, D., Fransen, E., Klewansky, T., De Roeck, E., Robberecht, C., Van Broeckhoven, C., Duyckaerts, C., Engelborghs, S., \& Vanmechelen, E. (2016). The Cerebrospinal Fluid Neurogranin/BACE1 Ratio is a Potential Correlate of Cognitive Decline in Alzheimer's Disease. Journal of Alzheimer's Disease, 53(4), 1523-1538. https://doi.org/10.3233/JAD-160227

Deary, I. J., Whalley, L. J., Lemmon, H., Crawford, J. R., \& Starr, J. M. (2000). The Stability of Individual Differences in Mental Ability from Childhood to Old Age: Follow-up of the 1932 Scottish Mental Survey. Intelligence, 28(1), 49-55. https://doi.org/https://doi.org/10.1016/S0160-2896(99)00031-8 
Dement, W., \& Kleitman, N. (1957). Cyclic Variations in Eeg during Sleep and Their Relation to Eye Movements, Body Motility, and Dreaming. Electroencephalography and Clinical Neurophysiology, 9(4), 673-690. https://doi.org/Doi 10.1016/0013-4694(57)90088-3

den Dunnen, W. F., Brouwer, W. H., Bijlard, E., Kamphuis, J., van Linschoten, K., Eggens-Meijer, E., \& Holstege, G. (2008). No disease in the brain of a 115-year-old woman. Neurobiology of Aging, 29(8), 1127-1132. https://doi.org/10.1016/j.neurobiolaging.2008.04.010

DeTure, M. A., \& Dickson, D. W. (2019). The neuropathological diagnosis of Alzheimer's disease. Molecular Neurodegeneration, 14(1), 32. https://doi.org/10.1186/s13024-019-0333-5

Dijk, D. J., Groeger, J. A., Stanley, N., \& Deacon, S. (2010). Age-related reduction in daytime sleep propensity and nocturnal slow wave sleep. Sleep, 33(2), 211-223.

Dubois, B., Feldman, H. H., Jacova, C., Hampel, H., Molinuevo, J. L., Blennow, K., DeKosky, S. T., Gauthier, S., Selkoe, D., \& Bateman, R. (2014). Advancing research diagnostic criteria for Alzheimer's disease: the IWG-2 criteria. The Lancet Neurology, 13(6), 614-629.

Dubois, B., Hampel, H., Feldman, H. H., Scheltens, P., Aisen, P., Andrieu, S., Bakardjian, H., Benali, H., Bertram, L., Blennow, K., Broich, K., Cavedo, E., Crutch, S., Dartigues, J. F., Duyckaerts, C., Epelbaum, S., Frisoni, G. B., Gauthier, S., Genthon, R., Gouw, A. A., Habert, M. O., Holtzman, D. M., Kivipelto, M., Lista, S., Molinuevo, J. L., O'Bryant, S. E., Rabinovici, G. D., Rowe, C., Salloway, S., Schneider, L. S., Sperling, R., Teichmann, M., Carrillo, M. C., Cummings, J., Jack, C. R., Jr., Proceedings of the Meeting of the International Working, G., the American Alzheimer's Association on "The Preclinical State of, A. D., July, \& Washington Dc, U. S. A. (2016). Preclinical Alzheimer's disease: Definition, natural history, and diagnostic criteria. Alzheimer's \& Dementia, 12(3), 292-323. https://doi.org/10.1016/j.jalz.2016.02.002

Dworak, M., McCarley, R. W., Kim, T., Kalinchuk, A. V., \& Basheer, R. (2010). Sleep and brain energy levels: ATP changes during sleep. Journal of Neuroscience, 30(26), 9007-9016. https://doi.org/10.1523/JNEUROSCI.1423-10.2010

Edwards Iii, G. A., Gamez, N., Escobedo, G., Jr., Calderon, O., \& MorenoGonzalez, I. (2019). Modifiable Risk Factors for Alzheimer's Disease. Frontiers in aging neuroscience, 11, 146-146. https://doi.org/10.3389/fnagi.2019.00146

Falk, H., Johansson, L., Ostling, S., Thogersen Agerholm, K., Staun, M., Host Dorfinger, L., \& Skoog, I. (2014). Functional disability and ability 75-year-olds: a comparison of two Swedish cohorts born 30 years apart. Age and Ageing, 43(5), 636-641. https://doi.org/10.1093/ageing/afu018 
Fan, L., Xu, W., Cai, Y., Hu, Y., \& Wu, C. (2019). Sleep Duration and the Risk of Dementia: A Systematic Review and Meta-analysis of Prospective Cohort Studies. Journal of the American Medical Directors Association, 20(12), 1480-1487 e1485. https://doi.org/10.1016/j.jamda.2019.06.009

Farrer, L. A., Cupples, L. A., Haines, J. L., Hyman, B., Kukull, W. A., Mayeux, R., Myers, R. H., Pericak-Vance, M. A., Risch, N., \& van Duijn, C. M. (1997). Effects of age, sex, and ethnicity on the association between apolipoprotein E genotype and Alzheimer disease. A meta-analysis. APOE and Alzheimer Disease Meta Analysis Consortium. JAMA, 278(16), 1349-1356.

Ferrucci, L., Gonzalez-Freire, M., Fabbri, E., Simonsick, E., Tanaka, T., Moore, Z., Salimi, S., Sierra, F., \& de Cabo, R. (2020). Measuring biological aging in humans: A quest. Aging Cell, 19(2), e13080. https://doi.org/10.1111/acel.13080

Flynn, J. R. (1984). The mean IQ of Americans: Massive gains 1932 to 1978. Psychological bulletin, 95(1), 29.

Folstein, M. F., Folstein, S. E., \& McHugh, P. R. (1975). "Mini-mental state". A practical method for grading the cognitive state of patients for the clinician. Journal of Psychiatric Research, 12(3), 189-198. https://doi.org/10.1016/0022-3956(75)90026-6

Fratiglioni, L., Grut, M., Forsell, Y., Viitanen, M., \& Winblad, B. (1992). Clinical Diagnosis of Alzheimer's Disease and Other Dementias in a Population Survey: Agreement and Causes of Disagreement in Applying Diagnostic and Statistical Manual of Mental Disorders, Revised Third Edition, Criteria. Archives of Neurology, 49(9), 927932. https://doi.org/10.1001/archneur.1992.00530330049015

Fratiglioni, L., Launer, L., Andersen, K., Breteler, M., Copeland, J., Dartigues, J.-F., Lobo, A., Martinez-Lage, J., Soininen, H., \& Hofman, A. (2000). Incidence of dementia and major subtypes in Europe: a collaborative study of population-based cohorts. Neurology, 54(11).

Fries, J. F. (1980). Aging, natural death, and the compression of morbidity. New England Journal of Medicine, 303(3), 130-135. https://doi.org/10.1056/nejm198007173030304

Fries, J. F., Bruce, B., \& Chakravarty, E. (2011). Compression of morbidity 1980-2011: a focused review of paradigms and progress. Journal of aging research, 2011, 261702-261702. https://doi.org/10.4061/2011/261702

Fyfe, I. (2015). Alzheimer disease: neurogranin in the CSF signals early Alzheimer disease and predicts disease progression. Nature Revievs Neurology, 11(11), 609. https://doi.org/10.1038/nrneurol.2015.178 
Gakuba, C., Gaberel, T., Goursaud, S., Bourges, J., Di Palma, C., Quenault, A., Martinez de Lizarrondo, S., Vivien, D., \& Gauberti, M. (2018). General Anesthesia Inhibits the Activity of the "Glymphatic System". Theranostics, 8(3), 710-722. https://doi.org/10.7150/thno.19154

Gerstorf, D., Ram, N., Estabrook, R., Schupp, J., Wagner, G. G., \& Lindenberger, U. (2008). Life satisfaction shows terminal decline in old age: longitudinal evidence from the German Socio-Economic Panel Study (SOEP). Developmental Psychology, 44(4), 1148-1159. https://doi.org/10.1037/0012-1649.44.4.1148

Gerstorf, D., Ram, N., Hoppmann, C., Willis, S. L., \& Schaie, K. W. (2011). Cohort differences in cognitive aging and terminal decline in the Seattle Longitudinal Study. Developmental Psychology l, 47(4), 1026-1041. https://doi.org/10.1037/a0023426

Green, M. J., Espie, C. A., Hunt, K., \& Benzeval, M. (2012). The Longitudinal Course of Insomnia Symptoms: Inequalities by Sex and Occupational Class Among Two Different Age Cohorts Followed for 20 Years in the West of Scotland. Sleep, 35(6), 815-823. https://doi.org/10.5665/sleep.1882

Hablitz, L. M., Vinitsky, H. S., Sun, Q., Staeger, F. F., Sigurdsson, B., Mortensen, K. N., Lilius, T. O., \& Nedergaard, M. (2019). Increased glymphatic influx is correlated with high EEG delta power and low heart rate in mice under anesthesia. Science Advances, 5(2), eav55447. https://doi.org/10.1126/sciadv.aav5447

Harada, C. N., Natelson Love, M. C., \& Triebel, K. L. (2013). Normal cognitive aging. Clinics in Geriatric Medicine, 29(4), 737-752. https://doi.org/10.1016/j.cger.2013.07.002

Hardy, J., \& Selkoe, D. J. (2002). The amyloid hypothesis of Alzheimer's disease: progress and problems on the road to therapeutics. Science, 297(5580), 353-356. https://doi.org/10.1126/science.1072994

Head, D., Bugg, J. M., Goate, A. M., Fagan, A. M., Mintun, M. A., Benzinger, T., Holtzman, D. M., \& Morris, J. C. (2012). Exercise Engagement as a Moderator of the Effects of APOE Genotype on Amyloid Deposition. Archives of Neurology, 69(5), 636-643. https://doi.org/10.1001/archneurol.2011.845

Hippius, H., \& Neundorfer, G. (2003). The discovery of Alzheimer's disease. Dialogues in Clinical Neuroscience, 5(1), 101-108.

Hita-Yanez, E., Atienza, M., \& Cantero, J. L. (2013). Polysomnographic and subjective sleep markers of mild cognitive impairment. Sleep, 36(9), 1327-1334. https://doi.org/10.5665/sleep.2956

Homer. (1955). Iliad. London : Dent; New York : Dutton, [1955].

Huang, L. K., Chao, S. P., \& Hu, C. J. (2020). Clinical trials of new drugs for Alzheimer disease. Journal of Biomedical Science, 27(1), 18. https://doi.org/10.1186/s12929-019-0609-7 
Huffman, C. (2017). Alcmaeon, The Stanford Encyclopedia of Philosophy (E. Zalta, N. , Ed. Spring 2017 ed.). Metaphysics Research Lab, Stanford University.

Hulur, G., Ram, N., \& Gerstorf, D. (2016). Terminal Decline. In V. L. Bengtson \& R. Settersten (Eds.), Handbook of Theories of Aging. Springer Publishing Company.

Hwang, J. Y., Byun, M. S., Choe, Y. M., Lee, J. H., Yi, D., Choi, J. W., Hwang, S. H., Lee, Y. J., Lee, D. Y., \& Group, K. R. (2018). Moderating effect of APOE epsilon4 on the relationship between sleep-wake cycle and brain beta-amyloid. Neurology, 90(13), e1167e1173. https://doi.org/10.1212/WNL.0000000000005193

Iliff, J. J., Wang, M., Liao, Y., Plogg, B. A., Peng, W., Gundersen, G. A., Benveniste, H., Vates, G. E., Deane, R., Goldman, S. A., Nagelhus, E. A., \& Nedergaard, M. (2012). A paravascular pathway facilitates CSF flow through the brain parenchyma and the clearance of interstitial solutes, including amyloid beta. Science Translational Medicine, 4(147), 147ra111. https://doi.org/10.1126/scitranslmed.3003748

Jack, C. R., Jr, Bennett, D. A., Blennow, K., Carrillo, M. C., Feldman, H. H., Frisoni, G. B., Hampel, H., Jagust, W. J., Johnson, K. A., Knopman, D. S., Petersen, R. C., Scheltens, P., Sperling, R. A., \& Dubois, B. (2016). A/T/N: An unbiased descriptive classification scheme for Alzheimer disease biomarkers. Neurology, 87(5), 539-547. https://doi.org/10.1212/WNL.0000000000002923

Jack, C. R., Jr., Knopman, D. S., Jagust, W. J., Petersen, R. C., Weiner, M. W., Aisen, P. S., Shaw, L. M., Vemuri, P., Wiste, H. J., Weigand, S. D., Lesnick, T. G., Pankratz, V. S., Donohue, M. C., \& Trojanowski, J. Q. (2013). Tracking pathophysiological processes in Alzheimer's disease: an updated hypothetical model of dynamic biomarkers. Lancet Neurology, 12(2), 207-216. https://doi.org/10.1016/S14744422(12)70291-0

Jack, C. R., Jr., Knopman, D. S., Jagust, W. J., Shaw, L. M., Aisen, P. S., Weiner, M. W., Petersen, R. C., \& Trojanowski, J. Q. (2010). Hypothetical model of dynamic biomarkers of the Alzheimer's pathological cascade. Lancet Neurology, 9(1), 119-128. https://doi.org/10.1016/S1474-4422(09)70299-6

Janelidze, S., Zetterberg, H., Mattsson, N., Palmqvist, S., Vanderstichele, H., Lindberg, O., van Westen, D., Stomrud, E., Minthon, L., Blennow, K., Swedish Bio, F. s. g., \& Hansson, O. (2016). CSF Abeta42/Abeta40 and Abeta42/Abeta38 ratios: better diagnostic markers of Alzheimer disease. Annals of Clinical and Translational Neurology, 3(3), 154-165. https://doi.org/10.1002/acn3.274 
Jansen, W. J., Ossenkoppele, R., Knol, D. L., Tijms, B. M., Scheltens, P., Verhey, F. R. J., Visser, P. J., Amyloid Biomarker Study, G., Aalten, P., Aarsland, D., Alcolea, D., Alexander, M., Almdahl, I. S., Arnold, S. E., Baldeiras, I., Barthel, H., van Berckel, B. N. M., Bibeau, K., Blennow, K., Brooks, D. J., van Buchem, M. A., Camus, V., Cavedo, E., Chen, K., Chetelat, G., Cohen, A. D., Drzezga, A., Engelborghs, S., Fagan, A. M., Fladby, T., Fleisher, A. S., van der Flier, W. M., Ford, L., Förster, S., Fortea, J., Foskett, N., Frederiksen, K. S., Freund-Levi, Y., Frisoni, G. B., Froelich, L., Gabryelewicz, T., Gill, K. D., Gkatzima, O., Gómez-Tortosa, E., Gordon, M. F., Grimmer, T., Hampel, H., Hausner, L., Hellwig, S., Herukka, S.-K., Hildebrandt, H., Ishihara, L., Ivanoiu, A., Jagust, W. J., Johannsen, P., Kandimalla, R., Kapaki, E., Klimkowicz-Mrowiec, A., Klunk, W. E., Köhler, S., Koglin, N., Kornhuber, J., Kramberger, M. G., Van Laere, K., Landau, S. M., Lee, D. Y., de Leon, M., Lisetti, V., Lleó, A., Madsen, K., Maier, W., Marcusson, J., Mattsson, N., de Mendonça, A., Meulenbroek, O., Meyer, P. T., Mintun, M. A., Mok, V., Molinuevo, J. L., Møllergård, H. M., Morris, J. C., Mroczko, B., Van der Mussele, S., Na, D. L., Newberg, A., Nordberg, A., Nordlund, A., Novak, G. P., Paraskevas, G. P., Parnetti, L., Perera, G., Peters, O., Popp, J., Prabhakar, S., Rabinovici, G. D., Ramakers, I. H. G. B., Rami, L., Resende de Oliveira, C., Rinne, J. O., Rodrigue, K. M., Rodríguez-Rodríguez, E., Roe, C. M., Rot, U., Rowe, C. C., Rüther, E., Sabri, O., Sanchez-Juan, P., Santana, I., Sarazin, M., Schröder, J., Schütte, C., Seo, S. W., Soetewey, F., Soininen, H., Spiru, L., Struyfs, H., Teunissen, C. E., Tsolaki, M., Vandenberghe, R., Verbeek, M. M., Villemagne, V. L., Vos, S. J. B., van Waalwijk van Doorn, L. J. C., Waldemar, G., Wallin, A., Wallin, Å. K., Wiltfang, J., Wolk, D. A., Zboch, M., \& Zetterberg, H. (2015). Prevalence of cerebral amyloid pathology in persons without dementia: a meta-analysis. JAMA, 313(19), 1924-1938. https://doi.org/10.1001/jama.2015.4668

Jelicic, M., Bosma, H., Ponds, R. W., Van Boxtel, M. P., Houx, P. J., \& Jolles, J. (2002). Subjective sleep problems in later life as predictors of cognitive decline. Report from the Maastricht Ageing Study (MAAS). International Journal of Geriatric Psychiatry, 17(1), 7377.

Jenkins, J. G., \& Dallenbach, K. M. (1924). Obliviscence During Sleep and Waking. The American Journal of Psychology, 35, 605-612. https://doi.org/10.2307/1414040

Jessen, N. A., Munk, A. S., Lundgaard, I., \& Nedergaard, M. (2015). The Glymphatic System: A Beginner's Guide. Neurochemical Resarch, 40(12), 2583-2599. https://doi.org/10.1007/s11064-015-1581-6 
Johansson, B., \& Berg, S. (1989). The robustness of the terminal decline phenomenon: longitudinal data from the Digit-Span Memory Test. $J$ Journal of Gerontology, 44(6), P184-186. https://doi.org/10.1093/geronj/44.6.p184

Jorm, A. F., \& Jolley, D. (1998). The incidence of dementia: a meta-analysis. Neurology, 51(3), 728-733.

Ju, Y. E., McLeland, J. S., Toedebusch, C. D., Xiong, C., Fagan, A. M., Duntley, S. P., Morris, J. C., \& Holtzman, D. M. (2013). Sleep quality and preclinical Alzheimer disease. JAMA Neurology, 70(5), 587-593. https://doi.org/10.1001/jamaneurol.2013.2334

Kales, A., Rechtschaffen, A., National Institute of Neurological Diseases and Blindness (U.S.). Neurological Information Network., \& University of California Los Angeles. Brain Information Service. (1968). A Manual of standardized terminology, techniques and scoring system for sleep stages of human subjects. U.S. National Institute of Neurological Diseases and Blindness, Neurological Information Network.

Kang, J. E., Lim, M. M., Bateman, R. J., Lee, J. J., Smyth, L. P., Cirrito, J. R., Fujiki, N., Nishino, S., \& Holtzman, D. M. (2009). Amyloid-beta dynamics are regulated by orexin and the sleep-wake cycle. Science, 326(5955), 1005-1007. https://doi.org/10.1126/science.1180962

Karlsson, P., Thorvaldsson, V., Skoog, I., Gudmundsson, P., \& Johansson, B. (2015). Birth cohort differences in fluid cognition in old age: comparisons of trends in levels and change trajectories over 30 years in three population-based samples. Psychology and Aging, 30(1), 8394. https://doi.org/10.1037/a0038643

Kay, D. W., Beamish, P., \& Roth, M. (1964). Old Age Mental Disorders in Newcastle Upon Tyne. I. A Study of Prevalence. British Journal of Psychiatry, 110, 146-158.

Kern, S., Zetterberg, H., Kern, J., Zettergren, A., Waern, M., Hoglund, K., Andreasson, U., Wetterberg, H., Borjesson-Hanson, A., Blennow, K., \& Skoog, I. (2018). Prevalence of preclinical Alzheimer disease: Comparison of current classification systems. Neurology, 90(19), e1682-e1691. https://doi.org/10.1212/WNL.0000000000005476

Kim, J., Basak, J. M., \& Holtzman, D. M. (2009). The role of apolipoprotein E in Alzheimer's disease. Neuron, 63(3), 287-303. https://doi.org/10.1016/j.neuron.2009.06.026

Kleemeier, R. W. (1963). Intellectual Change in Senium. Journal of the American Statistical Association, 58(302), 555-+.

Klerman, E. B., Davis, J. B., Duffy, J. F., Dijk, D. J., \& Kronauer, R. E. (2004). Older people awaken more frequently but fall back asleep at the same rate as younger people. Sleep, 27(4), 793-798.

Kliegel, M., \& Martin, M. (2003). Prospective memory research: Why is it relevant? International Journal of Psychology, 38(4), 193-194. https://doi.org/10.1080/00207590344000114 
Kliegel, M., Moor, C., \& Rott, C. (2004). Cognitive status and development in the oldest old: a longitudinal analysis from the Heidelberg Centenarian Study. Archives of Gerontology and Geriatrics, 39(2), 143-156. https://doi.org/10.1016/j.archger.2004.02.004

Kliegel, M., \& Sliwinski, M. (2004). MMSE cross-domain variability predicts cognitive decline in centenarians. Gerontology, 50(1), 39-43. https://doi.org/10.1159/000074388

Kronholm, E., Partonen, T., Laatikainen, T., Peltonen, M., Harma, M., Hublin, C., Kaprio, J., Aro, A. R., Partinen, M., Fogelholm, M., Valve, R., Vahtera, J., Oksanen, T., Kivimaki, M., Koskenvuo, M., \& Sutela, H. (2008). Trends in self-reported sleep duration and insomnia-related symptoms in Finland from 1972 to 2005: a comparative review and re-analysis of Finnish population samples. Journal of Sleep Research, 17(1), 54-62. https://doi.org/10.1111/j.1365-2869.2008.00627.x

Krysinska, K., Sachdev, P. S., Breitner, J., Kivipelto, M., Kukull, W., \& Brodaty, H. (2017). Dementia registries around the globe and their applications: A systematic review. Alzheimer's and Dementia, 13(9), 1031-1047. https://doi.org/10.1016/j.jalz.2017.04.005

Laird, N. M., \& Ware, J. H. (1982). Random-Effects Models for Longitudinal Data. Biometrics, 38(4), 963-974. https://doi.org/Doi $10.2307 / 2529876$

Leuzy, A., Chiotis, K., Lemoine, L., Gillberg, P. G., Almkvist, O., Rodriguez-Vieitez, E., \& Nordberg, A. (2019). Tau PET imaging in neurodegenerative tauopathies-still a challenge. Molecular Psychiatry. https://doi.org/10.1038/s41380-018-0342-8

Levenson, J. C., Kay, D. B., \& Buysse, D. J. (2015). The pathophysiology of insomnia. Chest, 147(4), 1179-1192.

https://doi.org/10.1378/chest.14-1617

Li, M., Chen, N., Cui, Y., \& Liu, H. (2017). Comparison of Different LGMBased Methods with MAR and MNAR Dropout Data. Frontiers in Psychology, 8, 722. https://doi.org/10.3389/fpsyg.2017.00722

Lim, A. S., Yu, L., Kowgier, M., Schneider, J. A., Buchman, A. S., \& Bennett, D. A. (2013). Modification of the relationship of the apolipoprotein E epsilon4 allele to the risk of Alzheimer disease and neurofibrillary tangle density by sleep. JAMA Neurology, 70(12), 1544-1551. https://doi.org/10.1001/jamaneurol.2013.4215

Lin, Y. S., Lee, W. J., Wang, S. J., \& Fuh, J. L. (2018). Levels of plasma neurofilament light chain and cognitive function in patients with Alzheimer or Parkinson disease. Scientific Reports, 8(1), 17368. https://doi.org/10.1038/s41598-018-35766-w

Liu, C. C., Liu, C. C., Kanekiyo, T., Xu, H., \& Bu, G. (2013). Apolipoprotein $\mathrm{E}$ and Alzheimer disease: risk, mechanisms and therapy. Nature Revievs Neurology, 9(2), 106-118. https://doi.org/10.1038/nrneurol.2012.263 
Lloret, M.-A., Cervera-Ferri, A., Nepomuceno, M., Monllor, P., Esteve, D., \& Lloret, A. (2020). Is Sleep Disruption a Cause or Consequence of Alzheimer's Disease? Reviewing Its Possible Role as a Biomarker. International Journal of Molecular Sciences, 21, 1168. https://doi.org/10.3390/ijms21031168

Loomis, A. L., Harvey, E. N., \& Hobart, G. A. (1937). Cerebral states during sleep, as studied by human brain potentials. Journal of Experimental Psychology, 21(2), 127-144. https://doi.org/10.1037/h0057431

Lopez-Otin, C., Blasco, M. A., Partridge, L., Serrano, M., \& Kroemer, G. (2013). The hallmarks of aging. Cell, 153(6), 1194-1217. https://doi.org/10.1016/j.cell.2013.05.039

Lovden, M., Fratiglioni, L., Glymour, M. M., Lindenberger, U., \& TuckerDrob, E. M. (2020). Education and Cognitive Functioning Across the Life Span. Psychological Science in the Public Interest, 21(1), 6-41. https://doi.org/10.1177/1529100620920576

Lucey, B. P., Hicks, T. J., McLeland, J. S., Toedebusch, C. D., Boyd, J., Elbert, D. L., Patterson, B. W., Baty, J., Morris, J. C., Ovod, V., Mawuenyega, K. G., \& Bateman, R. J. (2017). Effect of sleep on overnight CSF amyloid-beta kinetics. Annals of Neurology. https://doi.org/10.1002/ana.25117

Lucey, B. P., Hicks, T. J., McLeland, J. S., Toedebusch, C. D., Boyd, J., Elbert, D. L., Patterson, B. W., Baty, J., Morris, J. C., Ovod, V., Mawuenyega, K. G., \& Bateman, R. J. (2018). Effect of sleep on overnight cerebrospinal fluid amyloid beta kinetics. Annals of Neurology, 83(1), 197-204. https://doi.org/10.1002/ana.25117

Lucey, B. P., McCullough, A., Landsness, E. C., Toedebusch, C. D., McLeland, J. S., Zaza, A. M., Fagan, A. M., McCue, L., Xiong, C., Morris, J. C., Benzinger, T. L. S., \& Holtzman, D. M. (2019).

Reduced non-rapid eye movement sleep is associated with tau pathology in early Alzheimer's disease. Science Translational Medicine, 11(474). https://doi.org/10.1126/scitranslmed.aau6550 Mallick, B. N., \& Inoue, S. j. (1999). Rapid eye movement sleep. Dekker. Mander, B. A., Marks, S. M., Vogel, J. W., Rao, V., Lu, B., Saletin, J. M., Ancoli-Israel, S., Jagust, W. J., \& Walker, M. P. (2015). betaamyloid disrupts human NREM slow waves and related hippocampus-dependent memory consolidation. Nature Neuroscience, 18(7), 1051-1057. https://doi.org/10.1038/nn.4035

Mander, B. A., Winer, J. R., Jagust, W. J., \& Walker, M. P. (2016). Sleep: A Novel Mechanistic Pathway, Biomarker, and Treatment Target in the Pathology of Alzheimer's Disease? Trends Neurosci, 39(8), 552-566. https://doi.org/10.1016/j.tins.2016.05.002

Mander, B. A., Winer, J. R., \& Walker, M. P. (2017). Sleep and Human Aging. Neuron, 94(1), 19-36. https://doi.org/10.1016/j.neuron.2017.02.004 
Mattsson, N., Andreasson, U., Zetterberg, H., Blennow, K., \& Alzheimer's Disease Neuroimaging, I. (2017). Association of Plasma Neurofilament Light With Neurodegeneration in Patients With Alzheimer Disease. JAMA Neurology, 74(5), 557-566. https://doi.org/10.1001/jamaneurol.2016.6117

McKhann, G. M., Knopman, D. S., Chertkow, H., Hyman, B. T., Jack, C. R., Jr., Kawas, C. H., Klunk, W. E., Koroshetz, W. J., Manly, J. J., Mayeux, R., Mohs, R. C., Morris, J. C., Rossor, M. N., Scheltens, P., Carrillo, M. C., Thies, B., Weintraub, S., \& Phelps, C. H. (2011). The diagnosis of dementia due to Alzheimer's disease: recommendations from the National Institute on Aging-Alzheimer's Association workgroups on diagnostic guidelines for Alzheimer's disease. Alzheimer's \& Dementia, 7(3), 263-269. https://doi.org/10.1016/j.jalz.2011.03.005

Medic, G., Wille, M., \& Hemels, M. E. (2017). Short- and long-term health consequences of sleep disruption. Nature and science of sleep, 9, 151-161. https://doi.org/10.2147/NSS.S134864

Morin, C. M. (2004). Cognitive-behavioral approaches to the treatment of insomnia. Journal of Clinical Psychiatry, 65(Suppl 16), 33-40.

Muniz-Terrera, G., Matthews, F. E., Stephan, B., Brayne, C., \& Group, C. C. C. (2011). Are terminal decline and its potential indicators detectable in population studies of the oldest old? International Journal of Geriatric Psychiatry, 26(6), 584-592. https://doi.org/10.1002/gps.2566

Neuropathology Group. Medical Research Council Cognitive, F., \& Aging, S. (2001). Pathological correlates of late-onset dementia in a multicentre, community-based population in England and Wales. Neuropathology Group of the Medical Research Council Cognitive Function and Ageing Study (MRC CFAS). Lancet, 357(9251), 169175. https://doi.org/10.1016/s0140-6736(00)03589-3

Niemantsverdriet, E., Valckx, S., Bjerke, M., \& Engelborghs, S. (2017). Alzheimer's disease CSF biomarkers: clinical indications and rational use. Acta Neurologica Belgica, 117(3), 591-602. https://doi.org/10.1007/s13760-017-0816-5

Nilsson, L. V., \& Persson, G. (1984). Prevalence of mental disorders in an urban sample examined at 70,75 and 79 years of age. Acta Psychiatrica Scandinavia, 69(6), 519-527.

Noble, W., Hanger, D. P., Miller, C. C., \& Lovestone, S. (2013). The importance of tau phosphorylation for neurodegenerative diseases. Frontiers in Neurology, 4, 83. https://doi.org/10.3389/fneur.2013.00083

Nyberg, L., Lovden, M., Riklund, K., Lindenberger, U., \& Backman, L. (2012). Memory aging and brain maintenance. Trends in Cognitive Sciences, 16(5), 292-305. https://doi.org/10.1016/j.tics.2012.04.005 
O'Donnell, D., Silva, E. J., Munch, M., Ronda, J. M., Wang, W., \& Duffy, J. F. (2009). Comparison of subjective and objective assessments of sleep in healthy older subjects without sleep complaints. Journal of Sleep Research, 18(2), 254-263. https://doi.org/10.1111/j.13652869.2008.00719.x

Oeppen, J., \& Vaupel, J. W. (2002). Demography. Broken limits to life expectancy. Science, 296(5570), 1029-1031. https://doi.org/10.1126/science. 1069675

Ohayon, M. M. (2002). Epidemiology of insomnia: what we know and what we still need to learn. Sleep Medicine Reviews, 6(2), 97-111.

Ohayon, M. M., Carskadon, M. A., Guilleminault, C., \& Vitiello, M. V. (2004). Meta-analysis of quantitative sleep parameters from childhood to old age in healthy individuals: developing normative sleep values across the human lifespan. SLEEP-NEW YORK THEN WESTCHESTER-, 27, 1255-1274.

Ohayon, M. M., \& Reynolds, C. F. (2009). Epidemiological and clinical relevance of insomnia diagnosis algorithms according to the DSM-IV and the International Classification of Sleep Disorders (ICSD). Sleep Medicine, 10(9), 952-960. https://doi.org/10.1016/j.sleep.2009.07.008

Olsson, M., Arlig, J., Hedner, J., Blennow, K., \& Zetterberg, H. (2018). Sleep deprivation and cerebrospinal fluid biomarkers for Alzheimer's disease. Sleep, 41(5). https://doi.org/10.1093/sleep/zsy025

Opdebeeck, C., Martyr, A., \& Clare, L. (2016). Cognitive reserve and cognitive function in healthy older people: a meta-analysis. Aging, Neuropsychology, and Cognition, 23(1), 40-60. https://doi.org/10.1080/13825585.2015.1041450

OurWorldInData.org. (2020). Life expectancy, 1543 to 2015. OurWorldInData.org/life-expectancy

Pallesen, S., Sivertsen, B., Nordhus, I. H., \& Bjorvatn, B. (2014). A 10-year trend of insomnia prevalence in the adult Norwegian population. Sleep Medicine, 15(2), 173-179. https://doi.org/10.1016/j.sleep.2013.10.009

Palmore, E., \& Cleveland, W. (1976). Aging, Terminal Decline, and Terminal Drop1. Journal of Gerontology, 31(1), 76-81. https://doi.org/10.1093/geronj/31.1.76

Persson, G. (1980). Prevalence of mental disorders in a 70-year-old urban population. Acta Psychiatrica Scandinavia, 62(2), 119-139.

Peters, R. (2006). Ageing and the brain. Postgraduate Medical Journal, 82(964), 84-88. https://doi.org/10.1136/pgmj.2005.036665 
Piccinin, A. M., Muniz-Terrera, G., Clouston, S., Reynolds, C. A., Thorvaldsson, V., Deary, I. J., Deeg, D. J., Johansson, B., Mackinnon, A., Spiro, A., 3rd, Starr, J. M., Skoog, I., \& Hofer, S. M. (2013). Coordinated analysis of age, sex, and education effects on change in MMSE scores. The Journals of Gerontology Series B: Psychological Sciences and Social Sciences, 68(3), 374-390. https://doi.org/10.1093/geronb/gbs077

Pigeon, W. R. (2010). Treatment of adult insomnia with cognitive-behavioral therapy. Journal of Clinical Psychology, 66(11), 1148-1160. https://doi.org/10.1002/jclp.20737

Plummer, M. (2003). \{JAGS\}: A program for analysis of \{Bayesian\} graphical models using \{Gibbs\} sampling. Proceedings of the 3rd International Workshop on Distributed Statistical Computing, Vienna, Austria.

Porkka-Heiskanen, T., Strecker, R. E., Thakkar, M., Bjorkum, A. A., Greene, R. W., \& McCarley, R. W. (1997). Adenosine: a mediator of the sleep-inducing effects of prolonged wakefulness. Science, 276(5316), 1265-1268.

Portelius, E., Price, E., Brinkmalm, G., Stiteler, M., Olsson, M., Persson, R., Westman-Brinkmalm, A., Zetterberg, H., Simon, A. J., \& Blennow, K. (2011). A novel pathway for amyloid precursor protein processing. Neurobiology of Aging, 32(6), 1090-1098. https://doi.org/10.1016/j.neurobiolaging.2009.06.002

Prince, M., Bryce, R., Albanese, E., Wimo, A., Ribeiro, W., \& Ferri, C. P. (2013). The global prevalence of dementia: a systematic review and metaanalysis. Alzheimer's \& Dementia, 9(1), 63-75 e62. https://doi.org/10.1016/j.jalz.2012.11.007

Prinz, P. N., Vitaliano, P. P., Vitiello, M. V., Bokan, J., Raskind, M., Peskind, E., \& Gerber, C. (1982). Sleep, EEG and mental function changes in senile dementia of the Alzheimer's type. Neurobiology of Aging, 3(4), 361-370.

Puska, P. (2010). From Framingham to North Karelia: From Descriptive Epidemiology to Public Health Action. Progress in Cardiovascular Diseases, 53(1), 15-20. https://doi.org/https://doi.org/10.1016/j.pcad.2010.01.003

Rasch, B., \& Born, J. (2013). About Sleep's Role in Memory. Physiological Reviews, 93(2), 681-766. https://doi.org/10.1152/physrev.00032.2012

Riegel, K. F., \& Riegel, R. M. (1972). Development, drop, and death. Developmental Psychology, 6(2), 306-319. https://doi.org/10.1037/h0032104

Riley, J. C. (2005). Estimates of Regional and Global Life Expectancy, 18002001. Population and Development Review, 31(3), 537-543. 
Ritchie, C. W., Molinuevo, J. L., Truyen, L., Satlin, A., Van der Geyten, S., Lovestone, S., \& European Prevention of Alzheimer's Dementia, C. (2016). Development of interventions for the secondary prevention of Alzheimer's dementia: the European Prevention of Alzheimer's Dementia (EPAD) project. Lancet Psychiatry, 3(2), 179-186. https://doi.org/10.1016/S2215-0366(15)00454-X

Ritchie, K., \& Kildea, D. (1995). Is senile dementia "age-related" or "ageingrelated"?--evidence from meta-analysis of dementia prevalence in the oldest old. Lancet, 346(8980), 931-934. https://doi.org/10.1016/s0140-6736(95)91556-7

Roepke, S. K., \& Ancoli-Israel, S. (2010). Sleep disorders in the elderly. Indian Journal of Medical Research, 131, 302-310.

Rose, G. A. (1962). The diagnosis of ischaemic heart pain and intermittent claudication in field surveys. Bulleting of the World Health Organization, 27, 645-658.

Rosow, I. (1978). What Is a Cohort and Why. Human Development, 21(2), 65-75. https://doi.org/Doi 10.1159/000271575

Roth, T. (2007). Insomnia: definition, prevalence, etiology, and consequences. Journal of Clinical Sleep Medicine, 3(5 Suppl), S7-10.

Rowshan Ravan, A., Bengtsson, C., Lissner, L., Lapidus, L., \& Bjorkelund, C. (2010). Thirty-six-year secular trends in sleep duration and sleep satisfaction, and associations with mental stress and socioeconomic factors--results of the Population Study of Women in Gothenburg, Sweden. Journal of Sleep Research, 19(3), 496-503. https://doi.org/10.1111/j.1365-2869.2009.00815.x

Rydberg Sterner, T. (2020). Depression among Swedish 70-year-olds - Sex differences from a gender perspective University of Gothenburg]. Gothenburg.

Rydberg Sterner, T., Ahlner, F., Blennow, K., Dahlin-Ivanoff, S., Falk, H., Havstam Johansson, L., Hoff, M., Holm, M., Horder, H., Jacobsson, T., Johansson, B., Johansson, L., Kern, J., Kern, S., Machado, A., Mellqvist Fassberg, M., Nilsson, J., Ribbe, M., Rothenberg, E., Ryden, L., Sadeghi, A., Sacuiu, S., Samuelsson, J., Sigstrom, R., Skoog, J., Thorvaldsson, V., Waern, M., Westman, E., Wetterberg, H., Zetterberg, H., Zetterberg, M., Zettergren, A., Ostling, S., \& Skoog, I. (2019). The Gothenburg H70 Birth cohort study 2014-16: design, methods and study population. European Journal of Epidemiology, 34(2), 191-209. https://doi.org/10.1007/s10654-0180459-8

Rydberg Sterner, T., Gudmundsson, P., Sigstrom, R., Ahlner, F., Seidu, N., Zettergren, A., Kern, S., Ostling, S., Waern, M., \& Skoog, I. (2019). Depression and neuroticism decrease among women but not among men between 1976 and 2016 in Swedish septuagenarians. Acta Psychiatrica Scandinavica, 139(4), 381-394. https://doi.org/10.1111/acps.13005 
Sacuiu, S., Gustafson, D., Sjogren, M., Guo, X., Ostling, S., Johansson, B., \& Skoog, I. (2010). Secular changes in cognitive predictors of dementia and mortality in 70-year-olds. Neurology, 75(9), 779-785. https://doi.org/10.1212/WNL.0b013e3181f0737c

Saint-Aubert, L., Lemoine, L., Chiotis, K., Leuzy, A., Rodriguez-Vieitez, E., \& Nordberg, A. (2017). Tau PET imaging: present and future directions. Molecular Neurodegeneration, 12(1), 19. https://doi.org/10.1186/s13024-017-0162-3

Santos-Silva, R., Bittencourt, L. R., Pires, M. L., de Mello, M. T., Taddei, J. A., Benedito-Silva, A. A., Pompeia, C., \& Tufik, S. (2010). Increasing trends of sleep complaints in the city of Sao Paulo, Brazil. Sleep Medicine, 11(6), 520-524. https://doi.org/10.1016/j.sleep.2009.12.011

Satz, P. (1993). Brain reserve capacity on symptom onset after brain injury: A formulation and review of evidence for threshold theory. Neuropsychology, 7(3), 273-295. https://doi.org/10.1037/08944105.7.3.273

Savva, G. M., Wharton, S. B., Ince, P. G., Forster, G., Matthews, F. E., Brayne, C., Medical Research Council Cognitive, F., \& Ageing, S. (2009). Age, neuropathology, and dementia. New England Journal of Medicine, 360(22), 2302-2309. https://doi.org/10.1056/NEJMoa0806142

Schaie, K. W. (1965). A General Model for the Study of Developmental Problems. Psychological Bulletin, 64, 92-107. https://doi.org/10.1037/h0022371

Schaie, K. W., Willis, S. L., \& Pennak, S. (2005). An historical framework for cohort differences in intelligence. Research in human development, 2(1-2), 43-67.

Seblova, D., Berggren, R., \& Lövdén, M. (2020). Education and age-related decline in cognitive performance: Systematic review and metaanalysis of longitudinal cohort studies. Ageing Research Reviews, 58, 101005. https://doi.org/https://doi.org/10.1016/j.arr.2019.101005

Shokri-Kojori, E., Wang, G. J., Wiers, C. E., Demiral, S. B., Guo, M., Kim, S. W., Lindgren, E., Ramirez, V., Zehra, A., Freeman, C., Miller, G., Manza, P., Srivastava, T., De Santi, S., Tomasi, D., Benveniste, H., $\&$ Volkow, N. D. (2018). beta-Amyloid accumulation in the human brain after one night of sleep deprivation. Proceding of the National Academy of Sciences of the USA. https://doi.org/10.1073/pnas.1721694115

Siegler, I. C. (1975). The terminal drop hypothesis: fact or artifact? Experimental Aging Research, 1(1), 169-185. https://doi.org/10.1080/03610737508257957 
Sindi, S., Johansson, L., Skoog, J., Mattsson, A. D., Sjoberg, L., Wang, H. X., Fratiglioni, L., Kulmala, J., Soininen, H., Solomon, A., Johansson, B., Skoog, I., Kivipelto, M., \& Kareholt, I. (2018). Sleep disturbances and later cognitive status: a multi-centre study. Sleep Medicine, 52, 26-33. https://doi.org/10.1016/j.sleep.2017.11.1149

Skoog, I. (2016). Dementia: Dementia incidence - the times, they are achanging. Nature Reviews Neurology, 12(6), 316-318. https://doi.org/10.1038/nrneurol.2016.55

Skoog, I., Borjesson-Hanson, A., Kern, S., Johansson, L., Falk, H., Sigstrom, R., \& Ostling, S. (2017). Decreasing prevalence of dementia in 85year olds examined 22 years apart: the influence of education and stroke. Scientific Reports, 7(1), 6136. https://doi.org/10.1038/s41598$\underline{017-05022-8}$

Snijders, T. A. B., \& Bosker, R. J. (2012). Chapter 15. Longitudinal analyses. In Multilevel analysis : an introduction to basic and advanced multilevel modeling (2nd ed., pp. xi, 354 p.). Sage.

Spira, A. P., Gamaldo, A. A., An, Y., Wu, M. N., Simonsick, E. M., Bilgel, M., Zhou, Y., Wong, D. F., Ferrucci, L., \& Resnick, S. M. (2013). Self-reported sleep and beta-amyloid deposition in communitydwelling older adults. JAMA Neurology, 70(12), 1537-1543. https://doi.org/10.1001/jamaneurol.2013.4258

Spira, A. P., \& Gottesman, R. F. (2017). Sleep disturbance: an emerging opportunity for Alzheimer's disease prevention? International Psychogeriatrics, 29(4), 529-531. https://doi.org/10.1017/S1041610216002131

Spira, A. P., Yager, C., Brandt, J., Smith, G. S., Zhou, Y., Mathur, A., Kumar, A., Brasic, J. R., Wong, D. F., \& Wu, M. N. (2014). Objectively Measured Sleep and beta-amyloid Burden in Older Adults: A Pilot Study. SAGE Open Med, 2. https://doi.org/10.1177/2050312114546520

Sprecher, K. E., Bendlin, B. B., Racine, A. M., Okonkwo, O. C., Christian, B. T., Koscik, R. L., Sager, M. A., Asthana, S., Johnson, S. C., \& Benca, R. M. (2015). Amyloid burden is associated with selfreported sleep in nondemented late middle-aged adults. Neurobiology of Aging, 36(9), 2568-2576. https://doi.org/10.1016/j.neurobiolaging.2015.05.004

Sprecher, K. E., Koscik, R. L., Carlsson, C. M., Zetterberg, H., Blennow, K., Okonkwo, O. C., Sager, M. A., Asthana, S., Johnson, S. C., Benca, R. M., \& Bendlin, B. B. (2017). Poor sleep is associated with CSF biomarkers of amyloid pathology in cognitively normal adults. Neurology, 89(5), 445-453. https://doi.org/10.1212/WNL.0000000000004171 
Statistics Sweden. (2018). Life table by sex and age. Year 1970 - 2016. Statistics Sweden.

http://www.statistikdatabasen.scb.se/pxweb/en/ssd/START_BE_ B E0101 BE0101I/LivslangdEttariga/?rxid=b864c769-9fc7-4221902b-0a1000d370a5

Stern, Y. (2002). What is cognitive reserve? Theory and research application of the reserve concept. Journal of the International Neuropsychological Society, 8(3), 448-460.

Stern, Y. (2009). Cognitive reserve. Neuropsychologia, 47(10), 2015-2028. https://doi.org/10.1016/j.neuropsychologia.2009.03.004

Sterne, J. A., White, I. R., Carlin, J. B., Spratt, M., Royston, P., Kenward, M. G., Wood, A. M., \& Carpenter, J. R. (2009). Multiple imputation for missing data in epidemiological and clinical research: potential and pitfalls. $B M J, 338$, b2393. https://doi.org/10.1136/bmj.b2393

Strozyk, D., Blennow, K., White, L. R., \& Launer, L. J. (2003). CSF Abeta 42 levels correlate with amyloid-neuropathology in a populationbased autopsy study. Neurology, 60(4), 652-656.

Sun, B. L., Wang, L. H., Yang, T., Sun, J. Y., Mao, L. L., Yang, M. F., Yuan, H., Colvin, R. A., \& Yang, X. Y. (2018). Lymphatic drainage system of the brain: A novel target for intervention of neurological diseases. Progress in Neurobiology, 163-164, 118-143. https://doi.org/10.1016/j.pneurobio.2017.08.007

Thorsell, A., Bjerke, M., Gobom, J., Brunhage, E., Vanmechelen, E., Andreasen, N., Hansson, O., Minthon, L., Zetterberg, H., \& Blennow, K. (2010). Neurogranin in cerebrospinal fluid as a marker of synaptic degeneration in Alzheimer's disease. Brain Research, 1362, 13-22. https://doi.org/10.1016/j.brainres.2010.09.073

Thorvaldsson, V., Hofer, S. M., Berg, S., Skoog, I., Sacuiu, S., \& Johansson, B. (2008). Onset of terminal decline in cognitive abilities in individuals without dementia. Neurology, 71(12), 882-887. https://doi.org/DOI 10.1212/01.wnl.0000312379.02302.ba

Thorvaldsson, V., Hofer, S. M., \& Johansson, B. (2006). Aging and late-life terminal decline in perceptual speed: A comparison of alternative modeling approaches. European Psychologist, 11(3), 196-203. https://doi.org/10.1027/1016-9040.11.3.196

Thorvaldsson, V., Karlsson, P., Skoog, J., Skoog, I., \& Johansson, B. (2017). Better Cognition in New Birth Cohorts of 70 Year Olds, But Greater Decline Thereafter. The Journals of Gerontology Series B: Psychological Sciences and Social Science, 72(1), 16-24. https://doi.org/10.1093/geronb/gbw125

Tombaugh, T. N. (2005). Test-retest reliable coefficients and 5-year change scores for the MMSE and 3MS. Archives of Clinical Neuropsychology, 20(4), 485-503. https://doi.org/10.1016/j.acn.2004.11.004 
United Nations, D. o. E. a. S. A., Population Division. (2020). World Population Ageing 2019.

Van Cauter, E., Leproult, R., \& Plat, L. (2000). Age-related changes in slow wave sleep and REM sleep and relationship with growth hormone and cortisol levels in healthy men. JAMA, 284(7), 861-868.

van de Schoot, R., Kaplan, D., Denissen, J., Asendorpf, J. B., Neyer, F. J., \& van Aken, M. A. G. (2014). A gentle introduction to bayesian analysis: applications to developmental research. Child development, 85(3), 842-860. https://doi.org/10.1111/cdev.12169

van der Laan, N. C., Schimmel, A., \& Heeren, T. J. (2005). The applicability and the inter-rater reliability of the Comprehensive

Psychopathological Rating Scale in an elderly clinical population.

International Journal of Geriatric Psychiatry, 20(1), 35-40. https://doi.org/10.1002/gps.1244

von Strauss, E., Viitanen, M., De Ronchi, D., Winblad, B., \& Fratiglioni, L. (1999). Aging and the occurrence of dementia: findings from a population-based cohort with a large sample of nonagenarians. Archives of Neurology, 56(5), 587-592. https://doi.org/10.1001/archneur.56.5.587

Waern, M., Marlow, T., Morin, J., Ostling, S., \& Skoog, I. (2014). Secular changes in at-risk drinking in Sweden: birth cohort comparisons in 75-year-old men and women 1976-2006. Age and Ageing, 43(2), 228-234. https://doi.org/10.1093/ageing/aft136

Walker, M. P., \& Stickgold, R. (2006). Sleep, memory, and plasticity. Annuals Review of Psychology, 57, 139-166. https://doi.org/10.1146/annurev.psych.56.091103.070307

Wancata, J., Borjesson-Hanson, A., Ostling, S., Sjogren, K., \& Skoog, I. (2007). Diagnostic criteria influence dementia prevalence. American Journal of Geriatric Psychiatry, 15(12), 1034-1045. https://doi.org/10.1097/JGP.0b013e31813c6b6c

Wang, C., \& Holtzman, D. M. (2020). Bidirectional relationship between sleep and Alzheimer's disease: role of amyloid, tau, and other factors. Neuropsychopharmacology, 45(1), 104-120. https://doi.org/10.1038/s41386-019-0478-5

Wang, C. C., \& Lung, F. W. (2012). The role of PGC-1 and Apoepsilon4 in insomnia. Psychiatric Genetics, 22(2), 82-87. https://doi.org/10.1097/YPG.0b013e32834dc438

Wernicke, T. F., \& Reischies, F. M. (1994). Prevalence of dementia in old age: clinical diagnoses in subjects aged 95 years and older. Neurology, 44(2), 250-253. https://doi.org/10.1212/wnl.44.2.250

Westerberg, C. E., Mander, B. A., Florczak, S. M., Weintraub, S., Mesulam, M. M., Zee, P. C., \& Paller, K. A. (2012). Concurrent impairments in sleep and memory in amnestic mild cognitive impairment. Journal of the International Neuropsychological Society, 18(3), 490-500. https://doi.org/10.1017/S135561771200001X 
Wiberg, P., Waern, M., Billstedt, E., Ostling, S., \& Skoog, I. (2013). Secular trends in the prevalence of dementia and depression in Swedish septuagenarians 1976-2006. Psychological Medicine, 43(12), 26272634. https://doi.org/10.1017/S0033291713000299

Wilhelmson, K., Allebeck, P., \& Steen, B. (2002). Improved health among 70-year olds: comparison of health indicators in three different birth cohorts. Aging clinical and experimental research, 14(5), 361-370.

Winer, J. R., Mander, B. A., Helfrich, R. F., Maass, A., Harrison, T. M., Baker, S. L., Knight, R. T., Jagust, W. J., \& Walker, M. P. (2019). Sleep as a Potential Biomarker of Tau and beta-Amyloid Burden in the Human Brain. Journal of Neuroscience, 39(32), 6315-6324. https://doi.org/10.1523/JNEUROSCI.0503-19.2019

Wu, Y. T., Beiser, A. S., Breteler, M. M. B., Fratiglioni, L., Helmer, C., Hendrie, H. C., Honda, H., Ikram, M. A., Langa, K. M., Lobo, A., Matthews, F. E., Ohara, T., Peres, K., Qiu, C., Seshadri, S., Sjolund, B. M., Skoog, I., \& Brayne, C. (2017). The changing prevalence and incidence of dementia over time - current evidence. Nature Reviews Neurology, 13(6), 327-339. https://doi.org/10.1038/nrneurol.2017.63

Xie, L., Kang, H., Xu, Q., Chen, M. J., Liao, Y., Thiyagarajan, M., O'Donnell, J., Christensen, D. J., Nicholson, C., Iliff, J. J., Takano, T., Deane, R., \& Nedergaard, M. (2013). Sleep drives metabolite clearance from the adult brain. Science, 342(6156), 373-377. https://doi.org/10.1126/science. 1241224

Yaffe, K., Falvey, C. M., \& Hoang, T. (2014). Connections between sleep and cognition in older adults. Lancet Neurology, 13(10), 1017-1028. https://doi.org/10.1016/S1474-4422(14)70172-3

Yang, Z., Slavin, M. J., \& Sachdev, P. S. (2013). Dementia in the oldest old. Nature Reviews Neurology, 9(7), 382-393. https://doi.org/10.1038/nrneurol.2013.105

Zarit, S. H., Johansson, B., \& Malmberg, B. (1995). Changes in functional competency in the oldest old: A longitudinal study. Journal of Aging and Health, 7(1), 3-23. https://doi.org/10.1177/089826439500700101

Zetterberg, H., Skillback, T., Mattsson, N., Trojanowski, J. Q., Portelius, E., Shaw, L. M., Weiner, M. W., Blennow, K., \& Alzheimer's Disease Neuroimaging, I. (2016). Association of Cerebrospinal Fluid Neurofilament Light Concentration With Alzheimer Disease Progression. JAMA Neurology, 73(1), 60-67. https://doi.org/10.1001/jamaneurol.2015.3037

Zhi, X., Joas, E., Waern, M., Ostling, S., Borjesson-Hanson, A., \& Skoog, I. (2013). Prevalence of cardiovascular disorders and risk factors in two 75-year-old birth cohorts examined in 1976-1977 and 2005-2006. Aging Clinical and Experimental Research, 25(4), 377-383. https://doi.org/10.1007/s40520-013-0058-1 